Western University Scholarship@Western

Digitized Theses

Digitized Special Collections

1982

\title{
Forgetting Of Visual Discriminations By Pigeons
}

Philipp James Kraemer

Follow this and additional works at: https://ir.lib.uwo.ca/digitizedtheses

\section{Recommended Citation}

Kraemer, Philipp James, "Forgetting Of Visual Discriminations By Pigeons" (1982). Digitized Theses. 1210.

https://ir.lib.uwo.ca/digitizedtheses/1210

This Dissertation is brought to you for free and open access by the Digitized Special Collections at Scholarship@Western. It has been accepted for inclusion in Digitized Theses by an authorized administrator of Scholarship@Western. For more information, please contact tadam@uwo.ca,

wlswadmin@uwo.ca. 
The author of this thesis has granted The University of Western Ontario a non-exclusive license to reproduce and distribute copies of this thesis to users of Western Libraries. Copyright remains with the author.

Electronic theses and dissertations available in The University of Western Ontario's institutional repository (Scholarship@Western) are solely for the purpose of private study and research. They may not be copied or reproduced, except as permitted by copyright laws, without written authority of the copyright owner. Any commercial use or publication is strictly prohibited.

The original copyright license attesting to these terms and signed by the author of this thesis may be found in the original print version of the thesis, held by Western Libraries.

The thesis approval page signed by the examining committee may also be found in the original print version of the thesis held in Western Libraries.

Please contact Western Libraries for further information:

E-mail: libadmin@uwo.ca

Telephone: (519) 661-2111 Ext. 84796

Web site: http://www.lib.uwo.ca/ 


\section{CANAABIAN THESES ON MICROFICHE}

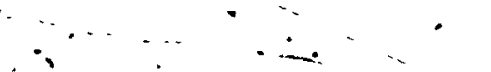

\section{THESES CANADIENNES SUR MICROFICHE}

National Library of C̈anada

Collections Development Biranch .

Canadian Theses on

Microfiche Service

Ottawa, Canada'

KIÁ ON4
Bibliothèque nationale du Canada

Direction du dévélöppement des collections

Service des thèses canàdiennes sur microfiche

\section{NOTITICE}

The quality of this microfiche is heavily debendent.upon the quality of the original thesis submitted for microfilming: Every: effort. has been made to ensure the highest quality of reproduction possible.

If pages are missing, contäct the university which granted the degree:

Some páges may have indistinct print especially if the original pages were typed with a poor typewriter ribbon or if the university sent us a poor photpcopy.

Previously copyrighted/materials Tjournal articles, published tests, etc.) are not filmed.

Réproduction in full or in part of this film is governed: by the Canadian Copyright Act, R.S.C. 1970, c. C-30: Please read the authorization forms which accompany this thesis.

\section{THIS DISSERTATION}

HAS BEEN MICEROFIEMED EXXCTLY AS RECEIVED
La qualité de cette microfiche dépend grandement de la qualité de la thèse soumise au microfilmage. Nous avons tout fait pour assurer une qualité supérieure de reproduction.

S'il manque des pages, velillez communiquer aveo l'université qui a conféré le grade.

La qualité d'impression de certaines pages peut laisser à désirer, surtout si les pages originales ont été dạctylographiées à l'ałde d'un rubạn usé ou si l'université nous a fait parvenir une photocopie de mauvaise qualité.

Les documents qui font déjà l'objet d'un droit d'auteur (articles de revue, examens publiés, etc.) ne sont pas microfilmés.

\section{-}

Là reproduction, même partielle, de ce microfilm est soumisè à la Loi canadienne sur le droit d'auteur, SRC 1970, c. C-30. Veuillez prendre connaissance des formules d'autorisation qui accompagnent cette thèse.

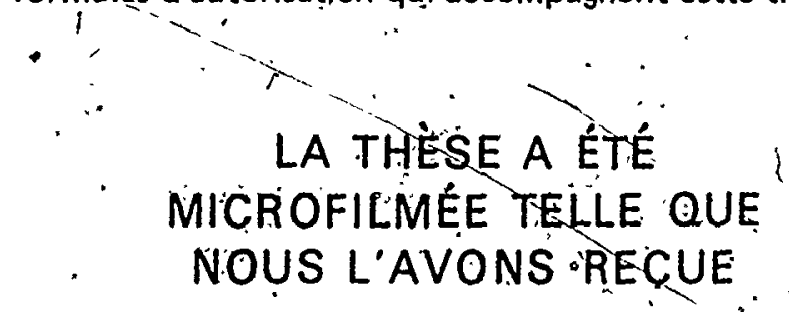



A series of three experiments examined the forgetting of visual discriminations in pigeons. The problems consisted of feature discriminations, with dot displays as the discriminative stimtil, and involved a successive go/no-go pecking-response. It was found in all three experiments that pigeons that had been trained to refrain from pecking an s- display, resumed pecking at these displays after reptention intervals. 'It was argued that these data represent the first unequivocal demonstration of forgetting of âscriminations in pigeons.

In addition to the simple demonstration of forgetting, it was found in Experiment $\dot{l}^{\prime}$ that the amount of forgetting progressively increased, in a negatively acgelerated fashion, over intervals of 1,10 and 20 days. Álso, it was found that more forgetting occurred for a reverse discrimination than for a single discrimination. In Experiment 2 it was found that acquisition was retarded and more forgetting' occurred. for discrimination's which involved highly similar stimuli. It was argued that these data represent the first reported instance of intraproblem. similarity effects on retention in animals. In Experiment 3 the role of contextual cues on forgetting was examined. It was found that a change in contextual cues between acquisition and retention festing enhanced forgetting; when the contextual cues present during original acquisition were conspicuous; when these cues were relatively inconspicuous, a change in context had no effect on forgetting.

A retrieval fallure model of memory processing was described and applied to the data from each of the three experiments. It was argued: 
1 that forgetting of discriminations involves selective retrieval failure of specific target memories, as a result of chariges in the retrievability of these memoxies over time. An explicit conceptual mechanism was postulated as a source of these changes in retrievability:

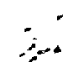

0

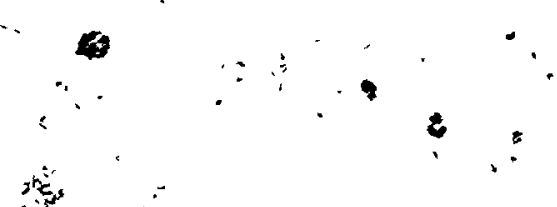

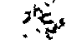
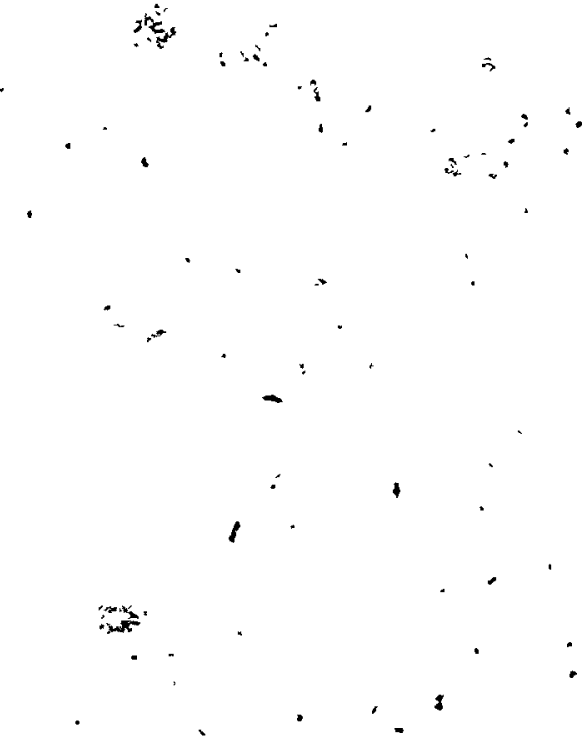

1
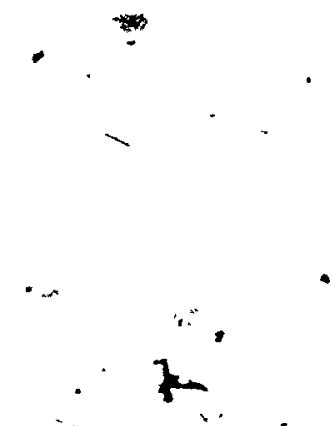

$$
\text { ) }
$$
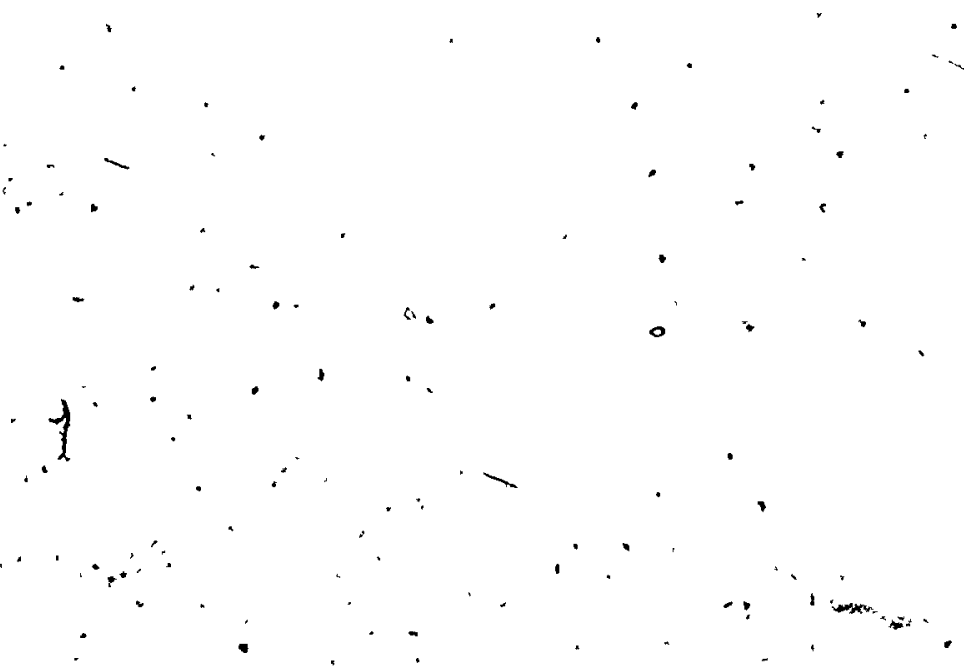

iv.

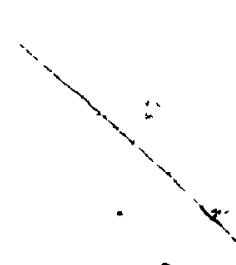




\section{ACKNOWLEDGENENTS}

I wish to extend appreciation to the members of my thesis advisory cominsttèe: Dirs. N. Innfs, G. Moran, H. Murray and W. Robertș. Their critilcal guidance has made this thesis a much better product than it . would have been otherwise. I also wish to thank J. Cesarini, R. Cornwall, J. Orphan, . Pulham and L. Shilson for their assistance in designing, constracting and providing the necessary equipment for this fesearch; their patience and skills will be remembered always.

I would like to especially thank my. Chief Advisor, Dr. W. Roberts. His oritical judgement from the beginning to end of this research has substantially improved this thiesis. Also, the research atmosphere he provided made this endeafour both stimulating and enjoyable. Most importantly, his, own scholarly achievements and research habits have provided a model exceizence I can only hope to someday equal and have positively influenced this research effort. This research was supported by a grant from the Natural Sciences and Engineering Research Council of Canada tó Dr. W. Roberts.

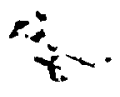


TABLE OF CONTENTS

CERTIEICATE of EXAMINATION $\ldots \ldots \ldots \ldots \ldots \ldots \ldots \ldots \ldots \ldots \ldots \ldots \ldots \ldots \ldots \ldots \ldots \ldots$

ABSTRACT $\ldots \ldots \ldots \ldots \ldots \ldots \ldots \ldots \ldots \ldots \ldots \ldots \ldots \ldots \ldots \ldots \ldots \ldots \ldots \ldots \ldots \ldots \ldots \ldots$

ACKNOWLEDGEMENTS $\ldots \ldots \ldots \ldots \ldots \ldots \ldots \ldots \ldots \ldots \ldots \ldots \ldots \ldots \ldots \ldots \ldots \ldots \ldots \ldots \ldots \ldots$

TABLE OF CONTENTS $\ldots \ldots \ldots \ldots \ldots \ldots \ldots \ldots \ldots \ldots \ldots \ldots \ldots \ldots \ldots \ldots \ldots \ldots \ldots \ldots \ldots$

CHÄPITR 1 - GENERAI INTRODUCTION .........................

1. Terminology and Conceptual Background ............. 1

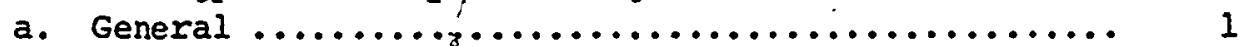

b. Classification of. Memory Research .............. 3

2. Theories of Forgetting ......................... 4

a. Decay Theory and Interference Theory ............ 4

b. Retrieval Failure Théory .................... 7

3. Variables Influencing Forgetting ................. 8

a. Retention Interval ......................... 8

b. Nature of the. Task ........................ 10

c. Interference ............................. 22

d. Contextual Determinants of Forgetting ........... - 36

e. Similarity ............................. 43

f. Sumary ............................... 46

4. Thesis outline ............................. 47

CHAPTER 2 - EXPERIMENT $1 \ldots \ldots \ldots \ldots \ldots \ldots \ldots \ldots \ldots \ldots \ldots \ldots \ldots \ldots \ldots \ldots \ldots . \ldots \ldots$

Introduction $\ldots \ldots \ldots \ldots \ldots \ldots \ldots \ldots \ldots \ldots \ldots \ldots \ldots \ldots \ldots \ldots \ldots \ldots \ldots$

Method ................................... 53

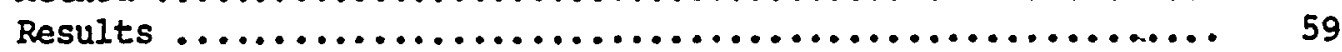

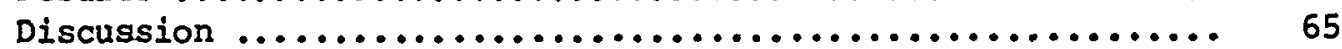

CHAPTER 3 - EXPERIMENT, 2 ............................ .93

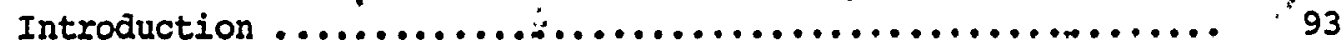

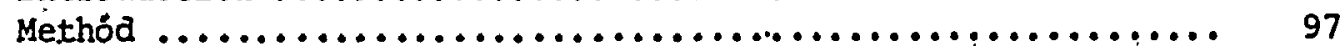

Results $\ldots \ldots \ldots \ldots \ldots \ldots \ldots \ldots \ldots \ldots \ldots \ldots \ldots \ldots \ldots \ldots \ldots \ldots \ldots \ldots \ldots \ldots$

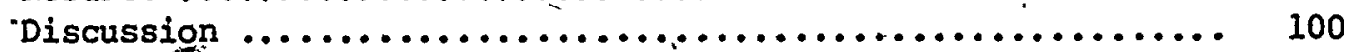

CHAPTER 4 - EXPERIMENT 3 ................................. 104

Introduction ................................. 104

Method ........................................ 107

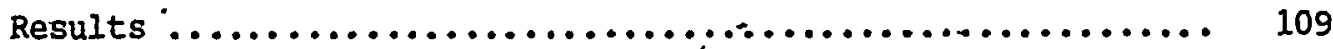

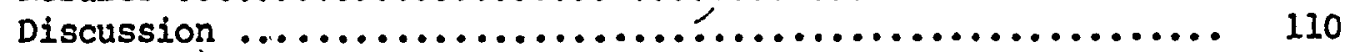

CHAPTER $\dot{5}-$ GENERAI DISCUSSION .......................... 115

REEERENCES $\ldots \ldots \ldots \ldots \ldots \ldots \ldots \ldots \ldots \ldots \ldots \ldots \ldots \ldots \ldots \ldots \ldots \ldots \ldots \ldots \ldots \ldots \ldots \ldots \ldots \ldots \ldots \ldots . . \ldots \ldots$

$\operatorname{VITA} \ldots \ldots \ldots \ldots \ldots \ldots \ldots \ldots \ldots \ldots \ldots \ldots \ldots \ldots \ldots \ldots \ldots \ldots \ldots \ldots \ldots \ldots \ldots \ldots \ldots \ldots \ldots \ldots . . \ldots \ldots$

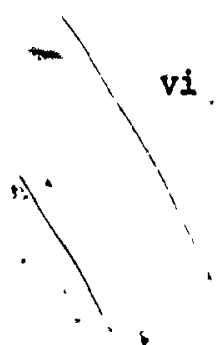




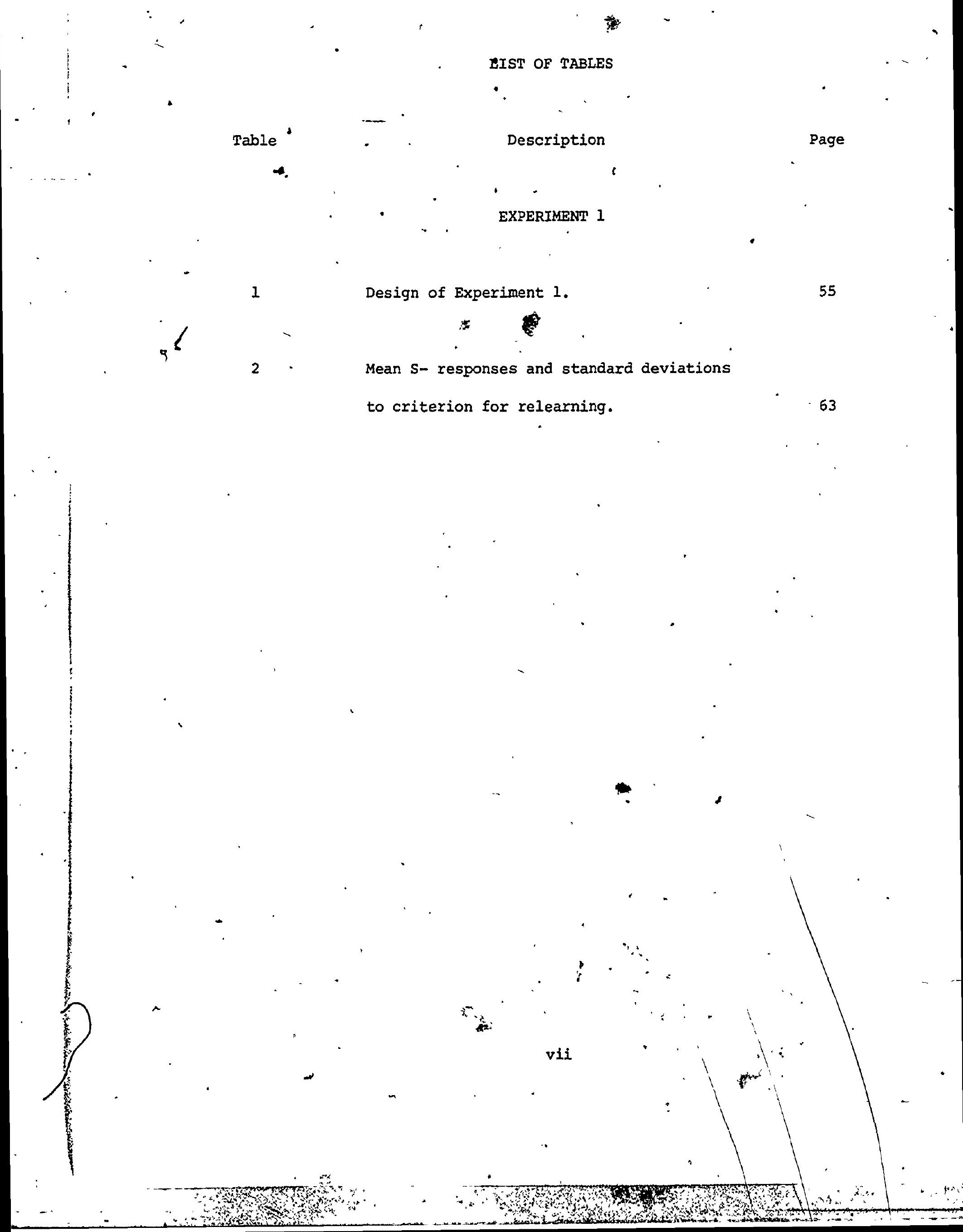


1- Mean S- responses to criterion during relearning.

An illustrated example of the memory processing assumed to occur during acquisition and retention of a successive discrimination according to the proposed retrieval model.

4 An illustrated example of the memory processing assumed to underlie the acquisition and retention of a reverse-successive discrimination. The figure presents hypothetical states of activation within target memories during presentation of both St andos- displays.

EXPERIMENT 2

5 Mean S- responses to criterion during acquisition and relearning after a 20-day retention interval for various contextual cue conditions.

- viii

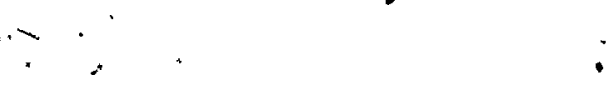




\section{CHAPTER $1^{\prime}$}

GENERAL INTRODUCTION

Recent trénds in the study of animal learning and behavior reveal that the field has undergone a considerable change during the past two de'cades. This chạnge has involved a general shift äway from a strict. behavioristic órientation and a turn to a more cognitive approach (Bolles, 1975; 1976). Accompanying. this paradigmatic shift has been a growing interest in the problems of animal memory and cognition (Hon1g \& James, 1971; Medin, Roberts \& Davis; 1976; Hulse, S. H., Fowler, H. \& Honig, W. .K., 1978; Spear, 1978). These new interests have served to both reunite human and animal research and revitalize the comparative study of animal cognition (Winograd, 1971; Wasserman, 1980). The research to be described in this thesis has been conducted within this conceptual context. It is based on the assumption that-understanding cognitive processes in a given species both enhancel our understanding of the behavior of that species, and provides a valuable contribution to the study of cognition in general. The specific research problem dealt with in this thesis concerns long-term forgetting in pigeons. In order to facilitate the discussion of this research, some background terminology will first be presentèd, along with a brief review 'of long-term forgetting in animals.

\section{Terminology and Conceptual Background}

a. General.

The current research has been conducted within the conceptual approach to memory processing outlined by ${ }^{-}$speat $(1971,1973,1976$, 
1 1978). Within this framework, the ter memory refe to a hypothetical construct believed to mediate environment-behavior interactions. "It can be regarded as on organism's representation of an event or learning episodp. The contents of these representations involve attributes or features, of the driginal event noticed by the organism. Memory processing refers to the establishment, modification, and utilization of these representations. The former two processes are concerned with information storage, while the latter refers to. information retrieval. Although the processes of storage and retrieval are hypothetical activities unavailable to direct observation, they can be studied indirectly in terms of the empirical concepts retention and forgetting. These two terms refer to evaluations of an organism's performance as a function of the passage of time, which is called a retention interval. Retention ,refers to some level of maintenance of performance after a retention interval, while forgetting is defined as a decrement in performance over a retention interval. Both terms are exclusively operatiional constructs which describe observable features of behavior. They, have been used, however, as indices of the underlying processes of storage and retrieval. The evaluation procedure used to assess whether forgetting or retention has occurred is referred, to as a retention test. It usualiy entails comparing some measure of performance before and after a retention interval. An obvious feature of this approach is' that it is forgetting which is actually under investigation in memory research. com-plete retention implies a null effect, whereas forgetting defines a measurable change in behavior which can be assessed in terms of various independent variables. Thu', it is not urfil forgetting occurs that a phenomenon becomés available for investigation. This may help explain 
why interest in animal memory research has bëen so modest until recent1y. Many of the early studies failed to find-significant forgetting, and this may" have" bolstered the permanancy of habits doctrine, already assumed by many S-R theorists (Gleitman, 1971; Spear, 1978).

b. "Classification of memory research.
'It is possible to classify two major areas of interest in animal memory research. These two areas are often referred to as short-term memory (STM) and long-term memory (LTM); this classification grew out of human memory research. The study of LTM has typically involved forgetting over relatively extended retention intervals, such as hours, days, weeks or longer. Studies of STM have involved forgetting over relatively brief intervals, on the order of seconds. While these two

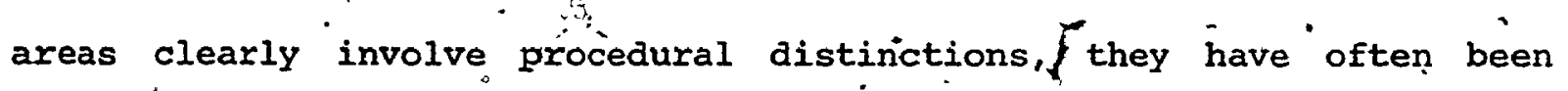
regarded as implicating different theoretical processes by many of the early multiprocess viès of memory (Atkinson \& Shiffrin, 1968; Simon, 1976; Waugh \& Norman, 1965). These theoretical assumptions render this dichotomy less useful, since many of these assumptions have now been çhallenged (Craik \& Lockhart,. 1972; Lewis, 1979). An alternative classification sçheme is one in which memory research is distinguished - purely in procedural terms. One such scheme involves the distinction between working memory and reference memory (Honig, 1978; 01ton, 1978). Working memory involves retention of information during or within an individual trial ôn some task, while reference memory refers to retention across ail.trials of a task. Examples of working memory incilude: * the afstractor task introduced independently by Brown (1958) and Peterson and Peterson (1959), Delayed Matching to Sample (D'Amato, 1973; 
Róberts \&, Grant, 1976) and the Radial Maze procedure (Olton \& Samuelson, 1976). The study of reference memory has involved a great variety of task's. All that is necessary is that performance be assessed after a retention interval separating two or more trials. Usually, a subject is given acquisition training to some criterion level of performance followed by a retention interval. A retention test is then administered. This most often entail's a comparison of performance during acquisition (or at the end of acquisition) with performance on the retention test. Reference memory involving animals has included the study of 5

habituation, classical conditioning, instrumental conditioning, stimulus control and complex behavioral tendencies, such as learning set and matching to sample performance.

2. Theories of Forgetting.

a. Decay Theory and Interference Theory.

There have been two major theoretical approaches to the analysis of forgetting:" decay theory and interference theory. Decay theories have attempted to explain forgetting in terms of the deterioration or decay of memories. The consolidation view held that information processing subsequent to the formation of a memory which had not become firmly "set", could result in the deterioration of that memory. Another version of decay theory postulated that memories spontaneously decayed over time. Both of these accounts, as well as other varieties, of decay theory, have suggested that forgetting can be understood as a matter of a disruption, in the storage process. They imply that the representa- 
tions themselves somehow deteriorate and become lost over time. While the decay position historically did not receive nearly the attention that interference theory attracted, there have been a number of recent 1 applications of the decay principle, especially with respect to the analysis of working memory in both humans and animals (Peterson \& Peterson, 1959; Atkinson \& Shiffrin; 1968; Craik \& Lockhart, 1972; Roberts \& Grant, 1976; Loftus \& Lofțus, 1979).

The primary theoretical approach to reference memory. has been interference theory. The basic tenet of this position has been that. forgetting results from the interference of learning experiences with each other at the time of a retention test. Over the course of the development of this theory a variety of principles have been implicated in attempt's to explain the actual source or mechanism of. this interference. Since interference theory primarily evolved within the context of human verbal learning research, many of its early concepts were related to the principles of $\mathrm{S}-\mathrm{R}$ associationism (Horton \& Turnage, '1976).

The earliest version of the theory relied on the notion of retrom active interference. The idea' was that forgetting of old associptions resulted from their being interfered with by subsequently formed associations. The classic study by Jenkins and Dallenbach (1924) serves as the quintessential case for this position. They found that subjects who spent a retention interval sleeping showed much less forgetting of verball material than subjects who spent the retention interval awake. The interpretation was that for the subject awake during the retention interval new associations were formed which competed with the previous associations. The specific form of this interference involved response competition. Verbal responses from subsequent associations interfered 
with responses from the original associations. '

The single factor interpretation of forgetting was eventually challenged in another classic study by Melton \& Irwin (1940). They found that simple response competition was insufficient to account for all of the forgetting found in interpolated-learning studies. Therefore, sthey, introduced an additional principle, which they termed factor $x$, as another source of forgetting. The idea was simply that in addition to response competition from subsequently learned assọciations, there was also an unlearning of the original associations. This process was envisioned as the extinction of conditioned responses. This exemplifies the intimate link between early interference accounts of forgetting and principles of conditioning.

Another major modification in interference theory involved the introduction of the proactive interference principle. It was argued that learned material could be interfered with by prior learning (proaction) as well as subsequent learning (retroaction). Underwood (1957) showed a strong relationship between the amount of forgetting of verbal materials and the subject's laboratory experience with such materials: More forgetting was obtained with greater amounts of previous experience. In addition, studies employing the proactive interference preparation directly manipulated prior experience and found similar results. This procedure involves comparing the forgetting of learned materials between a group given some prior learning experience with a group having had no such experience." It was typically found that the group given prior learning demonstrated more forgetting than the control group, which had not received the prior learning. Again, the notion of response competition was invoked to account for the forgetting of 
learned associdtions due to previoușly formed associations. In addition, the concepts of unlearning (i.e., extinction) and spontaneous recovery were utilized to deal with the common finding that proactive interference increased directly with the retention interval. This. serves as another instance of the application of conditioning principles to the analysis of forgetting. It was maintained that during the learning of new associations old associations underwent extinction. With the passàge of time, however, these associations recovered in strength and more successfully competed with recent learning. This resulted in greater amounts of forgetting at longer retention intervals. While many studies have provided support for these principles of interference, the problem has been that the data have not been unequivocal. Tested independently, the notions of unlearning and spontaneous recovery have often failed to conform to expectations derived from interference theory (Horton \& Turnage, 1976). In addtion, the general decrease in enthusiasm for $S-R$ associationism and its recently emphasized deficiencies have encouraged researchers to seek theoretical alternatives. One such approach is the retrieval failure account of forgetting formulated by Spear (1971, 1973, 1978). While it relies on the general notion of interference as the major principle of forgetting, it utilizes a different conceptual framework than traditional interference theory.

b. Retrieval Failure Theory.

The retirieval failure approach to forgetting outlined by spear (1973) can be viewed as a general theoretical framework or orientation, rather than as an explictly well defined model. The major components of this framework include a description of what a memory is, and an account 
of forgetting ing of the failure to effectively retrieve such memories. Spear regard's a memory as an organism's hypothetical representation of an event of learning episode. It is a multidimensional representation composed of various memory attributes. These attributes correspond to encoded versions of the teatures (both external and internal). present' during the original "event. 'When the organism confronts the original features, or features similar to the original, the.corresponding attributes representing these features are activated. When a sufficient number or type of attributes are so activated the memory itself will be retrieved. Forgetting is thus regarded as a failure to retrieve a target memory. This may result from either insufficient arousal of appropriate memory attributes, or the retrieval of a target memory in response to inappropriate features examined by the organism during the retention test.

\section{Variables Influencing Forgetting}

a. Retention Interval.

One of the most elementary factors influencing forgetting is the

length of the retention interval. That more forgetting should be found at longer retention intervals seems intuitively obvious and quite sensible. The earliest empirical support for this idea was provided by Ebbinghaus (Horton \& Turnage, 1976). In addition to demonstrating that forgetting increased with longer retention intervals, his research also described the time course of forgetting in detail. His classic retention curves portrayed forgetting as a monotonic, negatively accelerated, increasing function of the retention interval. The vast research since 
Ebbinghaus, including both animal and human investigations, has revealed that this original notion was somewhat simplistic and misleading. Subsequent research has shown that the effect of the rention interval interacts with a number of other important variables, and that no ideal "forgetting function" is to be found. Variables such as the nature of the task, the measure of retention employed, the amount of. interference from prior or subsequent learning, the degree of original learning, and the contextual environment in which learning and testing occur are all found to influence the rate of forgetting (Spear, 1978). Also, even the more basic assumptions concerning the time course of forgetting have been challenged. For example, not all forgetting has been found to increase morotonically. Perhaps the most dramatic case of nonmonotonic forgetting is the so called Kamin effect (Kamin,1957). This involves the occurrence of more forgetting at intermediate retention intervals (between one and six hours) than at shorter or longer intervals up to 24 hours (Brush, 1971; Spear, 1971, 1978). A number of other nonmonotonic forgetting curves have been reported as well (Sanders \& Barlow, 1971; . Holloway \& Wansley, 1973; Spear, 1978). This evidence clearly shows that the original Ebbinghaus function does. not represent all forgetting. Rather, it appears that any obtained forgetting function will be related to a variety of other variables. While the retention interval itself may provide only limited insight into the study of forgetting, when examined in combination with other important variables it certainly can help to unraỵel this complex process.

b. The nature of the task. .

That the nature of the learning event itself should influence the 
occurrence of forgetting is a none too radical proposal. And, indeed, the numerous studies of animal memory have revealed that certain learned events are quite susceptibre to forgetting, while others appear to be exceptionally well retained (Gleitman, 1971). A clear and systematic understanding of which tasks produce forgetting and which do not would be extremely valuable for any theory of forgetting. Unfortunately, orderly relationships between learning tasks and forgetting are, difficult, if at all possible, to discern. The following review will illustrate this problem.

Even with a relatively primitive form of learning, such as habituation, the findings are highly variable. There are a number of studies showing excellent retention of habituated responses over extendel retention intervals, as well as many reports of forgetting over the same and even shorter intervals. For example, excellent retention of habituation to novel tones has been found using conditioned suppression procedures with rats over intervals ranging from 30 seconds to 42 days (File, 1973; Leaton, 1974, 1976). Habituated startle responses in rats have also been found to be well retained up to six days (Moyen, 1963; Davis, 1972). Similarly, little if any forgetting has been reported for habituated responses involving: tonic immobility in chickens (Nash, Ronci \& Giraukas, 1976), escape movement in worms (Gardner, 1968, Ratner \& Gilpin, 1974), còntractile defense reactions in sea anemones (Logan \& Beck, 1978), spinal withdrawal reflexes in marine mollusks (Carew, Pinskèr \& Kandel, 1972; Carew \& Kandel, 1973), and body contraction in protozoa (Hamilton, Thompson, \& Eisenstein, 1974). Conversely, forgetting of habituation in rats has been reported for lick suppression after 72 hours. (File, 1973), head, shake responses after 24 hours (Askew, 
Leibrecht \& Ratner, 1969), and exploratory behayior in infants after one hour (Parsons, Fagan \& Spear, 1973). Also, forgetting has been found for habituated withdrawal reflexes in mollusks (Pinsker, Kupferman, Castellucci \& Kandel, 1969) and for contraction responses in worms (Gardner, 1968). Thus, for rats, marine mollusks, and worms there are data which show both excellent retention of habițuation and substantial forgetting.

In addition to these ambivalent findings, further confusion appears when the retention measures employed in these various studies are given closer scrutiny. For example, two studies which reported good retention of habituation in mollusks based their conclusions on relearning scores (Carew, Pinsker o Kandel, 1972; Carew \& Kandel, 1973). It was found in each study that considerable saivings occurred for subjects relearning the task relative to the acquisition of a naive control group. Examination of the early retention trials, however, reveals a considerable decrement for the relearning groups, relative to their terminal performance of acquisition. These decrements extended over at least ten: trials and would, therefore, seem to qualify as legitimate cases of forgetting. A similar criticism can be made of the reported retention of habituated movement responses in earthworms by Ratner and Gilipin (1974). Although a significant savings was found for reacquisition, relative to original acquisition, a considerable decrement again can be seen in the comparison of the early trials of relearning with the terminal performance of acquistition. This decrement appeared over a number of ten trial blocks, and would seem to indicate that forgetting had, indeed, occurred. Thus, not only are there reports of both forgetting and retention of habituation, but inconsistent measurement procedures 
and interpretational anomolies make this research difficult to collectively evaluate.

A. somewhat similar situation exists with respect to classical Conditioning. Research on the forgetting of classically conditioned responses has been primarily restricted to the study of aversive stimulus events involving fear (Brush, 1971). Some of the early studies tended to support the permanancy doctrine of S-R psychology: That once formed, habits are permanently preserved. For example, a well known study by Hoffman, Fleshlér \& Jensen (1963) tested retention in pigeons for key peck suppression to a tone that fàd been paired with shock; after $2 \frac{1}{2}$ years the presentation of the tone was stili-able to effectively suppress keypecking. A subsequent study by Hoffman, Selekman and Fleshler (1966) retested the same animals after an additional three years and again found no forgetting.

The, retention of conditioned suppression has also been tested in rats. Failures, to find any substantial forgettịng of suppresṣed water " licking in adult rats has been reported for intervals of 42 đays (Campbell \& Campbell, 1962) and 64 days (Berk, Vigorito \& Miller, 1979 ). Conditioned suppression of bar pressing has been found to be well. retained oversintervals of 21 days (Thomas, 1979). 42 days (Coutler, Collier \& Campbe1l, 1976), and $90^{\circ}$ days (Gleitman and Holmes, 1967). . lother measures of conditioned fear have also yielded excellent reten, tion. These include the Miller fear escape task (Campbell \& Campbell, 1962) and learned helplessness (Hannum, Rossellini \& Seligman, 1976)t That conditioned fear is permanent, however, is clearly not the case. For instance? Spedr and Parsons (1976) have shown that considerable forgetting occurs in rats on a "hurdle jumping, escape from fear task" 
after 28 days, in both adult and younger animals. McAllister and MicAllister (1968) reported forgetting in a similar test after just 47 hours.

In addition to these straight-forward demonstrations of forgetting, there are other findings which indicate that certain features of conditioned fear are susceptible to retention deficits. One well established finding is that younger rats often evidence substantial forgetting in situations in which adults do not (Campbell \& Campbell, 1962; Campbell \& Jaynes, 1966; Coulter, Collier \& Campbell, 1976). Another important 'effect concerns the asymetrical retention of conditioned excitation and conditioned inhibition. Hammond \& Maser (1970) used a delay conditioning procedure to establish conditioned suppression to a tone. With this procedure a temporal discrimination developed, in which significant suppression occurred near the end of the conditioned tone presentation, with little or no suppression occurring earlier. Such an arrangement has typically been interpreted as involving both conditioned excitation and inhibitions. The early segment of the conditioned stimulus comes to act as an inhibitory signal for fear, while the end segment becomes an excitatory signal for fear (Pavlov, 1927). In this study, it was found that after a 25 day retention interval the total amount of conditioned suppression was the same as at the end of acquisition; although, the distribution of suppressed behavior during the tone presentation changed over the interval. The acquired temporal discrimination, which yielded greater suppression at the end of the tone presentation, was absent after 25 days. It was concluded that the conditioned inhibitory properties associated with the early portions of the tone were forgotten. Similar reports of retention of a fear excitator and forgetting of 
a fear inhibitor have been found after 21 days (Thomas, 1979) and 35 days (Henderson, 1978).

An additional finding of importance concerns the forgetting of attributes of the CS. Thomas and Riccio (1979) showed that while the general ability of a conditioned stimulus to elicit fear may be preserved over a retention interval, some specific attributes of the stimulus may undergo forgetting. In this study the retention of conditioned fear to a tone was measured by its ability to block further conditioning to a light when the two stimuli were presented in compound. Following conditioning to the tone alone, compound conditioning was given to the light a - paired with either the same frequency tone used in the previous phase or a different frequency. They found that one day after initial training with the tone alone, only the original frequency tone blocked conditioning to the light, while, after a 21 day interval other frequencies also produced blocking. They argued that the frequency attribute of the tone had been forgotten after 21 days.

Collectively, the data on conditioned fear'suggest that while excelient retention may be found, sufficient 'evidence exists which shows that these responses do undergo forgetting, and that such conditioning is clearly not permanent. Also, a number of variables, such as age, form of conditioning (excitation vs. inhibition) and the precise features of the conditioned stimulus /may influence the occurrence of forgetting.

As with classigal conditioning, thegre have been several demonstrations of excellent tetention for instrumental conditioning. Skinnẹ 1938) reported that resistance to extinction for a positively rein-. forced bar-press, response in rats did not differ at one and 45 days. 
Gleitman (1971) also found that resistance to extinction did not decrease as a function of a 52 day retention interval; there was actually greater resistance after the long interval than when extinction was carried out immediately. In another frequently cited-paper, skinner (1950) describes data from a keypeck study with pigeons. The birds had been originally trained to peck at an illuminated disc for food reinforcement. It was found that four years following acquisition the birds quickly resumed pecking upon reintroduction into the test apparatus. It is interesting, however, that while skinner argued that the data showed that little forgetting had occurred over the four years, the alternative interpretation, that forgetting had indeed occurxed, has also been made (Gleitman, 1971). Skinner's retention test consisted of extinction, and he reported that the number of responses that resulted were "... of the order of one-half to one quarter of the responses it would have emitted if extinction had not been delayed four years" (p. 201). Such a decrement would clearly qualify as an instance of forgetting according to most contemporary definitißns. Nonetheless, there are. other reports of excellent retention for instrumental conditioning. Wendt (1937) trained a dog to flex his hind leg in order to terminate or ayoid electric shock to the fore paw. He reported no forgetting of this response after two and one-half years. Excellent long-term retention has also been found for escape training in paramecia (Huber, Rucker.\& MCDiarmid, 1974), and escape-avoidance behavior in rats (Dicara \& Miller, 1968). Excellent retention of punishment has been reported for a pecking fesponse in Japanese quail (Meinecke, 1974). The tendency, to peck a bead was suppressed in young, adult, and aged quail by coating it with an aversive substance. This suppression remained intact over eight

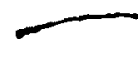


days. Also, retention was found to be a function of the severity of the punishment. The more aversive the substance placed on the bead, the better the retention of the suppressed pecking.

That instrumental conditioning is not always well rètained has also been documented. For example, Gleitman \& Bernheim (1963) found that the typical response pause associated with fixed interval reinforcement schecules was absent following a 24-day retention interval. Gagne (1941) found a progressive decline in zunway speeds in rats over in- ' creasing retention intervals from 3 to 28 days. Gleitman \& Steinman. (1963) similarly found that rats tested 64 days after being trained to run in a straight runway ran significantly slower than a group tested at

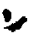
one day. Evidence is also available for forgetting of a runway response over an interval as short as 24 hours. 'Hill, Exlebacher, and spear (1965) found a decrease in running speed from the terminal trial of one day to the initial trial of the following day, in animals that had extensive priox nonreinforced experience in.the runway. In addition, Steinman (1967), while reporting a decrease in running speed over a 66 . day interval, found that subjects initially trained with a high" magnitude of reward still ran faster than a group given a lower magnitude of reward after the retention interval. Thus, certain characteristics of runway behavior may show forgetting while others may not,

Another instrumental response tendency found to undergo forgetting involves the depression effect accompanying shifts in reward magnitude. - When rats are reinforced with a' relatively high magnitude or desirable reward and are shifted to a lower magnizude or less desirable reward, a decrease in response, strength appears (Piejper \& Marx, 1963t. This so called depression effect can be attenuated or eliminated by imposing a 
delay interval between the reward shift. Gleitman \& Steinman (1964) found that a depression effect which appeared on a one-day retention test, as measured by running speed in a straight alley, was absent for a group shifted after a 68-day interval. Similarly, Gonzales, Fernhoff \& David (1973) found a progressive decline in the depression effèct for runway performance over intervals of $1,26,42$, \& 68 days; by the 68 th day the effect was completely abolished.

These findings, which suggest that rats forget the magnitude of reinforcement assodiated with acquisition, have been extraploated to account for resistance to extinction effects. One such.interpretation involves the well known contrast effect found with extinction'. Extinction proceeds more rapidly following reinforced training with higher magnitude rewards than with relatively lower values. One explanation of this, effect has been that a greater depression effect is assumed to accompany transfer to extinction from training with a high magnitude of reward than from a low mägnitude of reward. If this is the case, then the imposition of an extended interval between reinforced training and extinction should attenuate the depression effect, and thus reduce the differential rate of extinction typically found in comparing high and low reward conditions. .. Just such an effect has been reported by Gonzalez et al (1973). They found that when extinction was given one day after reinforced runway experience, a group given a higher magnitudé of reward extinguished faster than a group given a lower reward value. When extinction was carrièd out 68 , days after reinforced training, the groups did not differ in their rafes of extipction. A similar analysis has been applied to partial reinforcement, effects. A group given continuous reinforcement should experience a greater depression effect when $\Rightarrow$ 
transferred to extinction than a partially reinforced group. With an extended interval, between reinforced practice and extinction, the depression effect should be weakened and rates of extinction between groups given continuous and partial reinforcement should dissipate. Aiken and Gibson (1965) have reported such an effect: They found that rats given extinction one day after partially reinforced practice took longer to extinguish than a continuously reinforced group. After a 21 day interval, however, the extinction rates for the two groups did not differ:

Avoidance conditioning has been one of the most popular preparations used to study forgetting of instrumental conditioning. One of the most conspicuous and interesting problems in this area has been the so called Kamin effect (1957). This involves the U-shaped retention function, in which substantially more forgetting appears at intermediate intervals, of between one and six hours, than either immediately after acquisition or after 24 hours. The effect has been found for both active and passive avoidance, as well as signaled escape (Brush, 1971; Spear, 1971, 1978). In addition to this unusual nonmonotonic forgetting function, further forgetting of avoidance conditioning often occurs at more extended intervals. For example, Smith \& Spear (1979) have shown forgetting of active avoidance at intervals of 7,14 and 28 days. Conversely, excellent repention of active avoidance was found in adult rats after 30 days by Potash and Ferguson (1977). While both studies employed shuttle box avoidance and a isimilax acquisition criterion, there were $a$ number of minor procedural differences that could explain t the divergent results. These include different shock signals, location of the animals during intertrial intervals, and the type of retention 
test given (Smith and Spear employed an extinction test, while Potash and Ferguson used relearning). In addition, and perhaps of greatest importance, the measures of retention differed. Smith and Spear mea$x$ sured cross-over latencies during extinction and Potash. and Ferguson measured trials to criterion during relearning. It has been argued that latency measures may be more sensitive to forgetting (Gleitman, 1971), and this might explain the absence of forgetting reported by Potash and Ferguson. A similar criticism could be made of another reported failure to find forgetting of active avoidance with a runway procedure (Kirby, 1963). Based on a modified savings measure it was concluded that adult rats evidenced good retention over a 50 day interval, although infant animals did show forgetting over the same interval. The absence of forgetting in the adult animals in Kirby's study may again be a function of having used a less sensitive measure of forgetting.

This problem of variable measures of forgetting is a major obstacle in evaluating the highly diverse findings on long-term forgetting in animals. It is further illustrated in a study by Thompson, Konigsberg and Tennison (1965). They trained rats 25,50 and 100 days of age to. avoid shock in a shuttlebox. Retention was tested at intervals of 0,50 and 100 days. This involved an extinction test followed by a relearning test. Data from the extinction test, indicated that complete forgetting had occurred for all age groups at the 50 and 100 day intervals. Based on relearning, which involved a comparison between rates of reacquisition and the learning rates of a naive control group, significant retention was found for all age groups at all-delays. The problem is that while a savings measure may indicate that considerable retention 3 has occurred, such a measure ignores any absolute alecrements that may 
have occurred between the terminal performance of acquisition and the early phases of retention testing. These decrements, even if they are fairly transient, would seemingly need to be accounted for, and may provide important insights into memory processing. Reliance on savings measures alone may reduce the opportunity to observe these changes. Thus, perhaps the best strategy is to employ two or more measures of retention. As an example of this approach, Feigley and spear (1972) tested the retention of active avoidance in rats at one and 28 days. Based on initial test trial cross-over latencies, adult rats were found to exhibit significant forgetting over the 28 days. Relearning scores, however, showed no significant forgetting over the same interval.

The forgetting of stimulus control has been studied with both discrimination and generalization. A number of studies have investigated - forgetting of discriminations by using choice mazes. These have included both simultareous and successive problems, with both visual and spatial discriminanda. Forgetting of a positively reinforced, simultaneous, visual discrimination has been found for rats after a three-day interval with a T maze (Hill, Cotton, Spear \& Duncan, 1969) and after 28 days with a two-choice alley (Hamburg \& Spear, 1978). 'Bryan \& Spear (1976) found a Kamin Effect in rats for a negatively reinforced spatial $T$ maze discrimination. A similar forgetting function has been reported for a spatial $T$ maze discrimination in beetles. Greater forgetting was found after two days than after one, four or five days in beetles refrigerated during the retention interval (Alloway \& Routtenberg, 1967). This effect was obtained with both relearning and reversal learning 
tests of retention. Another unusual finding from this study was a reminiscence effect. Retention improved over the longer retention intervals. A subsequent study by'Alloway (1969) replicated the unusual two day deficit for both larval and adult beetles held in cold storage during the retention, interval. In addition, considerable forgetting over ten days was observed in a group maintained at waṛm temperatüres.

There have also been several studies which have failed to observe any significant forgetting with choice mazes. Campbell, Misanin, White and Lytle (1974) found no forgetting in adult rats and guinea pigs for a simultaneous spatial discrimination after 14 days. Rickard (1965) and Crowder (1967) also failed to find forgetting in rats for a $T$ maze spatial problem over a seven-day interval, while Kopenaal and Jagoda (1968) reported no forgetting of a spatial discrimination on a plus maze after 72 hoúrs. Data from complex multiple unit mazes, however, indicate that. in these more complicated situations, spatial discriminations are often forgotten (Tsai, 1924; Corey, 1931; Magdsick, 1936; Bunch, 1941); although, there have been reported failures to find forgetting even with these tasks (Anderson, 1940).

The situation with respect to simultaneous visual discriminations with mazes is similar to that for spatial discriminations. There are data showing both excellent retention and substantial forgetting for these problems. Good retention for simultaneous brightness discriminations has been reported for a $T$ maze task over a five-day interval (Chiszar \& Spear, 1968), in a Y maze after seven days (Daniels, 1971), in a two-choice straight alley after 14 days (Tryggvason \& Tees, 1974), and with a, four-unit alley discrimination over eight days (Thompson \& Fitzsimons, 1976). Also, Neylon and Brosgole (1974) reported excellent 
retention for a visual escape problem after six months in gerbils. (One problem with this study, however, again pertains to the method used to assess retention. While the overall relearning scores did show considerable savings, relative to original acquisition, the early relearning trials were markedly inferior to the terminal trials of acquisition. Thus, while these investigators concluded that exceptional retention had been demonstrated, it could be argued that forgetting had also oćcurred).

In contrast to the above examples of well retained discriminations, there are also reports of forgetting. Brightness discriminations were forgotten over 28 days in both a $T$ maze task (Hamburg \& Spear, 1978) and a Y maze task (Deutsch \& Leibowitz, 1966). It is interesting that the retention interval in which forgetting was obtained was considerably longer than in the above studies which failed to find forgetting. This illustrates the importance of employing relatively extended retention intervals. It is possible that in those cases in which forgetting did not obtain; the use of longer retention intervals may have yielded entirely different results. In addition to forgetting at long retention intervals, a Kamin Effect has also been obtained for a brightness discrimination in rats (Bryan \& Spear, 1976).

Forgetting of discriminations has also been examined for tasks involving response manipulanda as opposed to choice mazes. Gleitman and Jung (1963) found no forgetting of a spatial discrimination involving a keypress response in rats after 44 days. Excellent retention has also been found for visual discriminations in rats over $32^{\prime}$ days (Maier \& Gleitman, 1967), in 'nocturnal prosimians after 22 months (Ehrlich \& Musicant, 1976), in pigeons after 14 days (Behrend, Powers \& Bitterman, 
1970) and 30 days (Kehoe, 1963)', and with an elephant after eight years (Markowitz, Schmidt, Nadel \& Squier, 1975). Of particular interest is the fact that the author was unable to find a single study demonstrating long-term forgetting of a simultaneous discrimination involving response manipulanda. Thus, an important question to be addressed by any viable theory of forgetting would concern the contrast between simultaneous discriminations inyolving maze procedures and those involving response manipulanda. With choice mazes there is evidence of forgetting for both visual and spatial problems, but studies employing manipulanda have generally failed to produce forgetting for either visual or spatial problems. .

There have bèn comparatively few attempts to study forgetting of successive discriminations. This is despite the possibility that such - problems may be more susceptible to forgẹtting (Glèitman, 1971). In one of these studies Campbell, Jaynes and Misanin (1968) failed to find forgetting in adult rats for a successive bar-press discrimination over à retention interval as great as 150 days. Younger rats, however, have shown forgetting on a similar problem (Campbell \& Jaynes, 1969). Excellent retention over a three month interval has also been reported in monkeys for a classically conditioned colour discriminatión (Kimmel, Brennan, McLeod, \& Raich, 1979). In contrast, there is at least one report of forgetting of a successive discrimination. Ludvigson, MCCleary and Boedeker (1980) trained rats to run in a straight alley for food reinforcement. Discrimination training was then provided, during which responses on St trials continued to be rewarded, while reward was absent an S-trials. The dependent measure was running speed recorded in several different portions of the alley. A Kamin effect was report- 
$\therefore$

ed, in which the acquired slower running speeds during $S-$ trials dissipated at an intermediate. interval of 1.25 hours. The effect, however, was confined to the first segment of the alfey. The authors concluded that the subjects forgot to suppress responding during S- trials at the intermediate interval. An apparent confound with these results, however, is that not only was there an elevation in running speed on the early alley segment for S- trials, but there was also an elevation for St trials as well. Thus, the change in running speeds at the intermediate interval may represent a performance artifact. Following acquisition, the animals may have had a general increase in activity at the intermediate interval.

Forgetting of stimulus control has also been assessed through generalization tests. Perkins \& Weyant (1958), inyestigated generalization decrement as a function of a retention interval in rats. Running speeds were measured in straight alley that was either the same as was used for original acquisition or novel. These reteption tests were administered either 60 seconds or seven days after afquisition. They found that when tested at 60 seconds, animals ran significantly faster in the same alley as. employed during acquisition than in a novel alley, which differed in terms of brightness (i.e., white or black). At the seven day interval, however, running speeds for groups tested in the same alley and the novel alley div not differ. Steinman (1967) has also shown forgetting for brightness cues in a straight runway task over a 66-day interval.

The influence of retention intervals on generalization has also been studied in pigeons for keypecking tasks. Thomas \& Lopez (1962) found that wavelength generalization gradients, obtained from pigeons 
following variably reinforced responding to a coloured key, changed as a function of the interval between training and testing; they found significant flattening of the gradients obtained at one and seven days after acquisition, relative to gradients obtained immediately. The essential difference between the gradients was that subjects tested at one and seven days failed to restrict responding to the original stimulus value employed during acquisition. Two other features of this study are noteworthy. First, there was no difference between performance at one and seven days. This suggests that the forgetting associated with this preparation may reach asymptate at one day. This might explain why Thomas, Ost and Thomas (1960) failed to find any forgetting with a similar procedure after intervals of 1, 7, and 20 days.. Second, the absolute amount of responding for all stimuli tested was greater in the one and seven day groups than in the group tested immediately. This may indicate that the obtained forgetting may in part be motivationally based, and may not be purely a matter of memory processing. The group tested immediatelo may have beén less motivated to respenerally. Thus, the imposition of a retention interval between acquisition and testing may have influenced the birds' motivation or "willingness" to respond to novel stimuli, rather than their ability to recognize stimuli as novel, based on some memory for the original st.

A subsequent study by Thomas and Burr (1969) attempted to control for this possibility by prefeeding half of the subjects tested at a oneday interval. Flatter gradients were still obtained at a one-day interval as compared to an immediate test. In this study, original training consisted of a successive go/ no-go aiscrimination between two values of wavelength. It has generally been found that such training 
both sharpens subsequent generalization gradients, relative to single stimulus reinforced training, and causes the peak of such gradients to shift away from the original st in a direction away from the $s-$. (Rilling, 1977). In addition to the flatter gradients obtained at a one" day interval, Thomas and Burr found greater peak shifts for the subjects tested at one day. Again, this raises the question as to whether the performance changès associated with this paradigm entail only memory processes or involve some other mechanisms as well. If stimulus control is assessed according to the shape of the generalization gradients, then indeged, Thomas \& Burr have shown forgetting of stimulus control. The peak shift data, however, seem to contradict the notion that stimulus control was lost over the one-day retention interval. If the amount of peak shift reflects the degree of stimulus control established during discrimination training, then it would appear that no decrement had occurred. A greater peak shift resulted at the fone-day test than at the nondelayed test. These data seem to present interpretational difficulties. One response measure, the shape of the generalization gradient, showed a decrement over the retention interval, while another measure, the amount of peak shift, showed no such decrement and actually showed facilitation.

c. Interference.

The popularity of interference theory has lead researchers to emphasize interference as the primary or sole source of forgetting. This can be seen most clearly in a rather uncompromising statement by Spear. (1978) in which he asserts: "Forgetting' is caused by interference. There is no doubt about this, but the major task is to 
determine under what circumstances, and through what mechanisms, this occurs" (p. 186). This position certainly can be supported by both human and animal research, yet some more recent experiments may require a reevaluation of the decay principle (Loftus \& Loftus, 1979). Nonetheless, the evidence from animal studies clearly suggests that interference is a. primary determinant of forgetting.

The role of interference in animal forgetting has been studied in terms of two principle research strategies: the Retroactive (RI) and Proactive (PI) inferference tasks. In a RI design, the subject is first trained to criterion on some task and then, prior to a retention test, is exposed to some additional event. Enhanced forgetting as a function of the interpolated experience, relative' to a control group which receives no such experience, is defined as RI. Conversely, PI is defined as enhanced forgetting resulting from experience provided prior to the acquisition of the to-be-remembered event, relative to a control group given no such prior experience.

Studies of $R I$ in animals have involved both 'nonspecific and specific interference manipulations. Nonspecific RI involves interpolated activity which is not directly relevant to the original learning episode. The classic study by Jenkins and Dallenbach (1924), in. which the interpolated activity was either sleeping or remaining awake, exemplifies nonspecific RI. Similar manipulátions of nonspecific RI have been carried out with animals. These have involved the comparison of forgetting between groups whioh spend the retention interval in either a highly active or inactive state. For example, Minami and Dallenbach (1946) found more forgetting of a shock avoidance task in cockroaches (Periplaneta americana) that were given forced 
treadmill running immediately after acquisition than in an inactive group, which was wrapped in tissue paper during the retention interval. A similar effect has been found with beetles (Alloway, 1969); animals which were refrigerated following discrimination training, and which were consequently less active, showed much less forgetting than a group maintained at higher temperatures during the retention interval. Even with invertebrates, increased activity during retention intervals has been shown to increase-forgetting. Hicks, McDaniel and Hensley (1973) tested retention of an escape discrimination task in isopods 18 hours after acquisition. One group was rendered immobile during the retention interval by being wrapped in cotton, while another group was allowed to move about freely; significantly more forgetting was found for the active group.

Another way in which non specific RI has been studied has involved tests of retention after metamorphosis. Many of these studies, however, have found that metamorphosis does not seem to produce RI. Alloway (1972) reported good retention of a discrimination over metamorphosis in Grain Beetles (Tenebrio molitor), both in terms of relearning and reversal learning measures. Similarly, metamorphosis has been found not to produce RI in crested newts (Triturur cristtus) (Hershkowitz \& Samuel, 1973) and African Claw Toed Frogs (Xenopus laevis) (Miller \& Berk, 1977). These findings would tend to suggest that RI resulting from nonspecific sources may not simply be a matter of general behavioral or physiological activity during the retention interval. It seems that the activity must in someway involve information processing." Data germane to this argument can be found in a study by Parsons \& Spear (1972). They found that rats given environmental enrichment during a 60 
day retention interval - which consisted of being housed in a group cage containing other animals and stimulus objects not present in the nonenriched single cage environment - displayed more forgetting tha the nonenriched animals. They were also able to show that this effect was not related to general activity differences associated with the two environments. Thus, it would appear that for nonspecific RI to occur, the organism must actually process additional information during the interpolated activity. This may then somehow intexiere with the retrieval of the target event and produce enhanced forgetting.

The study of specific RI in animals has typically entailed the presentation of interpolated activity which is related to the original learning event. For example, Waters and Vitale (1944) trained rats on a 7 14 unit multiple $T$-maze, and then provided interpolated activity in the form of additional learning on another maze. They found, however, no evidence of RI with this procedure at either one or ten days; although, * similar studies with multiple unit mazes have.often reported RI (Waters . \& Vitale, 1944).

An obvious factor which would influence the occurrence of RI in such studies would be the similarity of the interpolated task to the original problem. The extensive research on RI in human verbal learning experiments has shown that the similarity between interpolated and original learning is the crucial variable determining interference (Bugelski \& Cadwallader, 1956; McGovern, 1964). Thus, in attempting to maximize interference effects in studies of RI in animals, researchers have often employed reversal training as the interpolated activity. As an example, Frankman (1957) found RI for a spatial discrimination in rats after reverse discrimination training. In addition, it was found 
that RI increased with the amount of reversal training given, and decreased as the retention interval increased; both of these results are consistent with human verbal learning research (Spear, 1978). Crowder (1967) also found RI from reversal learning to decrease over retention intervals ranging from 0 to one week, while Chiszar and Spear (1969) found a similar effect over 21 days. In the latter study it was also found that RI could be eliminated by providing reversal training in a different context from that used for original learning (Reactivation treatments have also been shown to be effective in reducing RI resulting from reversal training; Smith \& Spear, 1979). Crowder, cole and Boucher (1968) were able to produce RI in rats for both complete reversal and partial quetsal training on a three choice discrimination problem. For complete reversal, subjects experienced the same stimuli but with the reinforcement contingencies changed, so that the original St became an S- and one of the original S- became an St; partial. reversal involved reinforced experience with only one of the original sdisplays available. It was found that more RI resulted undex complete reversal than for a partial reversal condition. Reversal discrimination training has also been found to produce significant RI in pigéons for a - five choice colour discrimination (Kehoe, 1963).

While these studies taken collectively would seem to strongly support the notion that reversal training is a powerful source af RI in animals, there is a fundamental problem with all such studies that may limit their importance. Animals given raeversal training can not be instructed to provide responses correct for the originat problem as 'ffumans can' (Zentall, 1970;' Spear. 1978). The deficits noted in these studies may simply indicate the tendency of the animals to respond 
correctly according to the most recent contingencies. Thus, the exaggerafed decrements for originàl learning induced by reversal training may not actually reflect forgetting of the oxiginal problem, but rather max inaicate good retention of the reversal problem (spear, 1978).

As an alternative to the use of reversal training, Wickens, Tuber, Nield and wickens (1977) relied on a transfer paradigm that has frequently been used in verbal learning studies of RI. Following conditioned paw flexion to a light or tone $\mathrm{cs}$ in cats, additional conditioning was conducted in which the CS and $C R$ were changed in various combinations. One group was trained to flex the same paw, to a different.CS; a second group was trained to flex a different paw to the same CS̊; a third group 'was 'conditioned to flex a different paw to a different' CS, while a fourth group served as a control and received no additional conditioning. These various transfer conditions allowed RI to be assessed in terms of stimulus and responsè. similarity between original and interpolated learning. In terms of a CS alone retention test administered ten weeks after original conditioning, all of the interference groups showed more forgetting of the original conditioning than the control group which received no interpolated learfing; the latter group evidenced.no forgetting of the conditioned response. There were two unexpected results, however, which are not in accord with results. obtained in verbal learning experiments. First, the greatest interference occurred for the group given interpolated conditioning involving a new $C S$ and a new $C B$. This condition has typically resulted in little, if any,' RI in verbal learning research.' Second, when the groups were tested in relearning, only the group given training with a new cs and a. 
new $C R$ was different from the Control group. This kind of relationship is again atypical with respect to verbal learning studies. While these anomolies clearly suggest further research, the value of this'study is that it offers a sound alternative to reversal training procedures often employed in RI studies with animals. The most striking advantage of this preparation is that specific aspects of the learning event can be manipulated in terms of similarity; this factor has, unfortunately, not received adequate attention in previous animal memory research.

Studies of PI in animals have generally involved specific rather than nonspecific manipulations of interference. Often, discrimination reversal has again been used: A number of these studies have found significant PI, and have shown that PI increases with longer retention intervals. These results are consistent with data from verbal learning experiments. For example, Gleitman and Jung (1963) found significant PI after 44 days for a spatial discrimination in rats due to prior experience with the reverse discrimination; at one day there was no such effect. Similar findings with rats have been reported for a brightness discrimination over intervals of one and five days (Chiszar, \& Spear, 1968), and a visual discrimination over intervals of one and 32 days (Maier \& Gleitman, 1967), Prior training on a reverse discrimination has also been found to enhance forgetting in pigeons, as measured by generalization gradients (Burr \& Thomas, 1972). Greater flattening of such gradients was obtained one day after reverse discrimination training than one day after experience with a single discrimination. Partial reversals of discriminations have also been found to produce PI in animals. Maier, Allaway and Gleitman (1967) first trained rats on a 
two-choice simultaneous, visual discrimination. Half the animals then recieived a discrimination in which the previous $S+$ became an $S-$ and was paired with a new st. The other half was given a new-s- paired with the old s-, which was now changed to $s+$. Retention for the most recent discrimination was tested after one and 32 days. Significant forgetting occurred for both partial reversal conditions after 32 days, relative to terminal, agquisition performance, but not after one day. Although a control group was not included, a previous study by Maier and Gleitman (1967) found no forgetting of a single discrimination of the type tested, so that it could be concluded that PI was responsible for the forgetting observed. Koppenaal and Jagoda (1968) reported similar , results for a two-choice position discrimination. Rats were first trained to turn in one direction and then trained to make the opposite turning response on a plus maze. Progressive PI was found, relative to a group given single response training, over intervals of $.5,24$ and 72 hours. Finally, PI has also been established with conditioned avoidance in rats (Spear, 1971). Chiszar, Gordon and spear (1972) found more forgetting of active avoidance khen it was preceeded by passive avoidance experience. Also, the amount of PI was found to increase with the degree of passive, avoidance training and with longer retention intervals.

It is important to note, however, that not all studies which have attempted to study $\mathrm{PI}$ in animals have been successful. For example, Kehoe (1963) was unable to demonstrate PI for a five choice, discrete trial, colour discrimination in pigeons. Prior reinforced training with one of the colours as st did not interfere with the retention of a $a^{\infty} \ldots$ reverse discrimination, in which a new colour served as st, after 
intervals of 1, 10, and 30 days. Similar failures to find PI with the reverse discrimination procedure have been found for spatial problems in rats (Rickard, 1965; Crowder, 1967). While there have been attempts to explain these null results (Spear, 1967, 1971; Gleitman, 1971) these post hoc efforts are perhaps of Iimited value, due to their speculative nature. The more important point is that PI has been shown to occur with reversal procedures, and in those cases in which it has been found it has increased over time, which is consistent with human experiments. In addition, there have been other situations found to produce PI which do not involve discrimination reversal. For example, Chiszar and spear (1968) measured the latency for rats to consume food that had been tainted with quinine, either after prior experience with normal food or without such prior experience. Significant PI was shown in terms of. decreased latencies to consume the food after .60 minnutes in the group given prior food experience; after one minute no difference between the groups was observed. Spear (1967) has also reviewed evidence showing that experience with a given reinforcer magnitude can interfere with the retention of a subsequent reinforcer magnitude. Thus, the importance of PI as a source of forgetting is not restricted to reverse discrimination problems.

In addition to direct examination of $\mathrm{PI}$, there have been attempts to employ PI as an explanatory mechanism for various phenomena. For example, Gonzalez, Behrend and Bitterman (1967) argued that improvement in serial discrimination reversal (SDR) depends on PI. They postulated that over the course of SDR training PI accumulates and interferes with the retention of the most' recent discrimination. When the animals are then shifted to the next reversal of the discrimination, the poor 
retention of the previous problem facilitates performance on the new problem. Empirical support for this proposition has been provided by Behrend, Powers, and Bitterman (1970). These researchers tested pigeons for the retention of two-choice visual discriminations. All animals were first trained on a discrimination and then tested with relearning after one or 14 days. Following the retention test, reversal training was conducted with an additional retention test for this problem, again at either one or 14 days. This procedure was continued for two more reversals. Thus in all, retention tests were given for the original discrimination and the three subsequent reversals. While no forgetting was found at either interval for the original problem, forgetting of the subsequent problems did obtain with an increase in the amount of forgetting for each subsequent reversal. Also, more forgetting appeared at the 14 day intervals. They argued that these findings support the PI explanation of SDR. There are, however, problems with this explanation. First, while differences in the relearning'scores were obtained across successive problems and between the two jintervals, the absolute number of errors made during relearning do not appear to be different from performance at the acquisition criterion. The greatest mean errors reported for any of the problems or intervals was less than four, while the total number of errors allowable at criterion for the same number of trials was sixl Thus, in terms of performance at the end of acquisition and during retention testing, there is little if any evidence of forgetting under any of the conditions in the Behrend et al (1970) study. Another problem for the interference interpretation of SDR is that a subsequent study with rats by Calhoun and Handley (1973) seems to: oppose the PI explanation. In this experiment rats were trained on $a$ : 
series of 33 successive reversals of go/ no-go discriminations. The animals were then tested 32 days later. Half, received the same discrimination that they had on day 33, while the other half was given the reverse discrimination. If the PI argument of SDR is correct, then both groups should have performed similarly on their respective discriminations, since the accumulated PI would be expected to interfere equally with the retention of eithef discrimination. The results indicated, however, that there was better performance on the nonreversal discrimination than on the reversal problem. These results wourt, therefore, challenge the PI interpretation of SDR. Thus, while PI appears to be a potent source of forgetting in animals it has not always been obtained, and may not always be extended as an explanatory mechanism for other phenomena.

I

d.: Contextual determinants of forgetting.

There is considerable evidence implicating the importance of contextual cues in memory processing. Contextual cues have typically been defined as cues present during the learning episode, but which are not . necessary for learning to take place, although, these cues may exert an influence on both learning and retention: The concept of contextual cues can perhaps best be understood, in terms of Underwood's. (1969) distinction between categories of memory attributes: task dependent and task independent. Task dependent attribuțes pertain to those features of a learning event that are directly relevant to the occurrence of the target response. These would include such cues as the cs in classical conditioning and discriminative stimuli in instrumental conditioning. 
These are cues which are most highly correlated with the target response and the environmental events which define'the learning episode. The presence of such cues are a necessary condition for the target response to occur. All other cues which may be correlated with the learning event, but upon which the target response does not depend, would be defined as task independent. These can be referred to as contextual cues. For example, for a spatial discrimination in a $T$ maze, specific cues which define the appropriate choice arm and distinguish it from the incorrect arm would be task dependent attributes of the target memory representing this event. Any other cues, such as the texture of the maze floor, ambient odors or the internal physiological state of the organism during training, could all be considered contextual cues or task independent. While these cues can not aid the animal in choosing the correct alternative, which defines the target response, they can influence performance.

A study by Riccio, Urda and Thomas (1966) illustrates the importance of contextual cues. Pigeons were trained to peck an illuminated key for variable food reinforcement with the floor of the chamber either horizontal of inclined at 30 degrees. They were then given generalization testing in which key pecking was assessed under various angles of floor inclination. Even though the angularity of the chamber floor was not a necessary condition for reinforced pecking at the stimulus key, the results indicated that floor tilt did influence performance. Total responding to the key was less when the floor inclination during the generalization test differed from acquisition. Other experiments have similarly shown that features of the testing apparatus that are not directly relevant to the target response can have 
a dramatic influence on performance. For example, rats trained to runin a straight alley evidence slower running speeds when tested in an alley that differs in brightness cues (Perkins \& Weyant, 1958; Steinman, 1967). Miller (1960) reported that rats trained to run for food in a. straight alley could learn to persist approaching food when shocks were administered in the goal box, if the animals were gradually exposed to increasing shock intensities. This effect, however, only, appeared if the shocks were administered in the testing apparatus; $a$ gradual shock series provided outside the apparatus did not produce persistance.'

Hickis, Robles and Thomas (1977) reported significant effects for context manipulations on postdiscrimination generalization gradients. They trained pigeons on two separate interdimensional discriminations on. alternate days. One discrimination consisted of a particular value of wavelength as the $\mathrm{St}$ and a line orientation as the $\mathrm{s}-$. The other discrimination involved a different line orientation' as the $s+$ and a different wavelenth as the S-. In addition, contextual cues were either the same for both problems or different. They found that when the context was the same for both problems, generalization gradients obtained for both wavelength and line orientation were as if the animals had received intradimensional training, on these problems. Peak shifts were obtained on the colour dimension as if the two colour stimuli had been part of the same discrimination; the same occurred for the line orienta- tion dimension. When the contextual cues were different between the two problems, no peak"shifts were obtained on either dimension. Related context effects) have been obtained with classical conditioning. Desiderato, Butler and Meyer (1966) classically conditioned a light as a fear stimulus and then tested conditioning by examining the rates of ac- 
quisition in a hurdle-jump-escape task. When this training was conducted in a different apparatus than was used during initial conditioning, a significant-decrement was noted. Finally, Bouton and Bolles (1979) tested the ability of uS presentations to reinstate conditioned fear following extinction. They found that such a procedure was only successful if the US presentations occurred' in the same context as the subsequent reinstatement testing.

These examples show that exogenous contextual cues can significantly affect performance. Endogenous contextual cues have also been found to influence learned behavior. The phenomenon of state dependent retention is one such example. It has been shown that animals trained during a particular drug state show a deficit when tested in a different drug state (Overton, 1964; Bliss, 1972; Spear, 1978). Some of the unusual multiphasic retention functions that have been reported can also be interpreted as instances of endogenous contextual cue effects. For example, the highly regular multiphasic retention found with passive and active avoidance in rats, seems to be related to internal contextual cues which change periodically over the course of 24 hours (Holloway \& Wansley, 1973; Wansley and Holloway, 1975; Hunsicker, 1977; Spear, 1978).

One explanation of context effects relies on the notion that all stimuli present during learning become conditioned to exert stimulus control over responding. Any contextual cues present during learning will become part of a global stimulus associated with the learning event. According to this view, contextual cues function like any other stimuli which come to control performance. Learning is regarded as context specific, in that subsequent transfer tests or retention tests 
will be influenced by any contextual changes from original acquisition. Thus, changing the brightness cues associated with a straight alley that rats had been trained to run in, results in a general change in the global stimulus controlling such behavior; when this stimulus is altered a generalization decrement may result, and. running speeds may be' affected. A study by Welker, Tomie, Davitt and Thomas (1974) illustrates this position. Pigeons were first trained to peck a dark key in the presence of a houselight and tone. According to the global stimulus position, these contextual cues should have become a part of the stimulus controlling pecking. In the second phase of the experiment, all subjects were given successive discrimination training between a green key and a key containing a vertical line. For one group the houselight and tone were present only during the st, while another group had these cues available only during s-; a third group had the houselight and tone present during both st and s-trials. The results revealed significant differences between the groups in the rate at which the discrimination was learned. When the original contextual oues were present only during $S+$, acquisition was enhanced; their presence during only S- or both St and S- trials retarded acquisition. These results suiggest that the control developed by the contextual cues in phase I transferred to discrimination training. For the $s+$ alone group, this transfer was positive, and for the other two groups it yas negative.

While results such as these do seem compatible with a conditioning model of stimulus control, there are other data which indicate that contextual cues may operate independently of other task dependent attributes. One specific test of the conditioning model of context $\because$ effects was conducted by Gleitman (1971). According to the conditioning 
model, forgetting results from a change in the stimulus conditions between learning and testing. For some reason, the stimulus conditions become increasingly different over time (this assumption is needed in order to account for the pervasive finding that forgetting generally increases with the length of the retention interval). All stimuli present during the learning episode, including contextual cues, become a part of the global stimulus situation identified with the learning event. When any of these cures change over time, the global stimulus is altered and forgetting, as generalization decrement, may ensue. In two separate tasks Gleitman trained rats to respond under either an unchanging or variable contextual cue background. It was hypothesized that if the generalization decrement notion is correct, experience with the variable set of contextual cues would make changing cue conditions more familiar. This should reduce the likelihood that changing oue conditions over the retention interval would be noticed. Thus, less forgetting for this group, was expected than in a group exposed to a static set of contextual cues during acquisition. In neither task, however, was a significant difference in the amount of forgetting obtained between the two conditions.

A second, and perhaps more convincing body of evidence suggesting that contextual cues do not simply function as other task dependent attributes, involves context ranipulations during acquisition and tests of stimulus control. Chiszar and Spear (1969) found a substantial decrease in interference effects associated with reversal training for a spatial discrimination in rats, as a result of contextual cue changes. When reversal training was conducted in a different $T$ maze from that used for acquisition, RI was eliminated and $P I$ was substantially 
reduced; a similar effect was reported by zentall (1970). Thomas, Mckelvie, Ranney and Moye (1981) examined the influence of contextual. cues on interference in pigeons. They trained animals on ar successive go/ no-go wavelength discrimination followed by reversal training. The reverse discrimination took place in either the same or a different context as used for the original problem. Generalization testing was then conducted in either the same or different contexts experienced during reversal training. The group trained and tested in the same context for both problems produced gradients appropriate for the most recent problem: The gradients peaked at the reversal st value. The same result was obtained for the group trained in different contexts for the two discriminations and tested in the context associated with the reversal problem. The other context change group, which was tested in the context used for original discrimination training, showed "context"generated PI". The peak shifts did not appear at values appropriate for the reversal problem. Results from these studies are difficult to interpret with a conäitioning model ef context effects. It has generally been assumed that discrimination training within a given context reduces. the stimulus control conditioned to contextual cues, since these cues become less informative (Honig, 1969; Rescorla \& Wagner, 1972). Thus, retention of either an original discrimination or a reverse discrimination should be little affected by contextual cues associated with these problems. Data from Chiszar and Spear (1969) and sto Zentall (1970) indicate, however, that such an effect does occur. Thus, contextual cues may not simply function as other tasy dependent attributes and may exert independent control over memory processing. As of yet, there is no clear theoretical account of how this may. idccur. 
e. Similarity.

Theories of forgetting which have emphasized the principle of interference have generally agreed that the degree of similarity between original learning and interfering material is the fundamental parameter governing forgetting. The more similar the competing experience is. to the learning episode being tested, the more likely it will be that forgetting will occur (Spear, 1978). Attempts to study this variable in human learning and memory have typically sought to manipulate similarity along specific dimensions, usually involving the characteristics of verbal materials. Similarity has been varied for meaning, orthographic distinctiveness, associative relationships, and other dimensions upon which verbal materials have been normalized (Jung, 1968). The effects of these manipulations have been assessed for intralist acquisition, interlist transfer and retention. These tests have typically shown that both acquisition and retention are significantly influenced by similarity (Osgóod, 1949; Bugelski \& Cadwallader, 1956; Underwood, Runguist and Schultz, 1959; wimer, 1964).

While it has generally been accepted that similarity is also the primary parameter for interference in animals (spear, 1978), this issue has only rarely received empirical attention. In one such case, Maier, Allaway and Gleitman (1967) manipulated similarity in a stuay of RI. After training on a visual discrimination, rats received additioñal training with partial reversals of the original problem. Two groups were given problems composed of either the old $s+$ or $s-$ which were reversed in function and paired with new stimuli. It was found that the amount of PI after 32 days did not differ between the two groups. Unfortunately, a group given the standard complete reversal was not 
included, so that examination of the effects of reversal similarity on. PI were rather limited. A sțdy by Crowder, Cole and Boucher (1968) also examined the role of partial reversals in interference. They, however, included a complete reversal condition, as well as an extinction condition in which the original st was presented in isolation without reinforcement. They found that at both immediate and 48 hour retention tests the amount of RI increased with the degree of similarity between the interpolated learning and the original problem. The greatest amount of interference was obtained under the reversal condition, followed by the partial reversal; the least amount of RI occurred for the extinction condition. Zentall (1970) was able to show that the amount of RI found with rats given a reverse spatial discrimination was related to the similarity of the contextual cues, associated with the original and reversal problems. RI wofs greatest when the context remained the same, and declined as the degree of similarity between the two contexts decreased. Finally, Wickens et al (1977) manipulated the similarity of ' interpolated experience following classical conditioning in cats. They varied both the stimulus and response characteristics of. a second serieg of conditioning trials given after original açquisition. As described earlier, they unexpectediy found that then condition which yielded the greatest amount of RI jinvolved çonditioning with a new CS and new CR. This result is clearly in opposition to results from similar verbal learning'studies:

Although it appears that similarity is regarded as an important variable in animal forgetting (Spear, 1978)., other than the examples just mentioned, there has been conspicuously little research on this . issue. One plausible reason for this may have to do with the difficulty 
involved in measuring similarity for either stimuli or responses used in animal memory research. Nonetheless, studies such as wickens, et al (1977) illustrate the potential for such reserich. Another preparation which may be amenable to similarity manipulations is the study of generalization gradients, especially with pigeons. Their highly developed" visual capacities would allow for manipulations of visual similarfy between stimuli on a number of dimensions, such as size, shape, and wavelength. As of yet, fesearchers have not taken, advantage of this potential.

Another interesting question yet to be examined concerns the role of within problem stimulus similarity in the forgetting of discriminations. One would expect that discriminations in which the choice stimuli were highly similar would be moxe vulnerable to interference: and may yield greater forgetting than problems containing highly dissimilar stimuli. This may explain the excellent retention often repórted for discrimination problems. These studies may have employed highly dissimilar stimuli. A systematic investigation of this issue has thus far not been undertaken.

f.' Summary.

The present, review has clearly not covered all of the variables knowin to affect forgetting. It has, however, examined the major variables, and has concentrated on the variables investigated in the thesis research to be described. Based on this review, a number of conclusions can be arawn. Thesê. Introlude the following: .

1) Forgetting generally increases with the length of the retention interval; although, the time course of forgetting is, clearly 
influenced by other variables and nonmonotonic forgetting furctions do not always obtain. Thus, it seems valuable to evaluate the time course 'of forgetting as an empirical question for any new poparation used to study memory processing in animals.

2) It is extremely difficult to discern meaningful relationships between the nature of the learning event itself and forgetting. The highly diverse and unsystematic nature of the research makes it difficult to compare and contrast experiments both within and . petween the various types of tasks. The one valid conclussion that can be made is that all forms of learning appear to be susceptible to forgetting. TัThere is evidence of forgetting for habituation, cłassical conditioning, instrumental conditióning, stimulus control, and more complex learning. It is difficult, however, to explain why forgetting occurs in some situations and not others.

3). When forgetting does occur it is often the result of interference. Learning experience outside of the original learning episode enhances forgetting. ${ }_{\text {Both }} \mathrm{RI}$ and $\mathrm{PI}$ have been documented in animals. "This research has also shown that RI generally decreases over a retention interval, while PI increases.

4) Contextual cues have been shown to significantly influence memory processing: Changing contextual cues between learning and retention can drastically disrupt performance, and interference from competing experiences can be reduced by changing the contextual cues associated with these experiences. Also, $^{-*}$ 
exposure to contextual cues during a retention interval can S. often reduce subsequent forgetting.

5) The similarity of learning tly increase interference and subsequent forgetting. The variable of similarity, however, has not been adequately examined with animals. This research seems to be of great importance for both the development of memory theories, and for the comparison of animal and human research. =

\title{
4. Thesis Outline
}

\begin{abstract}
$\bar{x}$
Researchers have generally recognized the pigeon as a valuable laboratory species for the study of learning. Besides the obvious features which make the pigeon so popular, such as the ease with which they can be handled, maintained and trained, there are specific characteristics of these animals which render them particularly useful for learning research. Perhaps the most important is the pigeon's visual capacity; this includes both good visual acuity and colour vision. Both of these factors make the pigeon especially well suited for studies of visual stimulus control, and offer a much wider range of potential stimulus manipulations than is possible with other laboratory species, such as the rat. Thus, the pigeon has provided considerable data on the problems of discrimination and stimulus generalization.

Furecent years the pigeon has also been recognized as an excellent laboratory preparation for the study of memary processing. It is curious, however, that memory research on the pigeon has been primarily
\end{abstract}


restricted to the study of working memory. While there have been a great number of studies of working memory in the pigeon, there have been relatively few studies concerning reference memory. This is despjte the obvious value of such research. Based on the pigeon's visual capacity, a number of interesting questions concerning reference memory could be addressed that are not possible with less visual species, such as the rat. In addition, the vast literature on pigeon learning already available would provide an excellent foundation for reference memory research, and could offer the opportunity to develop memory models of learning phenomena. A more elaborate understanding of pigeon reference memory could also enhance the comparative analysis of memory processing, given that a substantial literature already exists on reference memory in other species. Finally, working memory has been more thoroughly studied in the pigeon than any other laboratory species, excluding humans. Thus, there seems to be a great potential for integrating research on working and reference memory in pigeons. This could have substantial bênefits for the study of memory processing generally. It would appear, therefore, that the study of pigeon reference memory is of great importance, and the paucity of such research can not be a matter of indifference.

One plausible explanation for the absence of an extensive interest in pigeon reference memory may be the difficulty in establishing a preparation which yields robust forgetting. A number of early reports of reference memory in pigeons failed to discover any significant forgetting (Skinner, 1950; Thomas, Ost \& Thomas, 1960; Hoffman, Fleshler and Jensen, 1963; Hoffman, Selekmo , \& Fleshler, 1966; Kehoe, 1963). The only preparation which has been shown to produce long-term forgetting in 
the pigeon has involved generalization testing. It has been found that generalization gradients obtained one day or more after initial training are significantly flattened, relative to an immediate test (Thomas \& Lopez, 1962; Thomas \& Burr, 1969; Burr \& Thomas, 1972; Thomas, McKelvie, Ranney \& Moye, 1981; Thomas \& McKelvie, 1982). While these studies demonstrate some loss of stimulus control over a retention interval, it is interesting that forgetting of discriminations has not yet been demonstrated in pigeons; although it has been well documented in rats. The only direct examination of this question, was by Kehoe (1963). Retention for a five choice colour discrimination was tested after intervals of 1,10 , and 30 days. No forgetting was obtained at any interval, even in a PI condition, which involved prior training on a reverse discrimination. Additional evidence of resistance to the forgetting of discriminations in pigeons can be found in some of the generalization studies. In some of these experiments generalization testing \% was preceeded by a successive go/no-go discrimination (Thomas \& Burr, 1969; Burr \& Thomas, 1972). Although both of these studies found flattening of generalization gradients at a one-day retention interval, close inspection of the reported data reveals that the original discrimination remained intact. The birds continued to peck at the original st and refrained from pecking the s-. Thus, the original discrimination was not found to evidence any forgetting.

Several pilot studies by the author further attest to the durability of well learned discriminations in pigeons. In one experiment, the retention of a simultaneous twio-choice pattern discrimination was tested 28 days following training on the last of five additional discriminations. These interpolated problems included both pattern 
and form discriminations. There was no forgetting discovered in any of the twelve subjects. In another experiment, an attempt was made to induce forgetting through a PI manipulation. subjects received preliminary training on three separate successive go/no-go discriminations involving pattern and form stimuli. They were then given training on a fourth compound discrimination. This consisted of two stimulus displays constructed by combining the elements of the three previous problems. The three previous $s-$ stimuli were combined into a single display and designated the $\mathrm{St}$; the three previous St stimuli were combined to form a new compound $\mathrm{s}-$. This reversal procedure was 'expected to enhance forgetting through PI. A retention test for the compound discrimination after 28 days revealed no forgetting by any of the six subjects. Finally, a third experiment was successful in producing forgetting of a two-choice visual discrimination. The problem - involved a successive go/no-go discrimination using a discrete trial procedure. Peck responses to st were followed by reinforcement while Sresponses were extinguished. The two stimulus displays consisted of either two or three green dots arranged horizontally on the response key. The learned behavior involved a cessation in pecking the 5 display. This response tendency was found to undergo substantial forgetting over 20 days. The following research "involved a more detailed analysis of forgetting found with this procedure, including the influence of interference, the length of the retention interval, similarity of the two displays, contextual change, and repeated testing. 


\section{CHAPTER 2}

Experiment 1 .

Forgetting of Visual Discriminations in Pigeons:

The Influence of Problem Type, Interference, and Retention Interval

There has been no published evidence showing forgetting of discriminations in pigeons. The only explicit attempt to examine this question failed to find any significant forgetting for a colour discrimination after intervals as long as 30 days (Kehoe, 1963). The only other related research has involved delayed generalization testing. These studies have shown some forgetting of stimulus control over a oneday interval (Thomas \& Burr, 1969; Burr \& Thomas, 1972). The forgetting obtained in these experiments involved the flattening of generalization gradients obtained one day after either single stimulus reinforced training or after discrimination training. The actual discriminations, however, did not show any substantial decrements over the same interval. Pigeons that had learned to refrain from pecking the S- display, while continuing to peck the St, showed no evidence of a disruption in this learned behavior. In addition, several pilot experiments by the author also failed to show any forgetting of visual discriminations in pigeons. These included both simultaneous and successive problems. It was only with one particular procedure that forgetting of a discrimination was obtained after a 20-day interval." The present experiment attempted to formally investigate the forgetting obtained with this' preparation, and to examine the influence of some important variables on this forgetting. The problem involved a successive, discrete trial, go/no-go discrimination." Pigeons were trained to peck an St display and to 3 
withhold pecks during the $\mathrm{S}$ - display. The two displays differed by a single feature. The discriminative stimuli involved displays containing either two or three green dots horizontadly arranged on the response key. Displays of this type have often resulted in what has been called the. "Feature Positive Effect" (Jenkins \& Sainsbury, 1970). This involves an asymetry in the rates at which the discriminations are learned. When the unique feature is located on the $\mathrm{St}$ display, acquisition readily results; when the unique feature appears on the Sdisplay, however, the discriminations are either never learried or are learned at an extremely slow rate. Pilot research revealed that the dot discriminations employed in this experiment were learned for both the feature positive (i.e., three dots $s+$, two dots $s-$ ) and feature negative (i.e., two dots $s+$ and three dots $s-$ ) conditions. It was of interest, thesefore, to examine whether differential forgetting might result for Fine two problem types. Thus, half of the subjects received a feature ósing ositive discrimination and the other half received a feature negative discrimination.

Another, variable manipulated in the present experiment was the length of the retention interval. This was to provide an empirical understanding of the time course of forgetting obtained with this procedure. Retention intervals of 1,10 and 20 days were employed.

The influence of PI was also examined in this experiment. Half of the birds were tested at each of the three retention invervals after single problem discrimination training; the remaining subjects were tested for a reverse discrimination learned immediately after acquisition of the original problem. This allowed for the effect of PI to be assessed at three different retention intervals. Evidence with rats has 
shown that prior reverse discrimination training enhances forgetting, and that the amount of PI increases with the length of the retention juterval (Gleitman \& Jung, 1963; Maier \& Gleitman, 1967; Chiszàr \& Spear, 1968).

In order to further evaluate the robustness of any obtained forgetting with this, procedure, animais in the one-day retention interval conditions were retested 20 days following the first retention test: This test was conducted purely as an empirical question and it was uncertain what the results might show.

Method

$\underline{\text { Design }}$

The present experiment consisted of a $2 \times 2 \times 3$ factorial design, with the factors consisting of two levels of Problem Type (Feature Positive vs. Feature Negative), two levels of Interference (Reversal and Nonreversal), and three levels of Retention Interval $(1,10$ and 20 days). The acquisition and relearning experience for each of the twelve experimental conditions is illustrated in Table 1.

Subjects

- Sixty, experimentally naivé, adult silver King pigeons served as subjects. All animals were ideftically housed in standard wire pigeon cages: They were food deprived to 808 of their ad libitum weights, and given unlimited áccess to watery the subjects were weighed and fed daily following each working session. The animals were randomly assigned to each of the 12 experimental conditions, yielding five subjects per condition. 


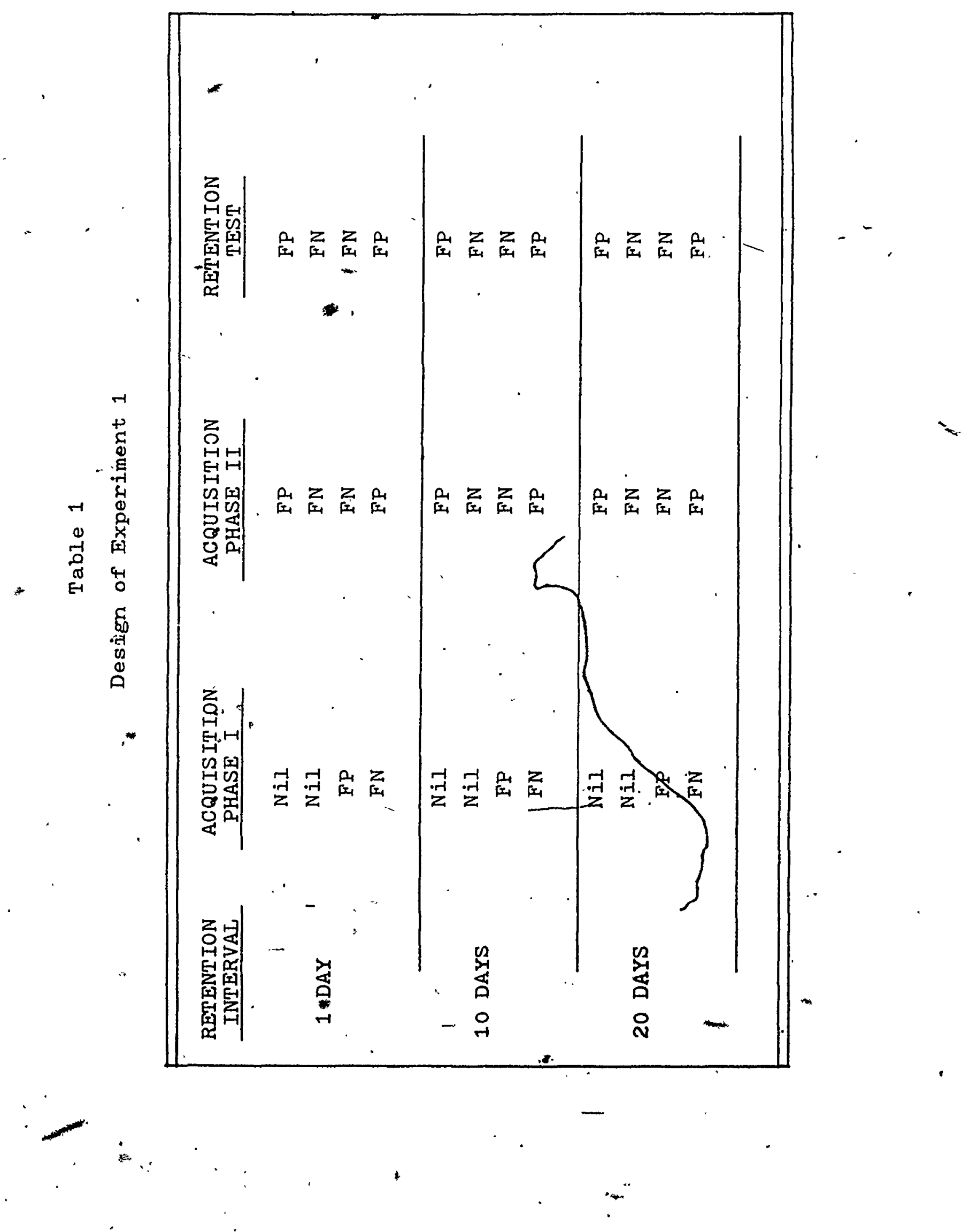


Apparatus

The first two phases of pretraining were carried out in a standard commercially available operant chamber for pigeons. This measured $31 \mathrm{~cm}$ $\times 35.5 \mathrm{~cm}$ (floor dimensions) $\times 35.5 \mathrm{~cm}$ (wall height). Each of the outer walls was of a sound attenuating material. The inside front wall contained three pecking keys mounted horizontally $24 \mathrm{~cm}$ above the floor, and spaced $8 \mathrm{~cm}$ apart centre to centre. Each key was $3 \mathrm{~cm}$ in diameter. A $6 \mathrm{~cm}^{2}$-food well was located $8 \mathrm{~cm}$ below the pecking keys and centered on the front wall. An electromechanical food hopper was mounted behind the food well, and standard stimulus projectors were located behind each pecking key. One side wall of the chamber consisted of a $16 \mathrm{~cm} \times 24 \mathrm{~cm}$ oneway viewing glass, which allowed observation into the chader. A houselight was mounted on the top of the front wall.

A second locally constructed chamber was employed for phase three of pretraining and all experimental phases thereafter. This chamber measured $30 \mathrm{~cm} \times 30 \mathrm{~cm}$ (floor dimensions) $\times 35 \mathrm{~cm}$ (wall height). The entire chamber was fitted into an enclosed sound attenuating cubicle, with one side wall of the cubicle consisting of hinged doors which allowed access to the inner chamber. Also, there was an opening in the end wall of the cubicle to allow for stimulus projection onto the back wall of the inner chamber. A single translucent pecking key was mounted $8 \mathrm{~cm}$ from the floor and centered on the front wall of the inner chamber. A food well measuring $6 \mathrm{~cm}^{2}$ was located $8 \mathrm{~cm}$ below the pecking key, and an electromechanical food hopper was mounted behind the food well. A Kodak carousel slide projector was placed outside the apparatus $44 \mathrm{~cm}$ away from the pecking key. A Ralph Gerbrands Co. model"G shutter was placed directly in front of the projector lens. 
Stimulus materials consisted of locally constructed slides. A $2 \mathrm{~cm}$ x $2.5 \mathrm{~cm}$ piece of black paper tape was covered with green celluloid and placed in standard $5 \mathrm{~cm}^{2}$-slide mounts. Each tape contained either two or three .2 cm-holes placed horizontally. The two outer holes were spaced $.5 \mathrm{~cm}$ apart centre to centre. For those tapes containing three holes, the third hole was centered between the outer two holes. The projector was aligned and focused so that the slides, when backprojected onto the pecking key, appeared as either two or three green dots bisecting the pecking key horizontally. Each projected dot appeared asta .7 cm-circle. For those slides containing two stimulus holes, a third .6 cm-hole was punched $.9 \mathrm{~cm}$, centre to centre, away from one of the other two holes. This allowed for illumination of a photocell mounted on the back of the front wall, and which served to control event programming according to which stimulus was being projected. Both chambers were controlled by event programming equipment located in a separate room. $\underline{\text { Procedure }}$

All subjects were individually hand shaped to keypeck in the pretraining chamber. This chamber was employed due to the availability of the viewing window, which was not available in the other chamber. Subjects were trained to feed from the food well when the hopper was activated, and then shaped to peck at a green centre key. Each peck at the key was then reinforced with two seconds access to grain, and keypeck training was complete. when 50 pecks occurred. The houselight remained on throughtout this phase of training. Each subject received a second post-shaping session in the pretraining chamber. This consisted of 36 discrete triais. "Noh trial was initiated with the illumination of the green centre key. A peck at this key resulted in two seconds 
access to grain, terminated the centre key stimulus, and initiated a seven second intertrial interval. The centre key remained on until a keypeck resulted. The houselight remained off throughout this and the remaining sessions of the experiment. The next session involved 36 discrete trials in the experimental chamber. During each trial a slide made of green celluloid was backprojected onto the pecking key. Each stimulus presentation remained on until a keypeck resulted, which time a seven second intertrial interval was initiated, and the subject was provided two seconds access to grain. Experimental testing began on the following session.

Each subject was randomly assigned to one of the 12 experimental conditions. All subjects first received training; on a go/no-go successive discrimination, which was either Feature positive or Feature Negative. Each daily session consisted of 72 trials, half of which were . St trials and half s-trials. Each trial began with the presentation of either an St or S- display, which remained on for a maximum of five seconds or until a keypeck occurred. All keypecks to $S+$ displays resulted in two seconds access to grain, and all keypecks, regardless of display, resulted in the initiation of a seven second"intertrial interval. For trials in which no responding occurred during the five second stimulus presentation, the intertrial interval began with the termination of the stimulus display. Trials within a session were arranged in six trial blocks of 12 trials each. An equal number of $\mathrm{St}$ and s- trials occurred within a block, and these trials were arranged in a random order within each block, with the restriction that no more than three successive trials could occur of the same type. While the stimulus arrangement within each trial block remained constant throughout the 
experiment, the order in which the trial blocks occurred was randomized across sessions, with the restriction that each session began with a trial block which consisted of an st display' as the first stimulus presentation. Discrimination training continued to a criterion of three successive trial blocks in which all st displays had been responded to, and in which no more than one response was emițted on $S$ - trials during each of the three trial blocks. Thus, the minimal ratio of $s+$ to $s-$ responses at criterion was set at $18 / 3$, which yields a discrimination ratio of .86. For̀ subjects in Nonreversal conditions, acquisition terminated once criterion had been reached, and the appropriate retention interval comenced at this time.

For those subjects in Reversal conditions, the next session consisted of reverse discrimination trầining. This was in all respects identical to origimal discrimination training, except that the contingencies of reinforcement assochted with the stimulus displays was revèrsed. In addition, a reforcement enrichment procedure was introduced in order to avoid total extinction, which may have resulted during the early trials of reverse discrimination training (Burr \& Thomas, 1972). This_entailed extending the duration of the sixth S+ display in each.trial block to 30 'seconds, and presenting five evenly spaced, twó-second presentations of grain reinforcement. This occurred only if the animal' had failed to respgnd to any of the previous stimulus. displays during that trial block. Reveerse discrimination training continued to the same criterion level employed for original acquisition. The retention, interval commenced for, subjects in Réversal conditions once criterion was achieved. During the retention interval the birds remained in their home cages, and were weighed and fed daily. Their weights during this time were maintained at $80 \%$ of their ad libitum 
values.

Retention testing began at 1,10 or 20 days following acquisition, . depending on the condition to which the subject had been' assigned. The subjects were reintroduced into the experimental chamber and exposed to

4 the events associated with the acquisition of the most recently learned discrimination. The sequence of events was _identical in èvery respect, including the reinforcement contingencies, "to the sequence of events which defined the most recent acquisition experience for each subject. Relearning was continued until the original criterion was reestablished. The experiment, then terminated for subjects in the $10-$ and 20-day Retention Interval conditions, for those "subjects in the one-day conditions, a second 20 -dăg rétention interval comenced after reestablfshing criterion. A second retention test, then followed, which was identical to the first retention test: Upon completion of the sècond retention test the experiment terminated for these subjects.

Acquisition Results

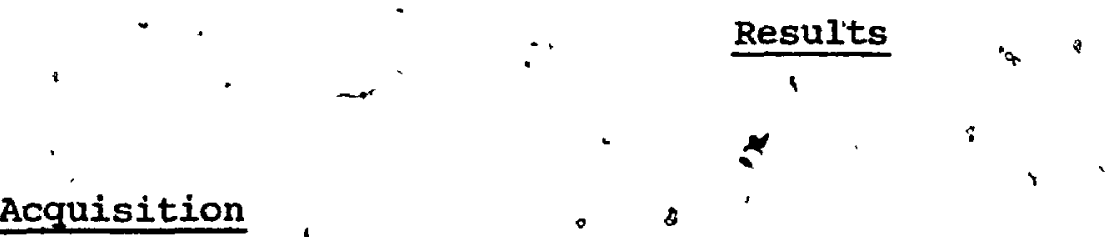

The change in behavior which defined learning in this experiment .was an evéntual decrease or cessation in pecking directed at the sdisplay. In ordey to evaluate any diffexençes betweèn the experimental conditions in terms of the rate of acquisition for the discrimination most recentiy. learned, an analysis of variance was performed on the mean' $\because$ s- responses to criterion. The factors included probleti. Type (Feáture Positive or Feature Negative), Interference (Reversal or Nonreversal). Retention-Interval (I, 10 or 20 days), and subjects (five per condi- 
tion). This analysis revealed a significant main effect for Interference, $F(1,8)=35.62, Q_{0}<.001$. It was found that subjects given reverse discrimination training made significantly more errors to criterion on their most recently learned problem than subjects not given - prior discrjmintion training. Meán errors to criterion were 226.0 and 89.3 for the Reversal and Nonreversal conditions respectively. No other main effects or interactions were significant at the .05 level."

In order to assess the occurrence of any feature positive effect, independent analyses were conducted for the original and reversal problems. The mean $s_{\bar{y}}^{*}$ responses to criterion for the original Feature Negative and Feature Bositive conditions were 79.0 and $96 . \dot{5}$ respective$1 y$, and did not differ significantly, $t(58)=1.22, \mathrm{p} 7.05$. Similarly, no significant difference was found for the reversal, Feature Positive (257.3) and Feature Negative $(202.3)$ conditions, $t(28)=1.16, \mathrm{p}$ ? 05 . Retention.

- Meaningful differences in the amount of forgetting between the various conditions could only be understood if the groups were equated at the end of acquisition. A stringent_acquisition criterion, was intended to achieve this obfective. In addition, an analysis of variance was performed on the mean number of $s$ - responses during the criterion trial blocks. This analysis included the factors of Problęm Type, Interference, Retention Interval, and Subjects. No significant differences at the .05 level appeared. "Thus, it can be assumed that the groups were performing equally at the end of acquisition.

Throughout relearning, all subjects responded to the s+ display on all occasions. Therefore, the performance measure of interest was the 
number of responses during S- trials. Table 2 presents the mean number of S- responses during relearning and standard deviations for each of the 12 experimental conditions.' It should be realized that with no forgetting, the maximum number of $\mathrm{s}$ - responses during relearning would $\checkmark$ be three, since the relearning criterion was the same as acquisition. As can be seen in Table 2, all groups showed evidence of forgetting, extept the two Non-reversal groups tested at one day.

In order to assess the relative degree of forgetting for the various conditions, an analysis of variance was performed on the mean number of S- responses to criterion during relearning. This analysis included the factors of Problem-Type, Interference, Retention Interval, and Subjects. Significant main effect's were obtained for Interference, $F(1,8)=11.28, \mathrm{p}\langle .01$ and Rețention Interval, $F(2,8)=6.83, \mathrm{p}\rangle$ .05. No other main effects or interactions were significant at the .05 level. The two significant main effects are graphically represented in. Figure 1. The mean number of $\mathrm{s}$ - responses to criterion during relearning are plotted as a function of Interference and Reténtion Interval, and are collapsed over Problem Type, since this variable was not found : to have a significant infiuence' on forgetting. ' It can be seen, that forgetting increased directly with the retention interval for both Reversal and Nonreversal conditions. Also, there was more forgetting at each interval for the Reversal conditions. Although a significant interaction between Interference and Rètention Interval was "not obtained, $F(2,59)=1.81, \mathrm{p}) \cdot 1$, there was a tendency for forgetting duè . to interference to increase ds the retention interval increased.

The mean number of $\mathrm{s}$ - responses required to reestablish criterion. for the one-day conditions, at both their first and second relearning 
Table 2

Mean S- Responses to

Criterion for Relearning

Retention

Interval

Nonreversal

- Reversal

$\varnothing$

\begin{tabular}{|c|c|c|c|c|c|c|}
\hline & & & & & & \\
\hline & & F.P. & F.N. & ' & F.P. & E.N. \\
\hline $1 \mathrm{DAY}$ & $\begin{array}{l}X \\
S D\end{array}$ & $\begin{array}{l}1.0 \\
1.3\end{array}$ & $\begin{array}{l}1.6 \\
2.5\end{array}$ & & $\begin{array}{l}10.2 \\
10.6\end{array}$ & $\begin{array}{r}7.6 \\
9.8\end{array}$ \\
\hline
\end{tabular}

\begin{tabular}{lllllll}
\hline 10 DAYS & $X$ & 11.0 & 11.2 & $\cdots$ & 23.8 & 29.0 \\
& SD & 13.2 & 18.8 & & 25.7 & 27.2
\end{tabular}

\begin{tabular}{llrrrrr}
\hline 20 DAYS & $X$ & 9.8 & 17.0 & & 40.8 & 31.8 \\
& SD & 13.9 & 11.0 & $*$ & 18.9 & 22.7
\end{tabular}

.

11.0

18.9

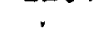


Figure 1. Mean S- responses to criterion during relearning. The data are collapsed ove-Problem Type.

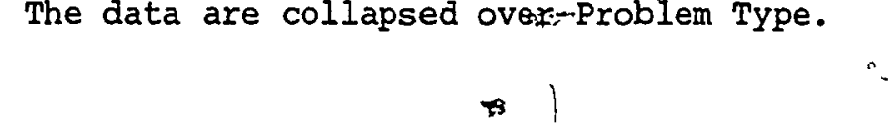



tests, were subjected to a mixed analysis of -variance. The within subjects factor was Test (Relearning at either 1 or 20 days). The three between subjects factors consisted of Problem Type, Interference and Subjects. Significant main effects were obtained for Test, $F(1,40)=$

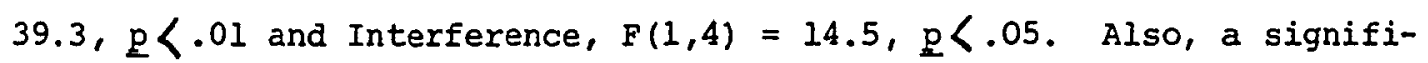
cant interaction was obtained between Test and Interference, $F(1,4)=$ $8,1,2<.05$. No other main effects or interactions were significant. Figure 2 presents the mean number of S- responses to criterion during both relearning tests for Reversal and Nonreversal conditions collapsed over Problem Type. It can be seen that more $s$ - responses occurred at the second relearning test than the first. Also, more S- responses were made by Reversal subjects than Nonreversal subjects at both the first. and second Tests: In addition, the significant interaction between Interference and Test indicates that the effect of Reversal training on forgetting was greater at the second relearning test.

\section{Discussion}

The only question of interest during acquisition was whether or not a Feature Positlve Effect might obtain' (Jenkins \& Sainsbury, 1970). This was considered possible, since the stimulus displays employed in this experiment were of the type often found to yield the' effect (Jenkins, 1973; Hearst, 1978). The present acquisition data, however, . showed no difference in the rates at which the Feature Positive and Feature Negative discriminations were learned. It is possible that while the current problem could be regarded as a feature discrimination (Hearst, 1978), various factors may have eliminated any Feature Positive 
$: \dot{\gamma}$

0

.

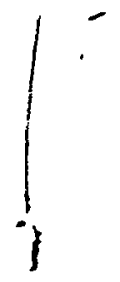

- Figure 2. Mean S- responses to criterion during relearning for groups tested at one day and retested at twenty days.' The data are . collapsed over Problem Type.

6

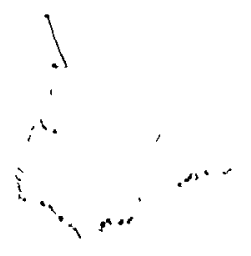



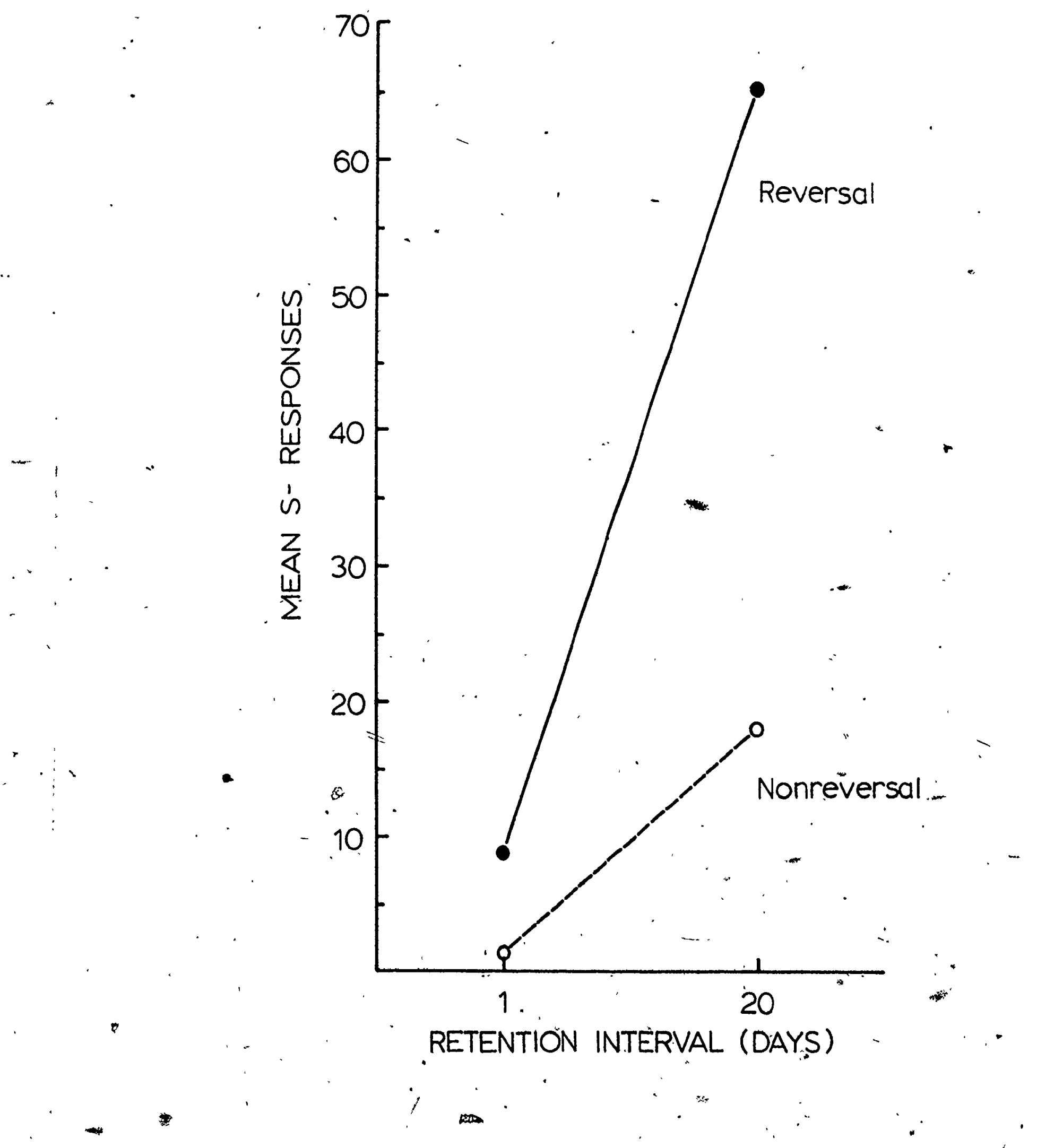
effect. These may have included the salience and compactness of the dot displays. With highly compact or highly salient features, the feature positive effect has often not been obtained (Sainsbury, 1971; Hearst, 1978). Either or both of these factors may have been responsible for the absence of the effect in the current situation.

The retention test data revealed substantial forgetting of the visual discrimination. This is the first reported instance of forgetting for a discrimination in pigeons. In addition, forgetting was found to increase directly over intervals of 1,10 and 20 days. Also, the rațe of forgetting under both Reversal and Nonreversal conditions appeared to be negatively accelerated. The only group which was not found to yield forgetting was the one-day Nonreversal condition. This contrasts with studies of generalization, in which forgetting appears to reach asymptote after one day (Thomas \& Lopez, 1962). This may suggest an important distinction between the forgetting of stimulus control as assessed by generalization testing versus, choice measures of discriminative control.

A further indication of the influence of retention interval can be observed in" the results from retesting for the one-day groups after a second 20-day interval. These subjects clearly showed a marked decrement on the second retention test from their previous performance at the one-day interval; this is despite any additional learning experience associated with the first retention test. Thus, it appears that the forgetting over 20 days in this preparation is quite robust.

It was, also found that PI significantly enhanced the amount of forgetting. Prior experience with a reverse discrimination greatly increased the amount of forgetting for the most recent discrimination, 
relative to a control group not given prior experience. This finding is consistent with results from other studies which have employed reversal training as a source of PI (Gleitman \& Jung, 1963; Maier \& Gleitman, 1967; Chiszar \& Spear, 1968; Burr \& Thomas, 1972).

Of perhaps greater importance is the contrast between the current findings and those reported by Kehoe (1963). In the Kehoe study, pigeons were first trained on a five choice colour discrimination, and. then given reversal training in which a different colour became the st. No forgetting of the most recent problem was discovered after an interval as great as 30 days. There are a number of procedural differences between the two studies which could account for the divergent results. These include the use of a successive discrimination and highly similar stimuli in the present, experiment, as contrasted h a simultaneous problem involving more discriminable stimuli (red and green keys as St stimuli) in the Kehoe study. Since interference has been shown to be related to the degree of similaxity between the competing - experiences (Spear, 1978); it could be argued that interference was potentially greater in the present experiment. This could have greatly influenced the forgetting. presently obtained. In' the Kehoe experiment the highly dissimilar stimuli may have yielded little interférence even with reversal training.

Although PI was found to increase' over the retention interval, the increase was not significant. Most studies of both human and animal PI have found interference to significantiy increase over longer retention intervals (Spear, 1978). In this respect, the current data are somewhat deviant, although differences were in the expected direction, and the résults from, the retesting for the-one day groups did show a significant. 
increase in PI over a 20-day interval.

- While interference and retention interval length did influence forgetting, the Problem Type variable did not. No differences in the amount of forgetting were found between the Feature Positive (three dots $\mathrm{S}+$ ) and the Feature Negative (two dots $\mathrm{S}^{+}$) problems. This is consistent with the absence of any problem type differences found for acquisition.

Forgetting of discriminations in pigeons has.not previously been reported (Kehoe, 1963\% Thomas \& Burr, 1969; Burr \& Thomas, 1972). The author was also unable to produce forgetting for visual discriminations in a number of pilot projects, which included conditions which putatively enhanced interference: The obvious question, therefore, is why forgetting occurred in the present situation. Not only was forgetting obtained, but it appeared to be quite robust; the effect was measureable with a relearning experience in which the original reinforcement contingencies were operative throughout testing. This suggests that the forgetting could be considered as a loss in performance and not merely a lapse (the former appears after the original contingencies have been reinstated, while the latter results only prior to their reinstatement; Spear, 1971). A number of factors, all consistent With extant data on forgetting in animals, would seem to have contributed to the occurrence of forgetting in this experiment. One important factor is the use of a successive, discrimination. Gleitman (1971) has argued that go/no-go measures, associated with successive problems may be more sensitive to forgetting than pure choice measures associated with simultaneous discriminations; such as employed by Kehoe (1963). Also, the discriminative stimuli used in the present experiment were highly similar. The two displays shared many features, such as the wavelength of the dots 
and the two dots common to bith displays. This featural overlap between the displays may have made discriminability difficult. This coild have increased the likelihood that the s- display could inappropriately retrjeve the target memory, and initiate a peck response. Finally, it is possible that considerable PI from pretraining could have influenced forgetting. This training consisted of reinforced pecking of a green key.. Since the dot displays were also green, the pretraining experience may have interfered with retention of the actual discrimination.

The present data also are compatible with a proposed "retrieval model of forgetting. While spear $(1971,1973,1976,1978)$ has outlined a general retrieval failure approach to forgetting, an explicit model of. retrieval failure has not yet been formulated. One possible model will be outlined below and will be applied to the current data.

The present model adopts the view that memories can be regarded as a subject's multidimensional representation 'of an event. These representations consist of ordered lists or collections of individual memory attributes (Bower, 1967; Underwood, 1969; Norman \& Rumelhart, 1970; Spear, 1973). The attributes correspond to the subject's encoded version of features present in the event represented. . These-will include any features noticed by the organism during the learning episode. For example, features associated with discriminative stimuli, exogenous and endogenous contextual cues, the target response, and reinforcement contingencies will all be represented by individual memorly attributes. Retrieval invoives the arousal of individual attributes. Specific attributes will be aroused or activated when the corresponding features for these attributes (or features similar to the oxiginal) are

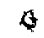
noticed by the organism. When a sufficient number or type of attributes 
are so aroused, the memory itself will'be activated or retrieved (Spear, $1973,1976,1978)$. The retrieval of the target memory will then initiate the target response, which is itself represented by an attribute in the target memory.

; The current model postulates two specific components' to this retrieval process. The first involves the notion that all attributes of a given memory are not equally influential in guiding retrieval, of that memory: ' Some attributes are more important than others. The concept of Activation Potential will be introduced as a hypothetical mechanism responsible for this differential influence over retrieval. It is argued that when attributes are activated, through recognition of corresponding features, they provide some hypothetical"value of activation. This value is termed their Activation potential (AP). The APs for attributes within "a memory may" vary, and those attributes with.". higher AP's are considered to have a greater influence over retrieval.

The second concept to be intrónced refers to the idea that each memory requires, some minimal level of activation in order to be, rer "trieved." This level is termed the Activation Threshoid (AT) of the $\therefore$ memory. The sum of the APs for active attributes within a memory corresponds to the state of activation for that memory. When this value reaches the AT the methory will be retrieved, and the target response will be genierated. "Thus, not all' attributes contained in the memory need be activated in order for the memory to be retrieved, the only requirement is that a combination of attributes be activated which have. APs. which exceed the AT for that memory.

The model assumes that each attríbute mas some base value AP. These values are detẹrmined, In part, by inherent desịn chayacteristics 
of the organism (this is similar, to the concept of, innate analyzer strength proposed by some theories of selective attention; sutherland \& Mackintosh, 1971), Through extensive' experience with a given feature, the AP for the corresponding attribute can be increased. Features which are consistently informative for the organism may have their corresponding atẗributes' AP indreased. For example, in a discrimination problem an organism is confronted with $\dot{a}$ variety of features; some af these featuges 'will be more relevant than pthers for the acquisition of the discrimination problem. "Features contained on the aiscriminative stimuli, and which differentiate. these stimult, would be noré reilevant and more informative. Thus, the Aps for attributes reprèsenting these features may be elevated above kase values: These increases in AP will allow the móre relevant attributes tọ exart more gontrol over retrieval than" attributes which represent less "inforwative features, such as features shared by the discriminative stimuli or contextual cues.

A, similar charige is assùmed possibie for ATs: The base values for ATs" are assumed to bê detẹminèd by a hypothetical central processing mechanism this mechanism would set Ais in accord with the overall state of the organism, we weil as the demanas of the situation " The establishment of AṬs will be more explicitly described later, but for now it should be assumed that these values will be such that not all attributes contained in the target memory need be aroused in ordex for

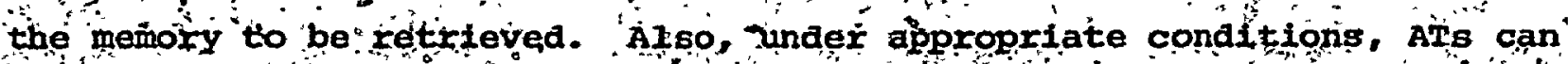
be ingreasea above base valueg ône guch conateion wil be when the retrteval of the tatget memp no Ionger results in consequences

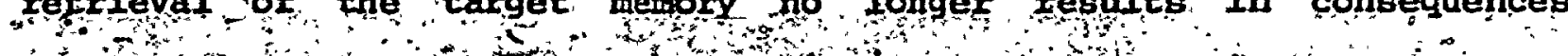

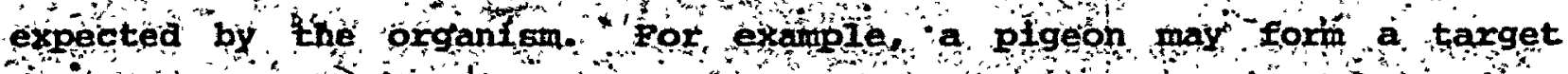
memox which represents the evon of fopd rewarded pocking of an 
illuminated disc. All the features present in the event and noticed by the organism. will be represented by individual memory attributes. This would include the target resporise of pecking and the consequences of pecking. (i.e., food presentation). :Th organism's expectancy for this situation is simply the correlation between the organism's representation of the event and subsequent experience. When -this correlation is disrupted, such as when the animal is transferred to an extinction schedule, the organism's expectancy will be disconfirmed. "Under these conditions, additional memory processing may ensue, so that the organism can now adapt to the altered conditions. The present model aśsumes that- thijs adational memory processing. can invplve elevations in the AR for the target memory. Such increases would prevent..the retrieval of the target memory, and the consequential occurrencefof the target response. Therefore, as a result of an extinction coñtingency

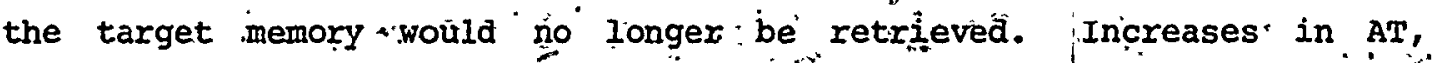
however, wili be femporary, and are expected to declfne during periods. of inactivation, such as.à retention interval.

While it is bélieved that the present model can be applied as a general account of recognition memory, it will be expressly described as. it applies to the discrimination learning and forgetting pxesently investigàted. "In order to facilitate a detailed presentation on the model refence wil be made to fogure

It is assumed that the acquisstion of a discrinination involves number of processing activities. The urtinate effect of this processing $\therefore$ on Will be to provide the organism with representation of the learning

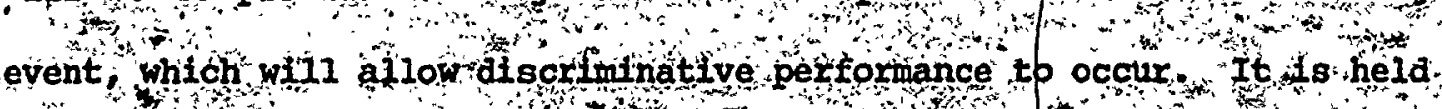

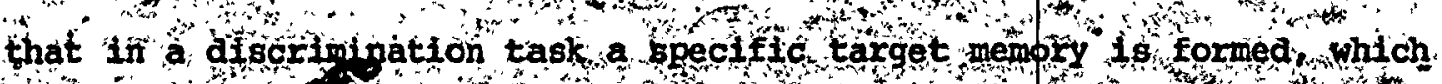




$$
-
$$




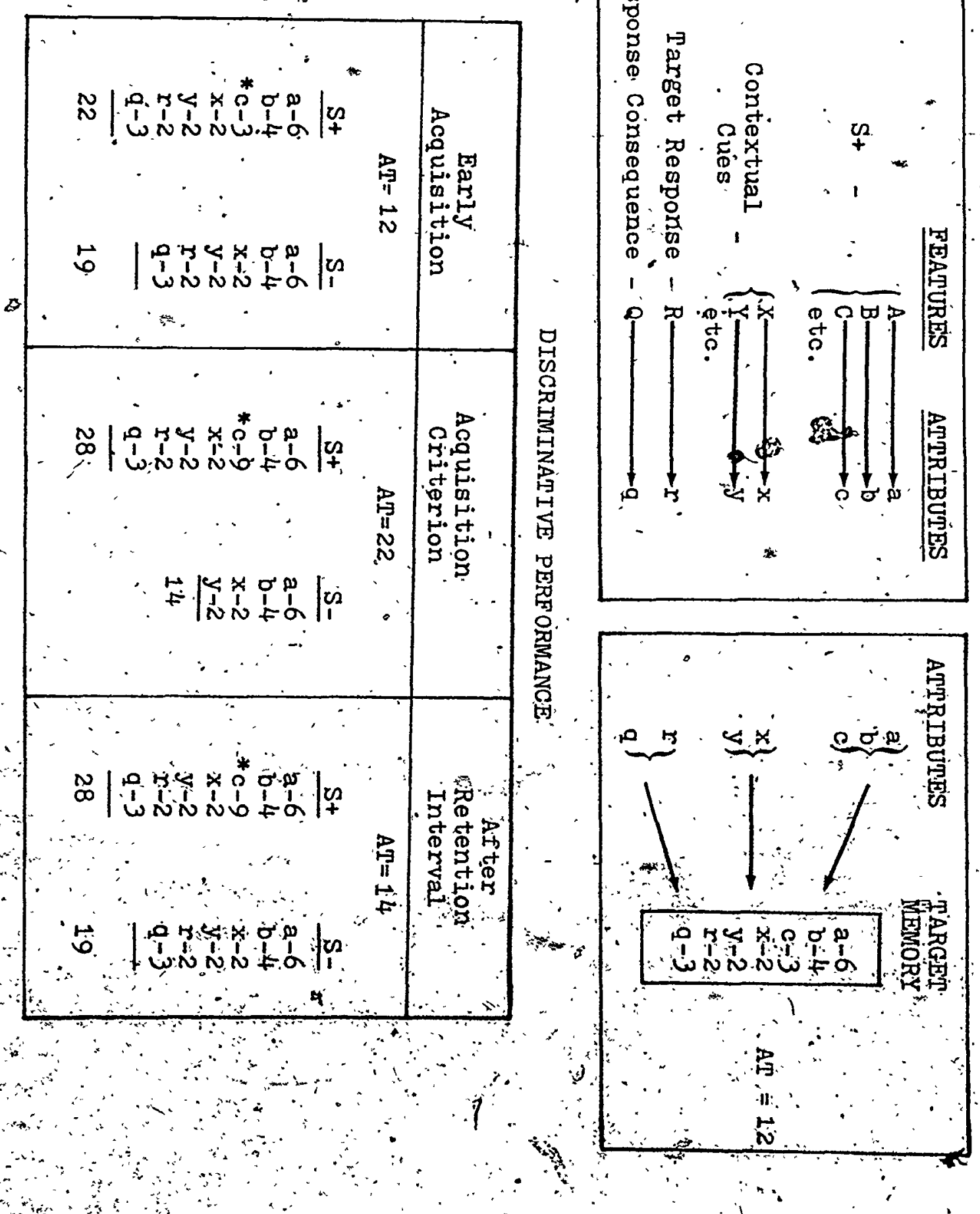

号 
when retrieved generates a specific target, response. For example, in the successive go/no-go discrimination employed in Experiment 1 , the 'target response entailed keypecking. The problem the pigeons faced was to keypeck only during appropriate stimulus conditions, when the $S+$ display" appeared and not during the s- display. During acquisition of s. this discrimination, a target memory was formed which represented the event of food rewarded keypecking of the st display. The attributes of this memory would have included representations of features contained in the event. These would have included features on the $s+$ display, contextual cues, the target response of keypecking and the presentation, of the reward.

The left top panel of Figure 3 illustrates the initial processing required for the formation of the target memory. Features available during st presentations would have been encoded as individual memory attributes. The target reponse and consequences of this response would also have been represented by attributes. 'These attributes would then have formed a collective unit, termed the targẹt memory; . This process is illustrated in-the right top panel of the figure. "The numbers next to each attribute corresponds to the hypothetical AP for that attribute. It can be, noted that at this stage of acquisition, the for the target memory was setidt 12 units. Thus, it can be seen from the figure that not,ali the target memory attributes would need to be activated in order for the memory to be retrieved; as long aswhe cumilative AP!'s exceeded

15 units the memory-would be rétrieved.

"The lower panel of Figure 3 illustrates the actuai course of discrimination. The figure presents thypothetical Aps in the target mentory that result during st and $s-$ presentations. Since the st and s- 
displays shared many features, presentation of the $\mathrm{s}-$. would have resulted in the activation of a number of attributes contained in the target mory. During the early stages of acquisition then, presenta-. tions of both $S+$ and $s-$ displays would have activated sufficient attributes to retrieve the target memory. As can be seen in the figure, even, though the total APs would have been greater during an "st presentation." than during an s- presentation (i.e., 22 versus 19), the s- would have provided sufficient features to achieve a cumulative state of activation above the AT. Thus, at this point target responses would have ifrequently occurred during s- presentations.

The current model assumes that discriminations involve the development of selective retrieval of the target memory, in which only St presentations are effective in retrieving. the target memory and generating the target response. The model postulates that selective retrieval results from elevations in the AT for the target memory; and concomityant increases in the APs for attributes representing features unique to the s+ display. In the hypothetical example illustrated, this would be attribute $c$. 'It can be seen that at criterion, when selective retrieval proficiency was highest, the Ap for attribute $c$ would have been increased above, its base value. Also, the AT would have increased 6 . . . from 12 to 22. Thus, s- presentations at this stage of training could no longer activate sufficient attributes to surpass the AT of the target. memory. Therefore, the target reponse of péking no longer would have occurred during an $S-$ presentation, "and discriminative performance would have been observed.

The model asserts that temporaxy increases" in ATs decline toward base válues during periods in which thẹ attributes temain inactive and 
the target memory is not retrievëd; this is typically the case during a retention interval. Decreases in these values are assumed to be responsible for decrements in performance which define forgetting. Again referring to Figure 3 , it can be seen that during early relearning trials, after a retention interval, the AT for the target memory would : 'have been sufficiently reduced to allow s- presentations to once again retrieve the memory. Thus, s- presentations would have again. resulted in the target response of pecking. With continued relearning experience, however, it is assumed that the ATs would have again increased in order to reesțablish selective retrieval. Once this occurred, successful discrimination would then have been in evidence.

The model also assumes that selective retrieväl failure will. underly forgetting found for reversal discrimination training, and that more forgetting will result for a reversal problem than for a single discrimination. . The primary source of the enhanced forgetting is considered to be the availability of two target memories which both yield the same target response. The model assumes that acquisition of a reverse discrimination requires the development of a new target memory, which represents reinforced responding to the new st of the/ reversal. problem. Although many or all of the attributes for this memory would have been already encoded, they wowld need to beorganized into a specific set, which defines the reversal target memory This memory would contain attributes representing features on the reversal st contextual con a de cues, the target responise and consequences of the target response

Selective retrieval of this memory wili entail a similar process to that which was assumed for original discrimination acquisition the upper paneis of Figure illustrate this process It can be seen that 
$\because:$

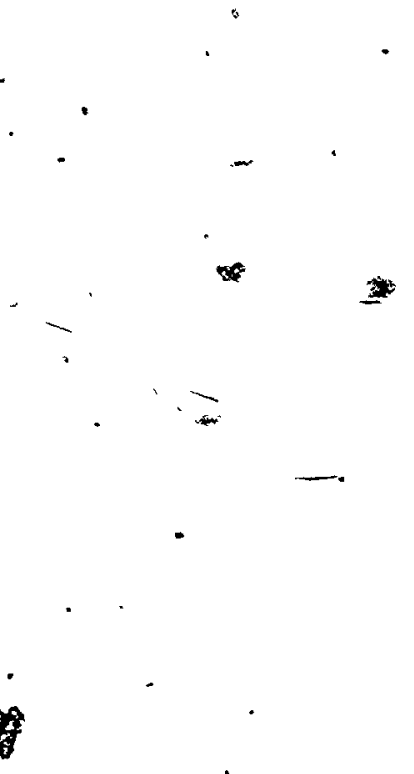

$\therefore \quad c$

,

Figure 4. An illustrated example of the memory processing assumed to underlie the acquisition and retention of a reverse-successive discrimination." The' figure presents hypothetical states of activation within target memories during presentation of both $s+$ and $s-$ displays. *

8
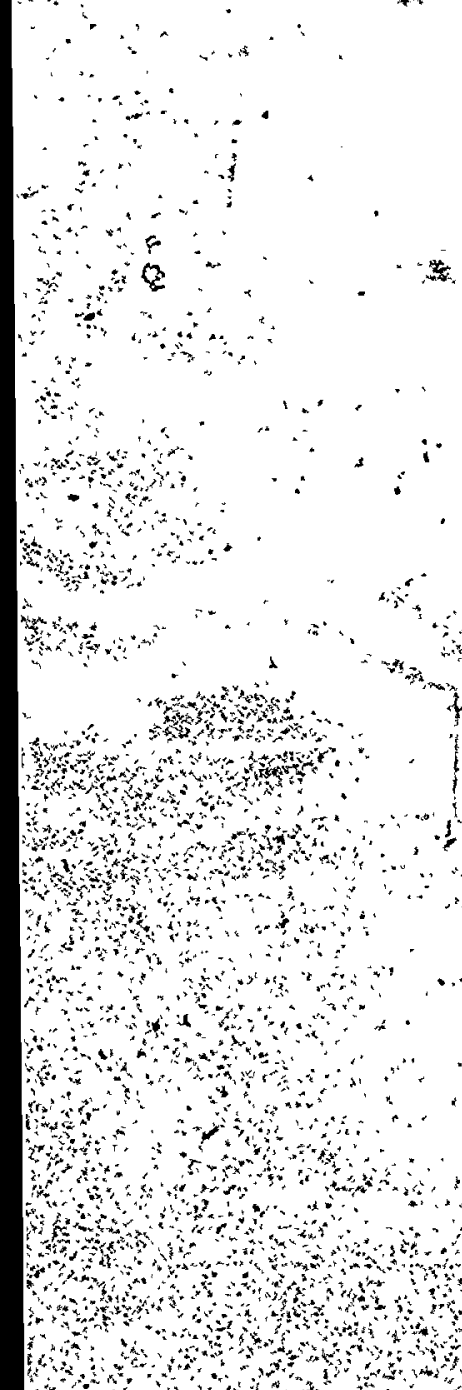

स

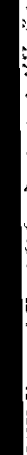

30

$x^{2}$

$\cdots$ 


\section{REVERSAL TARGET MEMORY}

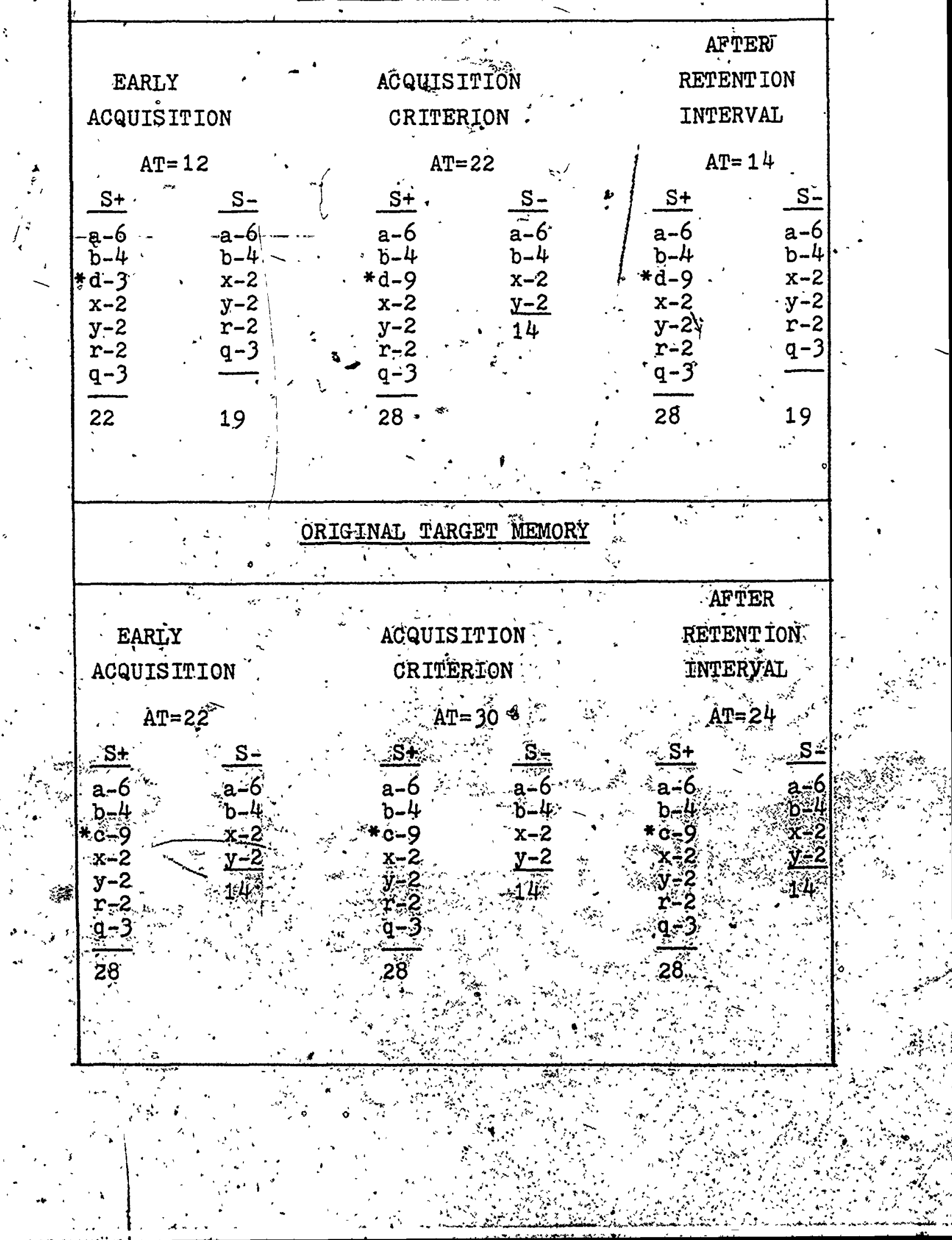


during early reversal acquisition, both the $\mathrm{S}+$ and $\mathrm{s}-$ presentations would have effectively retrieved the reversal target memory, due to featural overlap between the two displays. At reversal criterion, however, selective retrieval would have been established, and the swould no longer have beento to retrieve the reversal target memory. This would have resulted from incieases in the target memory. AT and APs for attributes unique to this memory (attribute $a$ in the figure). Increases in the AT for the reversal target memory would have dissipated over a retention interval. Therefore, during the early trials of relearning, selective retrieval would have again been reduced, and. the target response would have frequently resulted during s- presentations. This is the same-course of events as outlined for acquisition and forgetting of the original discrimination; For a reversal discrimination, however, additional processing îs assumed; and an additional source of forgetting is postulated.

During the early trials of reversal acquisition, the s- display (which was formerly the $s+$ in the original problem) would have effectively retrieved the original target memory, which would have initiated the same target response as the reversal target memory. This is illusitrated in the lower left panel of Figure 4. In order to prevent these inappropriate responses during reversal training, it is assumed that the AT for the original target memory would have been increased to a value beyond which attributes aroused during reversal s- presentations would hiàve been sufficient to retrieve that memory. "This is 11lustrated in the Iower center panél of the figure. Over ... retention interval, - however; this AT would have declined. Tus, during the early, reieatring ... trials, the $s-$ would have been once again effectivie in retrieving the 
original target memory, and the target response would have frequentiy resulted.

According to this analysis, after a retention interval following acquisition of a reverse discrimination, there would be two target memories available, which would both produce the same target response. The enhanced forgetting observed for reverse discriminations. is accounted for in terms of the increased probability of generating a target response from the retrieval of either of two. target memories. Not only would there be selective retrieval failure for the reversal target memory, but the original target memory would again be retrievable during s- presentations. Such a situation would require more processing during rélearning to reestablish effective selective retrieval.

According to the present model, the essential process assumed to underlie both the acquisition and forgêtting of discriminations is selective retrieval. Acquisition entails memory processing which yields highly proficient-selective retrieval, of at target memory: The target memory is retrieved only during specific stimulus conditions (i,e., when thie s+ is presented). Similarly, forgetting involves memory processing which reduces selective retrieval proficiency: The target memory is retrieved during inappropriate stimuitus conditions (i.e., when the $S-$ is presented). The memory processing postulated to underilie both the development and degeneration of selective retrieval involves changes in APs and ATs. In order to provide a more rigorous description of these changes, an explicit set of procéssing rules will be delinineatèd.

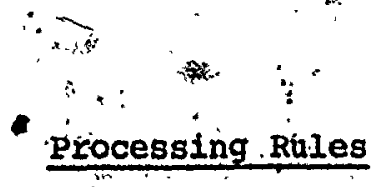

Ruje 1. Each target memory is assumed to have some base value ar. 
This value is set by a central processor in accord with the state of the organism. This value can be expressed as a proportion of the maximum cumulative APs for the target memory: It is expressed by the following equation: . :

$$
A T_{b}=P\left(\Sigma A P_{t}\right)
$$

where,

$$
\begin{aligned}
& \mathrm{AT}_{\mathrm{b}}=\text { the base value } \mathrm{AT} \text { for a given target } \\
& \text { memory, } \\
& \mathrm{AP} \mathrm{P}_{\mathrm{t}}=\begin{array}{l}
\text { the sum of the APs for all atributes } \\
\text { in the target memory, }
\end{array} \\
& \mathrm{P}=\text { a proportionality constant determined. } \\
& \text { by a central processor. }
\end{aligned}
$$

7 Rule 2. In order for selective retrieval to occur, the AT for the tairget memory must be raised to some critical value above, the base value... This value is termed the Activation Threshold Increment (ATI), and is given by the following expression:$$
A T I=\left(A P_{S-}-A T_{b}\right)+C
$$
where,

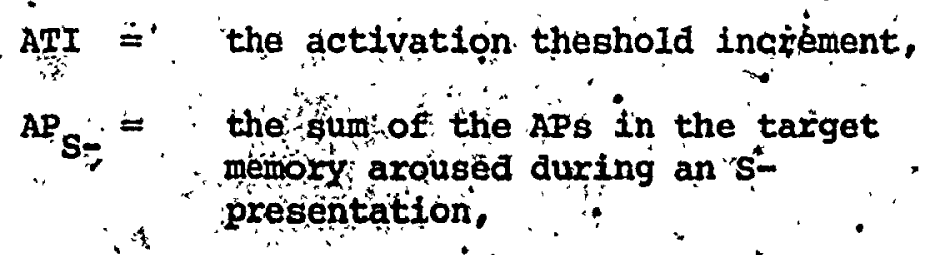




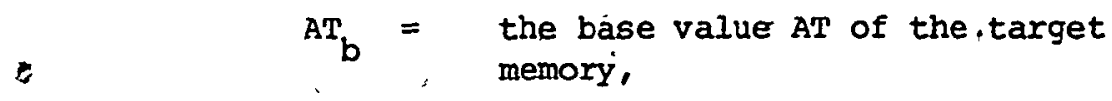

-It can be see that the magnitude of the increase in the AT

for selective retrieval will depend upon both the composition of the target memory and the similarity of the features,between the st' and S- displays. Since base value ATs are determined as a proportion of the cumulative APs for the attributes in the target memo-' ry, the greater the number of attributes in this memory, the higher will be the ATI for a given s-. Also, 'as the number of shared features between the St and s- displays increases, the hidger will be the ATI for:a given target memory.

Rule 3 . It is assumed that both APs and ATs increase as a negatively accelerated function of retrịeval experience (i.e.. triais during acquisition). It is assumed that these rates are independent of the base' values, and only refer to. initidl increases. The rate of increase for ATs is expressed by the following:

$$
A T_{n}=A T_{n-1}+J\left(I / A T_{n-1}\right) ; \&
$$

where

$$
\text { AT }=
$$

the magnitude of the At between successive: retrieval experienoes (1,e.e triats)

\section{AT} existing on the previlous retrievai experience (1 etoprevious triail, 


$$
\begin{aligned}
J^{\prime}= & \text { a rate constant, set by a central } \\
& \text { processing mechanitsm, which reflects } \\
& \text { the state of the organism. . . }
\end{aligned}
$$

A similar expression defines the rate of increments for APs. The only differences would be in the rate constant.J. The model allows this rate parameter to differ for ATs and"APs.

One obvious implication of this rule is that the higher the Ari, the longer it wili take to achieve selective retrieval, proficièncy. Thus, when the st and s-, shate many features (Rule 2) it will take longer to establish selective retrievar, than when the two displays share relatively few features: Therefore, the more simila'r the displays in a discrimination pfoblem the longer wirl be the course of acquisition.

Rule 4. During periods of inactivation (such as during retention intervals) ATs decliné toward base values. The rates of decline exend upon the values existing prior to the period of iffactivation:

The rate of decline for ATs is expressed by the following ': equation:

$$
A T_{t} \Rightarrow A T_{t-1}-K\left(A T_{t-1}\right)
$$

where

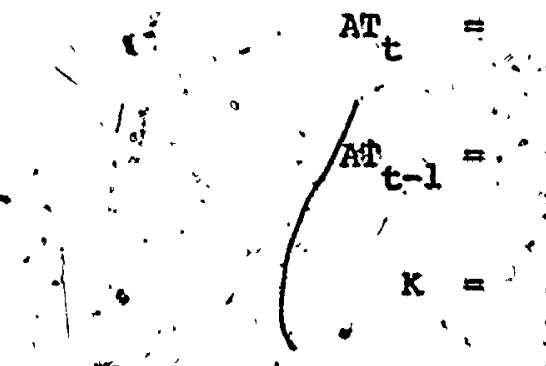

the magnitude of the AT at some time, $: t$, 

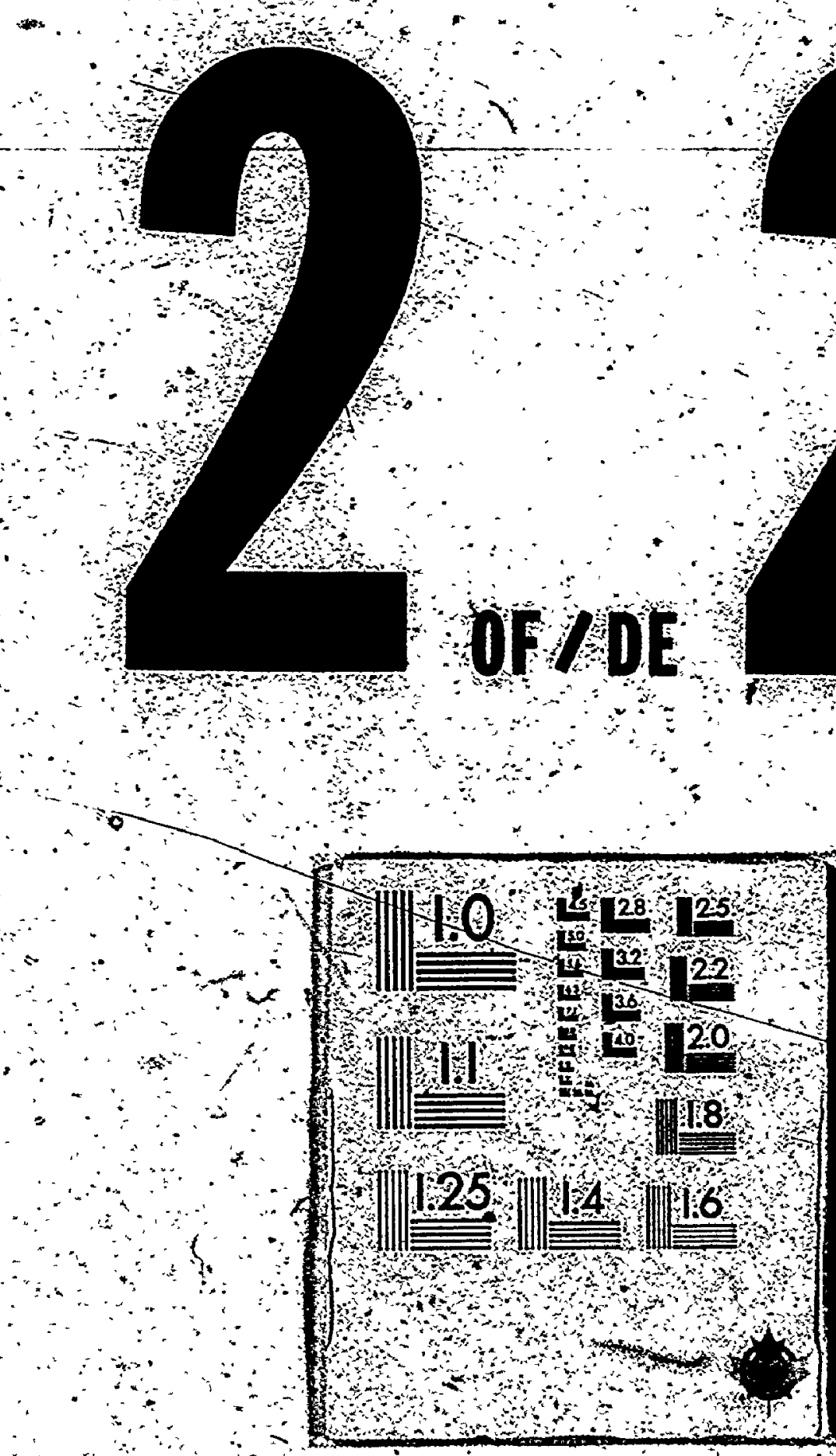

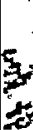

$\theta^{\circ}$

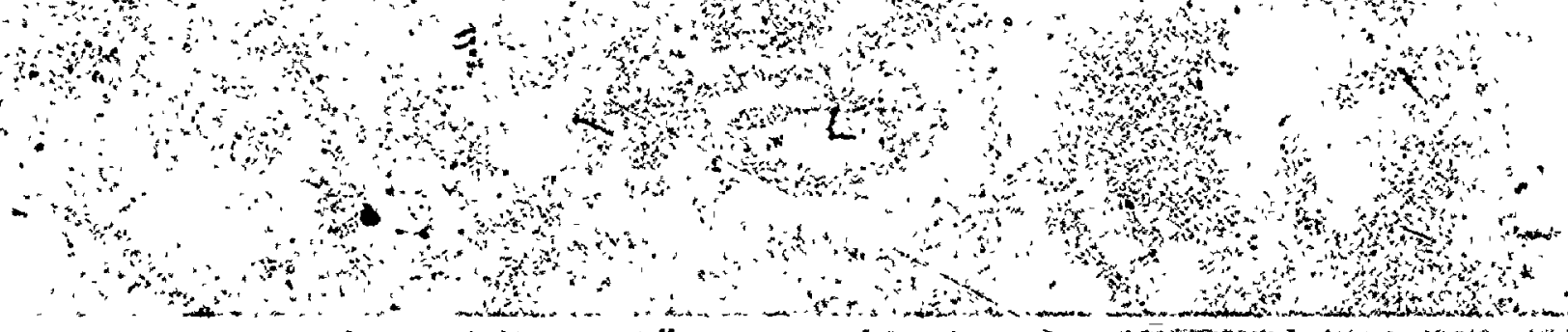


There are two important implications of this rule.-Firșt, since forgetting, is assumed to résult from selective retrieval failuxe, and since decreases in ATs are assumed to underlie this selective retrieval failure, Rule 4 implies that forgetting will typically prọceed in a negatively accelerated fashion. 'second, since the rate of decline for ATs is assumed to be influenced by the valiue of AT prior to the period of decline, more forgetting (as greater selective retrieval failure) is expected for situations in which the ATI is greater. This implies that as the similarity between the discriminative stimuli increases, forgetting is expected to increase, since similarity will influence the ATI (Ruile 2).

Rule 5. Following periods of decline, ATs are reinstated at. faster rates than for original increases. Also, these rates are influenced by the APs in the target mémory, which are aroused during exposure to appropriate features. . The rate of reinstatement for ATs is given by the-following equation:
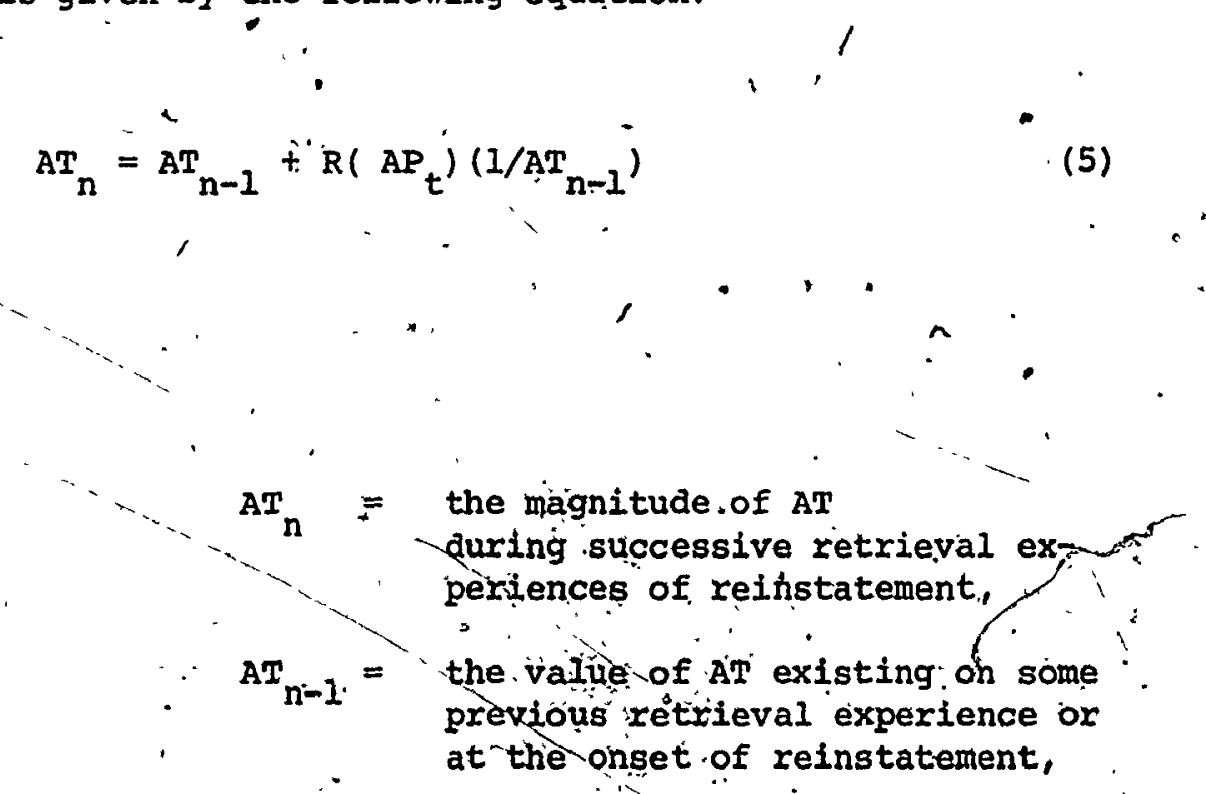
of reinstatement and reactítation. It has been frequently shown that exposing subjects to limited aspects of an original learning event during retention intervals can mitigate subsequent forgetting (Spear, 1978).. It is believed that the present model is capable of accounting for this effect. Finally, Rule 5 implies that the process of reinstatement will be influenced by the composition of the target memory and the precise features presented during a reinstatement period. Specifically, Rule 5 states that as the number of features represented in the target memory increases, the rate at which ATs are reinstated will also increase, assuming that these features are present during a reactivation period. Thus relearning, as the reestablishment of proficient selective retrieval following a retention interval, is expected to proceed faster when the target memory contains many attributes and these attributes are aroused during relearning.

It is believed that this retrieval model can be successfully applied to the data from Experiment 1. It is argued that two different sources of selective retrieval failure appeared; one source for the forgetting of the single discrimination, and an additional source for the forgetting associated with reversal learning. The first source of forgetting involved selective retrieval failure for the original target memory. The displays in this experiment shared a number of features. In addition, features corresponding to contextual cues were also shared between the two types of stimulus presentations. This high degree of featural overlap made it likely that presentation of both the $s+$ and $s-$ displays would activate $a$ number of attributes contained in the target 
1 .

memory. This' would have reduced the probability that only the St display would selectively retrieve that target memory. Thus, during acquisition $s-$ presentations would have frequently resulted in the target response of pecking the display. With continued training, however, the APs for attributes corresponding to unique features on the St display would have been increased. These features would include the presence or absence of the third dot. In addition, the AT of the target memory would have also increased. Once this occurred, target, memory attributes aroused during s- presentations would no longer have been sufficient to retrieve that memory. These concurrent changes would have. increased the probability that only the st display would retrieve the target memory. Over the retention interval, however, ATs would have , declined. Thus, forgetting would have then appeared as the inappropriate retrieval of the target memory in response to the S- display.

The greater forgetting over longer retention intervals can be accounted for in terms of the temporal course of the decline in ATs. The reversion to base values is expected to proceed gradually (Rule 4). Thus, the performance of the groups at the various retention intervals represents a gradual return to performance proficiency associated with different stages of acquisition. At one day, little change in the target memory AT may have occurred, so that selective rètrieval operated at a level of proficiency achieved at criterion. For the 10- and 20-day groups, however, the decrease in ATs would have been greater, and their performance during relearning would have corresponded to the retrieval proficiency associated with different stages of precriterion performance.

The enhanced forgetting due to PI requires a more complex explana- 
tion. It is assumed that during reversal learning, the extinction contingency associated with the former st display resulted in an elevation int the AT for the original target memory. This would have reduced the probability that the new S- would retrieve that memory. In addition, a new target memory, representing, reinforced responding to the new st, would have developed.. It is assumed that the original target memory. remained intact, but became less retrievable due to an increase in its AT. Over the retention interval there would have been' a decrease in the ATs for both the original and reversal target memories. Thus, after a retention interval there would have been an increase in the probability that the new $s$ - would again retrieve the old target memory; this should have resulted in the target response of pecking, which was originally represented by this memory. In addition, the decrease in the AT for the reversal target memory would have resulted in an increase in the probability that the new S- display would also inappropriately retrieve that memory; this would also result in the target response of pecking. Therefore, following a retention interval after reversal learning there . would have been an increase in the probability of either display retrieving a target memory which would produce the target response. Thus, the enhanced forgetting due to PI can be understood in terms of the availability of two target memories which yield the same target response, and the loss of selective retrieval for these memories due: to decreases in ATs over the retention interval.

The increase in PI found for the one-day subjects retested after an additional 20-day interval can be accounted for in terms of differential rates of decline in ATs for the original and reversal target memories. According to Rule 4, it is assumed that higher ATs will decrease faster 
than lower ATs. Also, in order to prevent the reversal s- from retrieving the original target memory, the AT for this memory would have increased to a value even greater than necessary for selective reversal target memory at the end of reversal acquisition. Thus, the rate ' of ' decline in AT for the original target memory is expected to be greater than for the reversal target memory. This suggests that at shorter $\bullet$ retention intervails inappropriate retrieval of the original target memory will precede selective retrieval failure, of the reversal target memory. This would yiet a single source of forgetting at relatively short retention intervals. After more prolonged retention intervals, ' however, both selective retrieval failure for the reversal target memory ; and inappropriate retrieval of the original target memory would occur.

- This should produce two sources of selective retrieval failure, and therefore'more PI woula be expected at longer retention intervals. 


\section{CHAPTER 3}

Experiment 2

The Effects of Similarity on the Forgetting of

Discriminations in Pigeons

Theoretical approaches to interference effects on forgetting have generally accepted similarity as the fundamental parameter (Spear, 1978). It has been argued that both RI and PI increase directly with the degne of similarity between the target task and conflicting experiences. These effects have been empirically demonstrated in verbal learning research for both transfer and retention losgood, 1948; Bugelski' \& Cadewallader, 1956; Underwood, Runquist \& Schultz, 1959; Jung, 1968). Research with rats has also shown interference effects to increase with the degree of similarity between conflicting learning episodes (Crowder, Cole \& Boucher, 1968; Zentall, 1970).

In addition to between-task interference effects, similarity might also be expected to influence forgetting as a within task variable. For example, the degree of forgetting for a discrimination might be related to the degree, of 'similarity between the stimuilus alternatives. While most researchers would likely accept this assumption, the issue has actually not received sufficient empirical examination in animal memory research. The purpose of the present experiment was to attempt such an investigation, and to test implications of the proposed retrieval model for similarity effeqts on forgetting.

Separate groups of pigeons were trained on one of three two-choice, successive, go/no-go discriminations. Each problem involved dot displays as the discriminative stimuli of the type used in Experiment 1. 
One of the displays in each problem contained two green dots. The alternative displays contained,either three green dots (Group G=3), five green $\operatorname{dots}^{-}$(Group G-5), or two green. dots and one red dot (GroupR). The relative rate of acquisition and the degree of forgetting after 20 days was assessed for' the three problems.

In addition to the empirical question concerning the relationship between stimulus similarity and the forgetting of discriminations, this experiment also provided a good opportunity to test the proposed retrieval model. This model is explicitly designed to deal with similarity effects of the type examined in this experiment.

According to the present model, any features noticed by the organism during the learning episode will be encoded as memory attributes. Eventually some of these attributes will organize into a set or unit which defines the target memory. The retrieval of this memory will result in the target response. The problem the organism faces duringa discrimination task is to selectively retrieve the target memory during s+ presentations and not during $\dot{s}-$ presentations. The subject's discriminative performance will reflect. the proficiency of selective retrieval. : The model assumes that selective retrieval proficiency is a direct function of the degree featural overlap (i.e., similarity) between S+ presentations and S- presentations; the more attributes in the target membry that are activated during an $s-$ presentation, the higher the probability will be that an s- presentation will retrieve the target-memory and result in a target response. Thị is a consequence of the assumption that not all attributes in the target. memory. need be activated in order for the memory to be retrieved. The only demand is that enough attributes be activated which have cummulative APs above 
the AT, for that target memory. The greater the featural similarity between an St and S- presentation, the more likely it will be that the S- will activate sufficient attributes to surpass the AT for the target memory.

The model assumes that acquisition entejils memory processing beyond the formation of a target memory. This additional processing involves increases in APs and ATs above base values. By increasing the APs for attributes representing features unique to the S+ display, and elevating the AT. for the target memory, the probability of an $S$ - presentation retrieving the target memory is reduced. In order for this selective - retrieval to occur, it is postulated that both APs and the AT for the target memory must be elevated to some critical value. This value will be determined by the number of attributes contained in the target memory and the degree of featural overlap between St and S- presentation: The greater the number of attributes in the target memory, and the greater the featural overlap between stimulus presentations, the higher will be the critical APs and ATs necessary for selective retrieval (Rule 2).

The model also assumes that increases in AP and AT occur gradually, and follow a negatively accelerated function of the amount of retrieval experience (Rule 3). Thus, the higher the critical value of AT required for selective retrieval, the more processing time needed to reach this value. This leads to an explicit prediction concerning acquisition xates and the degree of similarity between St and S- presentations: As similarity between stimulus presentations increases, the length of time required to establish proficient selective retrieval will also increase. In the present experiment, it was assumed that similarity.was greter 
for Group G-S than for Groups G-5 or $R$. Therefore, it was predicted that Group $\mathrm{G}-3$ would take longer to acquire the discrimination than the other two groups; the differences in similarity between the latter two groups was less obvious, 'and therefore no explicit prediction was made concerning their relative rates of acquisition.

The present model also proposes that ATs decline in a negatively accelerated manner during periods of inactivation. According to Rule 4, the rate of decine for ATs will be a function of the magnitude of the AT required for selective retrieval (Rule 2). The greater the critical AT, the faster-will be the rate of decline during a period of inactivation. Since it is assumed that the critical values for ATs are greater for discriminations involvirig more similar stimulus presentations (Rule 2), larger decrements in these values are expected for such problems during retention intervals. Therefore, it should take Ionger to reestablish critical ATs, following a retention interval, for discriminations that have more similar stimulus displays. Consequently, more forgetting should occur for these problems. In the present experiment, more forgetting (as indexed by $s$ - responses during relearning) was predicted for Group $G-3$ than for Groups $G-5$ and $R$, due to the assumed higher degree of similarit between the stimulus displays in the former group. Again, the similarity differences for the latter two groups were less obvious, and no expliẹit prediction concerning any differential forgetting for these groups was made. 
Method

Subjects

Eighteen, adult, naive Silver King pigeons served as subjects: These animals were housed in individual wire pigeon cages in a common animal holding room. Théy were reduced to 808 of their ad libitum weights and maintained at these values throughout the experiment. They were alfowed free access to water. Each subject was weighed and fed following each working session or at the same time of day during nonworking intervals.

\section{Apparatus}

The same pretraining chamber used in Experiment I was employed. The experimental apparatus consisted of an inner chamber measuring $30 \mathrm{~cm}$ x $30 \mathrm{~cm}$ (floor dimensions) $\times 35^{\circ} \mathrm{cm}$ (wall height). This chamber was placed inside of a sound attenuating cubicle. One wall of this cubicle contained hinged doors, which allowed access to the inner chamber. A single transparent pecking key was located $8 \mathrm{~cm}$ from the floor, and centered on the front wall of the inner chamber. A $6 \mathrm{~cm}^{2}$ food well was placed $8 \mathrm{~cm}$ below the pecking key, and an electromechanical food hopper was mounted behind this opening. miniature light bulb socket, containing five butes, was mounted directly behind the pecking key. When illuminated, the lightbulbs projected circular dots, $.7 \mathrm{~cm}$ in diameter, onto the pecking key. The bulbs were arranged in the form of a plus sign, with three bulbs horizontally arranged and evenly spaced, and two additional bulbs evenly spaced above and below the centre horizontal bulb. For all discriminations, one of the stimulus displays consisted of two green dots. This was accomplished by covering the outer two hor- 
izontal bulbs with green celluloid. The other displays contained éither five green dots, three green dots or two green dots and one red dot." For the five dot display, all bulbsewere illuminated and covered with green celluloid. During the three green dot display, the three horizontally arranged bulbs were illuminated and covered with green celluloid. For the two green/one red dot display, the three horizontal bulbs were illuminated, and the outer two blilbs were covered with green celluloid, while the centre bulb was covered with red celluloid. Event programing and response recording was controlled by electromechanical relays located in a separate rgom.

Procedure

Three pretraining sessions, identical to those used in Experiment $1^{\circ}$ were conducted. Experimental testing.began on the following day. The subjects were randomly assigned to ore of the three discrimination problems with ste subjects pet group. Half of the subjects in each group received a Feature Positive discrimination, in which the S+ contained either three or five dots and the s-contained two dots. The other half received a Feature Negative discrimination, in which the two dot display was $S+$ and the three or five dot displays were designated S-. 'Daily sessions consisting of 72 trials were presented until criterion was reached. The acquisition criterion, intratrial events, and trial arrangement was identical to the procedure used in Experiment 1. Following criterion a 20-day fetention interval commenced. This was followed by a relearning test, in which the same procedure used during, acquisition was employed. Relearning continued to the same criterion used fọ original acquisition. 
Acquisition

Results'

The mean S- responses to criterion for the Groups G-3, G-5, and $R$ were $524.2(S D=275.0), 104 \quad(S D=39.7)^{\circ}$, and $53.8 \quad(S D=17.8)$ respectively. These means were found to differ significantly, $F(2,15)=15.5, \underline{Q}$ .001. Individual comparisons, using the Tukey procedure, revealed that Group G-3 made significantly more S- responses to criterion than either Group G-5 or Group R; the latter two groups did not differ significantly.

$\underline{\text { Relearning }}$

A oneway analysis of variance for $s$ - responses on the criterion trial blocks of acquisition revealed that the three groups, did not differ. Thus, these groups were considered to be performing with equal proficiency at the end of acquisition. Relearning was again assessed in terms of s- responses to criterion, since ail, subjects responded to sf displays on all bccasions. The mean $s-$ responses to criterion during relearning were $110.0 \quad(S D=80.3), 4.3 .(S D=2.6)$, and $3.0 \quad(\underline{S D}=2.5)$ for Groups G-3, 'G-5, and respectively. These means were found to differ '. significantly, $F(2,15)=15.7, p<.001$. Individual comparisons, -using the Tukey procedure, revealed that Group G-3 made significantly more -sresponses to criterion than either Group G-5 or Group R; the lattor two groups did not differ significantly. It is clear that while Group G-3 showed considerable forgetting, Groups $G-5$ and $R-1$ showed very littie: \&s

forgetting, both groups performed at nearly the same level of profici- . ency achieved at the end of. acquisition.

One potential problem for interpreting the finding that Group G-3. 
showed more forgetting than the other two groups, concerns the differ= ences between these groups during original acquisition. Group G-3 made more s-responses to criterion during acquisition than either of the other, two groups. Therefore, the differences found between the groups during telearning, might simply reflect a learning rate difference due to similarity, and may 'not' indicate that greater forgetting had aetually resulted for Group G-3 (Underwood, 1954, 1964). In order to obviate this interpretational problem, an analysis of variance was performed on 1 the percent savings scores for each group. These scores were calculated - by the following:

\section{$\frac{S-\text { responses acquisition - S- responses relearning }}{S-\text { responses acquisition }} \times 100$}

These scores were $80.8,94.1$ and 95.8 for Groups $G-5, G-3$ and $R$, respectively. It was found that these scores differed significantly between the three groups, $F(2,15)=12.05, p<.001$. Between yroup comparisions, using the Tukey method, revealed that Group G-3 had significantly lower savings scores than either Group. G-5 or Group R, while the latter two groups did not differ significantly.

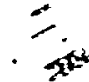

\section{Discussion}

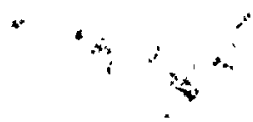
discriminations in pigeons is influenced by the similarity between the stimulus displays. The group considered to have the most similar displays, Group G-3, took longer to acquire the discrimination and showed more forgetting over the 20-day interval than the two groups considered to have problems involving less similar displays, Groups G-5 and R. No significant differences were found between the latter two groups for 
either acquisition or relearning, although, there was an indication that group G-5 did have more difficulty learning the discrimination.

The role of similarity in forgetting with animals has typically been examined through between task-interference effects. It has been found that conflicting experiences interfere more with the retention of the to-be-remembered event when these experiences are more similar (Crowdèr, Cole \& Boucher, 1968; Zentall, 1970; Wickens et al., 1977). Similarity as a wițhin task variable has not been previously investiqated. It is believed that the present data represent the first reported instance of differential forgetting due to within task similarity in animals. As such, they extend the range of empirically demonstrated similarity effects, and suggest a preparation that can be further used to stydy this issue. :

- The present data are also in accord with the proposed retrieval model. It was hypothesized that if differential acquisition and forgetting was to occur between the groups, faster acquisition and less forgetting would be expected, for the groups having the least degree of similarity between the stimulus displays (i.e., Groups $G-5$ and $R$ ). The data confirmed these predictions.

The successful application of the proposed retrieval model to $r$ the dàta from this experiment also encourages extending this analysis to the negative results reported by Kehoe (1963). In the Kehoe experiment pigeons, were trained to respond to one of five simultaneously presented stimuli. Some of the birds were then given reversal training in which a "different coloux became the St. There was little forgetting found for either the original problem or a reverse discrimination. The current model suggesț that a discrimination problem essentially involves 
selective retrieval; subjects must come to retrieve à particular target - memory only in response to a specific stimulus array. Further, the . similarity between any stimulus presented and the stimulus represented in the target memory will determine the effectiveness of selective retrieval. The greater the similarity, the higher the probability will be that some inappropriate stimulus display will retrieve the target "memory". According to the present model, this is due to the arousal of target memory attributes during presentations of stimulus displays containing features identical or similar to those contained in St display. If a sufficient number of attributes with cumulative APs greater than the AT of the target memory are aroused, the memory will be retrieved. The probability of this occurring is a direct function of the featural similarity between the stimulus presentations.

When featural overlap is great, the APs for attributes unique to the target memory may be increased. This will allow distinguishing features of the S+ display to control retrieval. Also, the AT for the target memory will increase. This will reduce the likelihood that other features, not unique to the target display, will guide retrieval. These latter increases, however, will degenerate over periods of inactivation, such as during a retention interval. When this occurs, selective retrieval will again be reduced and the resulting decrement in performance will define forgetting.

When a discrimination problem involves displays which are highly dissimilar (i.e., they share few features), selective retrieval may occur more easily and without necessitating any increases in APs or ATs above base values. Under these circumstances little change in selective retrieval would be expected over a retention interval. Therefore, 
little forgetting would be expected. Such a situation may have occurred in the Kehoe study. The stimulus values used by Kehoe may have been sufficiently different to avoid the necessity of raising APs and ATs. Thus, little change in selective retrieval probability would have been expected over the 30-day retention interval. A similar argument could be made for Groups $G-5$ and $R$ in the current experiment. For Group G-3, however, the displays may have contained sufficient featural overlap to require increases in the APs and the ATs for the target memory. The forgetting evidenced by this group could, therefore, be accounted for in terms of a decline in the target memory AT during the twenty-day retention interval.

Finally, it is interesting that Groups $G-5$ and $R$ did not show different degrees of forgetting, or for that matter show any forgetting at all. This would indicate that a single red dot is as different from a display containing two green dots, as five green dots are. A more detailed investigation of this issue, involving a greater number of featural arrangements, could perhaps provide a greater understanding of intratask similarity effects for both acquisition and forgetting. 


\section{Experiment 3}

The Influence of Contextual Cues on the

Forgetting of Visual Discriminations in

Pigeons

There is considerable evidence which shows that contextual cues can substantialiy influence learning and retention in animals. Contextual cues are typically defined as cues present during a behavioral event, but upon which the occurrence of the target response is noncontingent. This definition would include both exogenous contextual cues associated with the external environment, as well as endogenous contextual cues, involving internal events within the organism during the behavioral episode. It hat been found that changes in contextual cues following acquisition can deleteriously affect subsequent transfer learning and retention (Perkins \& Weyant, 1958; Riccio, Urda \& Thomas, 1966; Steinman, 1967; Welker, Tomie, Davitt \& Thomas, 1974). Also, there are data which show that contextual change can affect stimulus control. Contextual cues associated with specific learning episodes have been found to influence subsequent discrimination learning (Welker, Tomie, Davitt \& Thomas, 1974), and to reduce forgetting of stimulus control due to interfering experiences (Chiszar \& Spear, 1969; Zentall, 1970; Thomas, McKelvie, Ranney \& Moye, 1981).

The present experiment attempted to examine the influence of contextual cues on the forgetting of a visual discrimination in pigeons. All subjects were trained on a successive discrimination involving the

\section{4}


- 潘

aot displays used in Experiment 1. A relearning test was then given 20 days after acquisition. For half of the animals, relearning took place in the presence of the same contextual cues asspciated with original acquisition; the other haif were tested in the presence of different contextual cues. In addition, the specific characteristics of the contextual cues and their potential influence on forgetting were assessed. Two different contextual cue environments were employed. A deprived contextual environment involved a standard operant chamber for pigeons and the absence of a houselight and tone. An enriched contextual environment cönsisted of a wooden compartment fitted into the operant chamber. The walls, floor and ceiling of the inner chamber contained random black and white patterns; a houselight and tone were always present. It was assumed that the enriched environment provided a more salient set of contextual cues than the deprived environment, and it was of interest to examine how these different sets of contextual cues might influence acquisition and for-

getting. Thus, half of the animals were trained in the enriched environment and tested in the same (Group $\mathrm{E}-\mathrm{E}$ ) or deprived environment (Group E-D). The other half were trained in the deprived environment and tested in the same (Group D-D) or enriched environment (Group D-E). This experiment also provided another opportunity to test the proposed retrieval model. The contextual cue arrangements employed in this experiment were expected to influence both acquisition and forgetting of the visual discriminations. With respect to acquisition, the model suggests that as the number of attributes contained in the target memory increases, the higher will be the critical APs and target memory AT necessary for selective retrieval (Rule 2). Therefore, with more features 
present in the learning context, more attributes will be contained in the target memory. This should lead to higher APs and ATs in situations involving more numerous contextual cues. Since APs and ATs increment gradually, more processing will be required in order to establish proficient selective retrieval when the critical values are higher (Rule 3). Thus, acquisition is expected to proceed faster when fewer salient contextual cues are available. With respect to the current experiment, it was predicted that subjects trained in the contextually impoverished environment would reach acquisition criterion sooner than subjects trained in the contextually enriched environment.

The model also predicts differential forgetting "for the various test conditions. It is expected that the effects of testing in the same or different contextual environments experienced during acquisition will interact with the nature of these environments. For groups trained in the contextually deprived environment, there would be few attributes representing contextual cues in the target memory. Therefore, selective retrieval of the target memory would be expected to be little influenced by the contextual cues present during acquisition or relearning. Thus, no difference in the amount of forgetting of the discrimination was predicted between Group $D-D$ and Group $D-E$. For the groups trained in the contextually enriched environment, however, it was expected that many more contextual cues would be represented in the target memory. Although the availability of these cues was expected to retard acquisition, relative to a less salient contextual environment, it was also assumed that they would enhance performance during the relearning test, and decrease forgetting. This prediction follows from Rule 5 of the model, in which it is assumed that ATs can be reinstated more 
readily to values, necessary for selective retrieval, when more attributes are present in the target memory and are aroused during reexposure to the corresponding features. Thus, the rate of increase for ATs is partly determined by the number of attributes which make up the target memory. This implies that relearning will be faster when the number of attributes contained in the target memory is greater. This is due to the rapid reinstatement of ATs necessary for selective retrieval, which had declined during the retention interval. For the present experiment, it was anticipated that the group trained in the presence of salient contexțual cues and tested in the same environment, Group E-E, would evidence less forgetting than Group E-D, which was trained with salient contextual cues, but tested without these cues.

Method

Subjects

Twenty-four, adult, naive silver King pigeons served as subjects. Each subject was housed in an individual wire pigeon cage located in a common animal holding room. Each subject was food deprived to $80 \%$ of its ad libitum weight, and maintained at this value throughout testing. They were weighed and fed following each working session or at the same time of day during nonworking intervals. Unlimited access to water was provided.

Apparatus

The same general apparatus, stimulus materials and recording equipment used in Experiment 1 ' were employed. Subjects trained in the" 
contextually deprived environment were trained in the experimental chamber used in Experiment) 1. The contextually- enriched environment involved the placement of a locally constructed wooden compartment inside of the operant chamber. This insert consisted of two wooden sidewalls, a floor and a ceiling, each measuring $12 \mathrm{~cm}^{2}$. A third gide wall was constructed of cardboara and was placed against the front panel of the operant chamber. This cardboard wall had openings which allowed access to the pecking key and food magazine. The fourth sidewall was provided by the hinged doors of the sound attentuating cubicle that enclosed the operant chamber. Three of the sidewalls, the floor, and ceiling of the inner chamber contained black and white random patterns. houselight was inserted through a hole in the ceiling of the inner chamber, and a $2,000 \mathrm{~Hz}$ tone was provided by a sonalert placed 'within the sound attenuating cubicle.

Procedure<smiles></smiles>

Following the pretraining procedure used, in Experiment 1 , the subjects were randomly assigned to one of the four conditions. For the pretraining phase conducted in the experimental apparatus, the context appropriate för acquisition was emiployed. All subjects were then trained on a successive distrimination. Half of the subjects in each group were given a Feature Positive discrimination (i.e., three dots S+' and two dots $\mathrm{s}-1$, while the other half received a Feature Negative discrimination (i.e., two dots St and three dots s-). Two of the groups. - were trained in the contextually deprived environment (Groups D-D and $D-E)$. This involved training in the standard pigeon chamber without a houselight or tone. The other two groups (Groups E-E and E-D) were trained in the contextually enriched environment. This consisted 
of training in the wooden chamber insert with both the houselight and tone present throughout the session. Acquisition consisted of the same general procedure used in Experiment 1, and the same criterion was employed. A 20-day retention interval commenced once criterion was achieved, and was then followed by a relearning test. Relearning involved the same procedure followed during acquisition, and the experiment terminated for each subject once they reestablished criterion performance. Relearning was conducted in the context appropriate for each condition.

Results

\section{Ácquisition}

Differences in acquisition rates were asséssed with respect to the contextual environment in which learning took place. The, mean sresponses to criterion for subjects trained in; the contextually deprived and contextually enrichéd environments were $85.25 \quad(\underline{S D}=34.4)_{3}$, and 108.58 $(\underline{S D}=35.7)$ respectively. These differences were not found to be significant, $t(22)=1.63, p>.05$. Also, no differences between the four conditions were obtained for performance during the oriterion trial blocks of acquisition. Therefore, the groups were performing with equal proficiency at the end of acquisition.

Retention

All subjects responded to the St displays on all occasions during the retention test. Therefore, the data of interest were the mean Sresponses to criterion during relearning. An anaiysis of variance as performed on these' data, with the factors consisting of Acquisition 


\begin{abstract}
(enriched versus deprived contextual environments), Retention (the same or different context used during acquisition), and subjects (six in each group). Significant main effects were obtained for Acquisition, $F(1,23)$ $=13.69, \mathrm{p}<.05$ and Retention $F(1,23)=17.64, \mathrm{p}<.01$. Also, a sig- nificant interaction was found between Acquisition and Retention, $F(1,23)=10.24, \mathrm{Q}<.05$. The mean $\mathrm{S}$ - responses to criterion during relearning are plotted for each of the four conditions in Figure 5 . Group comparisons revealed that no difference was obtained between groups $D-D$ and $D-E$, and a sịnificant difference was obtained between . groups $E-E$ and $E-D, t(10)=2.5, p<.05$. Thus, a change in context between acquisition and relearning had a detrimental effect, only when acquisition took place in a highly salient contextual environment.
\end{abstract}

\title{
Discussion
}

It was predicted that groups trained in the environment containing numerqus contextual cues would take longer to reach criterion during acquisition. This prediction 'was based on the assumption that higher APs and a higher AT for the target memory would be required when the contextual cues represented in the target memory were more numerous. Since APS and ATs are assumed to increment gradually over the course of acquisition training, higher values would require more experience. The data failed, however, to show a significant difference between the rates of acquisition for the contextually enriched and contextually deprived conditions, although, the differences were in the expected direction. one poten al reason why these differences failed to reach significance, could pertain to the parametric values of contextual cues that were used 
i i

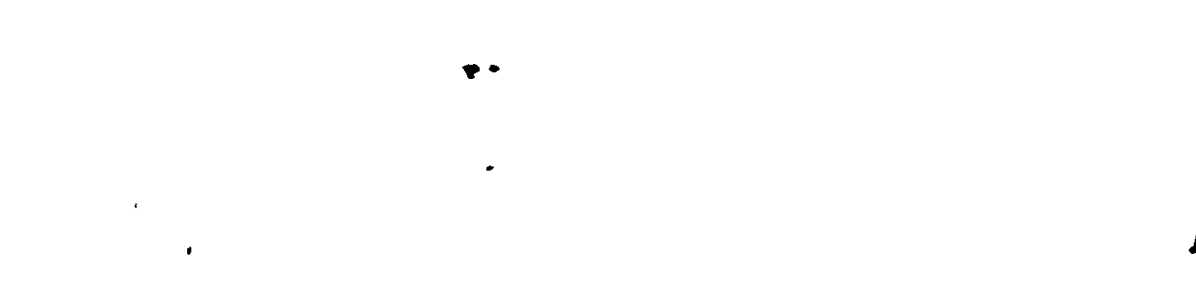

Figure 5. Mean S- responses to criterion during acquisition and relearning after a 20-day retention interval for various contextual cue conditions. 


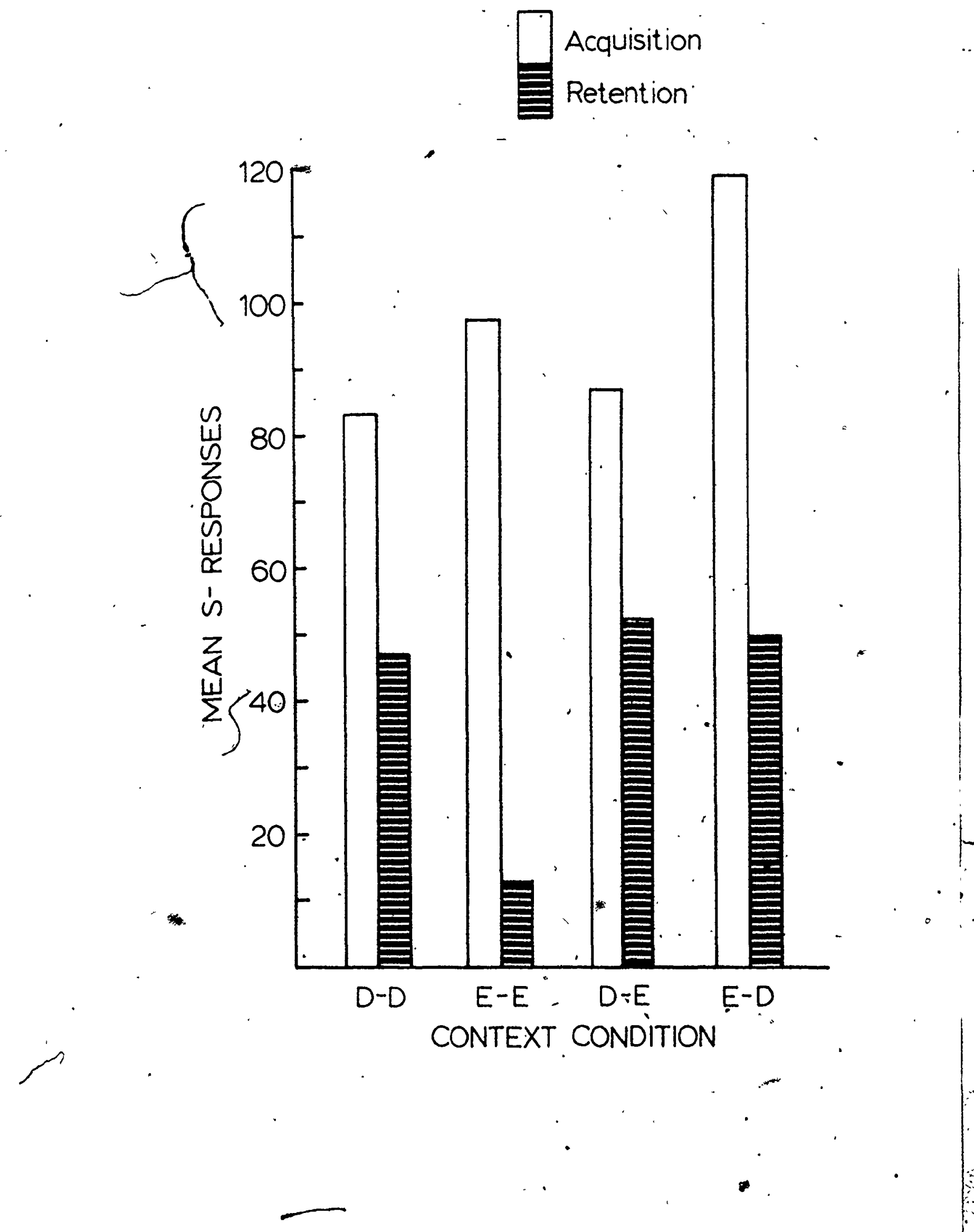


in the experiment. It is difficult to determine a priori what salient and numerous contextual cues would be for any organism in any sițuation. Thus, while the "contextual environments may have been nominally distinct, the functional differences between the conditions may not have been. sufficient to produce a statistically reliable difference. It would, therefore, seem valuable to reexamine this issue with other. contextual cue manipulations.

The results on forgetting were much more supportive of the model. It was predicted that a change in contextual cues would interact with the nature of the cues themselves. Specifically, it was predicted that with relatively few salient contextual cues available during acquisition, a change in the contextual environment during retention testing would have little influence on forgetting, That groups $D-D$ and $D-E$ showed equivalent degrees of forgetting confirms this prediction. A change in the contextual environment during testing was expected to enhance forgetting, relative to a no change condition, when these cues were gre numerous. This prediction was based on the assumption that APs and ATs are reestablished, following some period of decline, at a faster rate when the target memory contains more attributes and these attributes are aroused during relearning. The presence of the relatively copious contextual cues during_testing for Group B-E would have facilitated the reestablishment of ATs necessary for. selective retrieval. The absence of these cues for Group E-D would have resultèd. in a prolongation in the reestablishment of these values. Thus, it was predicted that more forgetting, fs indexed by $s$ - responses to criterion during relearning, would occur in Group E-D than Group E-E. The data on forgetting showed just such a relationship. 
The assumptions tested' in the present experiment also, have implications for other memory phenomena. - In partiçular, the model suggests an explanation for the important phenomena of reinstatement and reactivation. Numerous studíes have shown that re-exposure to various aspects of à learning episode during a retention interval can attenuate forgetting (Campbell \& Jaynes, 1966; Spear \& Parsons, 1976; Spear, 1978; Spear, Hamberg \& Bryan, 1980). The current model would explain these effects in terms of the same principle argued to reduce the forgetting for a group trained and tested with salient contextual cues in the present experiment. It was postulated that when the target memory contains numerous attributes, including those representing, contextual cues, the presence of the features represented by these attributes during a retention test can facilitate the reestablishment of ATs. It - is assumed that it is the arousal of these attributes during exposure to the corresponding features that is responsible for the facilitation; the occurrence of the target response is not necessarily implicated in this process. Thus, it is consistent with the model that exposure to aspects. of the learning episode, which do not require or allow target 'responding, may activate sufficient attributes to elevate and ATs that may have declined during a retention interval. Accordingly, reinstatement and reactivation treatments are believed to enhance retention by the effects these experiences have on ATs associated with target memories. In addition, the effects of these treatments would be expected to depend upon when they are adminiştered, what specific cue combinations or experience were provided, and the composition of the memories involved. 
General Discussion

Although the pigeon has been frequently employed In $_{n}$ the study of animal working memory, there has been comparatively little interest in the study of pigeon reference memory. Among the infrequent attempts that have been made to examine this issue, forgetting has often not been observed (Skinner, 1950; Thomas, Ost \& Thomas, 1960; Hoffman, Fleshler \& Jensen, 1963; Hoffman, Selekman \& Fleshler, 1966). The only preparation which has reliably produced substantial forgetting in pigeons has involved the" study of dellayed generalization testing. These studies have examined the shapes of generalization gradients obtained immediately or one day or more following either reinforced training with a single stimulus or a successive discrimination. Gradients obtàined one day or more following initial training have been found to be flatter than those obtained immediately (Thomąs \& Lopez, 1962; Thomas \& Burr, 19े69).

It is interesting that while the delayed generalization studies have shown evidence of long-term forgetting in the pigeon for stimulus control, there has been no convincing demonstration of forgetting for discriminations in pigeons. In those experiments that have assessed, generalization following successive discrimination training, there has been no indication that forgetting occurred for the discrimination itself, oven though the gradients were different for immediate and delayed tests (Thomas \& Burr, 1969; Burr \& Thomas, 1972).

The data from explicit attempts to study forgetting of discrimina- - tions in pigeons have also failed to show unequivocal evidence for forgetting. A study by Kehoe (1963) found no evidence of forgetting for a discrete trial color discrimination after intervals as great as 30 days.

\section{5}


Similarly, Behrend, Powers and Bitterman (1970) found no forgetting of a single two-choice discrimination after 14 days; although, they did report progressive forgetting for a series of subsequent reverse discriminations over the same interval. Ćlose inspection of these data, however, brings into quiestion whether forgetting actually occurred. Performance during the retention test did not seem to differ from performance at the end of acquisition, even though the relearning scores did differ for each subsequent reversal problem. These scores do not indicate, however, a performance decrement relative to acquisition performance, and it can therefore be argued that forgetting did not actually result.

Finally, several experiments by the author also failed to show any forgetting for visual discriminations in pigeons. These studies involved manipulations which have often produced substantial forgetting in other situations. Forgetting occurred, with only one of these conditions. The experiments reported in this thesis represent a detailed investigation of the forgetting obtained, with this preparation, and it is argued that these data provide the only unequivocal demonstration of forgetting for discriminations in pigeons yet reported.

The general procedure used in the three experiments involved acquisition and retention testing for a discrete trial, two-choice, successive, visual discrimination. The discriminative stimuli were small dot displays presented on a single pecking-key. The learned behavior involved the cessation in pecking the stimulus display during an s- trial, with continued responding to the st display. 'In all three experiments, evidence was obtained which showed forgetting of the disorimination. Animals resumed pecking the S- display following intervals of 10 and 20 2 
days, without showing any failure to continue pecking the St display.

In addition to the simple demonstration of forgetting, a number of variables were examined with respect to their influence upon the obtained forgetting. For example, the'length of the retention interval was found to significantly influence the amount of forgetting observed with this preparation (Experiment 1). It was found that forgetting increased in a negatively accelerated fashion over intervals of 1,10 and 20 days, for both a single discrimination and a reverse discrimination. In addition, for a group retested 20 days after an original oneday retention test, significantly more forgetting occurred after the 20-day interval. Thus, longer retention intervals were found to enhance forgetting as both a between and within suggest that the forgetting observed in this preparation is quite robust after a 20-day interval.

The role of interference was examined in terms of the retention of reverse discriminations. The forgetting obtained for a reverse discrimination was found to be greater than the forgetting obtained for a single discrimination at intervals of 1,10 and 20 days (Experiment 1 ). These data are consistent with the results from similar studies of delayed generalization testing (Burr \& Thomas, 1972).

Another variable examined was the role of within problem similarity. It has been shown that PI and RI increase directiy with the degree of similarity between conflicting learning experiences ( Boucher, 1968; Zentall, 1970). Experiment 2 examined whether similarity might also influence forgetting as a within task variable. The degree of similarity between the two displays was varied, and it was found that 
slower acquisition and greater forgetting resulted when the similarity was greatest. A discrimination involving three green dots versus two green dots was found to undergo substantial forgetting over 20 days, whereas problems involving two green dots verșus five green dots, or two green dots versus two green and one red dots were not. It is believed that this represents the first example of within problem similarity effects reported with animals. As such, it not only offers important empirical insights into animal memory processing, but also suggest a procedure which can be used to more extensively study this phenomenon. The influence of contextual cues was examined in Experiment 3. Previous research has shown that a change in contexts between acquisition and retention testing can drastically affect performance (Perkins \& Weyant, 1958; Steinmąn, 1967; Chiszar \& Spear, 1969; Zentall, 1970; Thomas et al., 1981. This experiment studied the effects of changing contextual cues on forgetting of visual discriminations, with respect to the nature of the contextual cues. Separate groups of subjects were trained in the presence of either conspicuous or inconspicuous contextual cues. It was found that a change in the contextual cues between acquisition and relearning, administered 20 days later, resulted in significantly more forgetting than when these cues remained the same, but only if original training had taken place in the presence of a salient contextual environment. Changing contexts had no significant effect on forgetting when acquisition occurred in an environment containing few conspicuous contextual cues. It is believed that this finding establishes a previously unreported relationship between contextual control over performance and the nature of the contextual cues themselves. 
In addition to the empirical study of forgetting in the pigeon, a.. retrieval model was presented and subsequently applied to the data from each of the three experiments. The model is essentially a detailed elaboration of a retrieval failure account of forgetting, such as has been advocated by Spear $(1971,1973,1976,1978)$. The model asserts that discriminative performance involves the establishment of specific target memories, which when retrieved result in the occurrence of a specific target response. During acquisition of a discrimination, memory processing occurs which results in selective retrieval of a target memory. This processing ensures that a target memory will be retrieved only during specific stimulus conditions (i.e. during an St presentation). Over a retention interval, changes in the retrievability of target memories occur which result in a disruption in selective retrieval, and thus produce a performance decrement defined as forgetting.

The current model offers an explicit hypothetical mechanism for both retrieval and retrieval failure. It relies on the view that memories consist of organized sets of attributes. The attributes themselves are the organism's encoded version of features present and noticed by the organism during a learning episode. It is assumed that attributes are aroused or activated whenever the organism notices the corresponding features. As an attribute is activated it provides some hypothetical value of activation (AP), and it is assumed that attributes vary in their values of activation. The retrieval of a target memory depends on the arousal of individual attributes. Once the cumulative activation level for those attributes which have been aroused during feature recognition reaches some hypothetical value of activation (AT), 
the memory will be retrieved. Once a memory is retrieved, any target response, which is itself represented by an attribute in the target memory, will be generated.

The model further assumes that selective retrieval of target memories requires changes in ATs for target memories and increases in APs for relevant attributes (i.e. those attributes which represent . features which are most informative for the particular discrimination). specifically, it is assumed that ATs and APs increase so that target memories become retrievable only during specific feature presentations (i.e. during an S+ stimulus presentation and not during an S-presentation). Over retention intervals, during which target attributes are not activated, ATs are assumed to decline. It is postulated that it is the decline in ATs which is responsible for selective retrieval failure, which yields forgetting of a discrimination. As a target memory AT declines, the probability of that memory being retrieved during inappropriate feature conditions (i.è. during an s- presentation) increases, and this results in the decrement in discriminative performance which defines forgetting.

An important characteristic of this analysis, is that forgetting of a discrimination is argued to involve the enhanced retrievability of a specific themory over a retention interval, and not that forgetting involves a decrease in the retrievability of a memory. This somewhat counter-intuitive view of forgetting is supported by the form of the performance decrement noted throughout the four experiments. Responding during st presentations remained unchanged over retention intervals, while the learned tendency not to respond during.s- presentations diminished over retention intervals. 
The model holds that acquisition of a discrimination involves elevations in Aps and ATs, which produce highly proficient selective retrieval. A set of processing rules were described which delineate the specific changes in APs and Ats postulated to occur during both acquisition and retention intervals. Application of these rules to the results of each of the three experiments was offered as an account of these findings. That forgetting was found to increase with greater retention intervals, and to increase in a negatively accelerated fashion, was accounted for in terms of the rate at which ATs are believed to decline during periods of inactivation (Rule 4). The greater forgetting found for reverse discriminations, relative to a single discrimination; was explained in terms of the availability of two target memories which both yield the same target response--one for the original discrimination and one for the reverse discrimination--and the selective retrieval failure for these memories, which results from decreases in ATs during a retention interval.

The similarity of the two discriminative displays was expected to influence both acquisition and forgetting. Slower acquisition and greater forgetting were predicted for problems involving more similar displays. These predictions were based on the assumption that the : critical value to which an AT must be raised in order to promote proficient selective retrieval, would be higher for problems containing more similar displays (Rule 2), and the additional assumptions that higher critical AT's take longer to reach (Rule 3) and suffer more deterioration during a retention interval (Rule 4).

Finally, the model was also applied to contextual cue effects. It is assumed that contextual cues are represented by corresponding attri- 
butes in the target memory. The activation of these attributes during both discriminative acquisition and retention testing was expected to influence performance. The model predicts that when a greater number of contextual cues are represented by attributes in the target memory, development of proficient selective retrieval will take longer (Rules 2 and 3). Accordingly, the rate of acquisition of a discrimination is expected to be a direct function of the number of contextual cues represented in the target memory. Acquisition is predicted to be slower when more contextual cues are encoded. The results from Experiment 3 did not strongly support this prediction. No'sigrificant difference was found in the rates of acquisition for two groups trained in the presence of two different levels of contextual cues; although, the differences were in the expected direction, and it was argued that the parametric difference between the two cue conditions may not have been sufficient to realize a significant difference in acquisition rates between the two conditions.

The role of contextual cues was alsorasted during retention testing. It was predicted that when trained in the presence of 'relatively few contextual cues, the contextual environment during a retention test should little affect performance. When trained with more numerous contextual cues present, however, it was expected that a change in context during a retention test should enhance forgetting, relative to a no change condition. This was based on the assumption that ATs, which may have declined during a retention interval, are reinstated more quickly when more attributes are contained in the target memory and are aroused through presentation of the corresponding features (Rule 5). The data from Experiment 3 directly support this hypothesis. More forgetting 
was found in a group trained with more numerous contextual cues and:tested without thesecues, than in a group trained and tested with the : numerous contèxtual' cues available. For groups trained without numerous contextual cues, the amount of forgetting did not differ with respect to the contextual cue environment during the retention test. This previously unestablished relationship between the nature of contextual cues and their impact on performance during retention testing, and the successful prediction of this relationship by the proposed retrieval model is believed to be a strong indication of the viability of this model. No other extant model of animal memory processing seems capable of accounting for this phenomenon.

Both the empirical findings from the three experiments and the retrieval model outlined above suggest a number of future research possibilities. Of empirical interest would be attempts to isolate the factors responsible for the forgetting found in.the current preparation. For example, similar experiments could be conducted with the same type Ef stimuli used in the abote experiments, but employing a simultaneous discrimination. This would allow the relative"importance of the go/nogo nature of the discrimination problem as a factor in the obtained forgetting to be assessed. In addition, a number of stimulus variations could be manipulated with the successive discrimination currently employed to further explore the role of stimulus similarity on memory processing. Also, similar parametric manipulations of contextual cues could be examined, in order to further study the importance of the nature of the contextual cues on memory processing.

With respect to the proposed retrieval model; there appear to be a number of research possibilities which could further test the validity 
of this model. For example, the model clearly implies that selective retrieval will be reinstated following forgetting faster when the target memory contains more attributes, and these attributes are aroused through presentation of corresponding features. Further tests of this assumption using nondiscriminative performance could extend the generalizability of the model as an account of the phenomena of reinstatement and reactivation. Also, both of these phenomena could be studied with the present preparation.

Perhaps the most explicit area that the proposed model can be further tested involves the nature of the stimuli used in discrimination problems. The model clearly states that for discriminations in which there is little featural overlap between the stimulus displays, forgetting is expected to be minimal. For example, a simple successive discrimination involying white and black discriminative stimuli would not be expected to undergo much forgetting. This is based on the assumption that for problems involving highly dissimilar stimuli, increases in ATs may not be required; it may be possible to establish proficient selective retrieval in such situations without necessitating increases ịn ATs. Thus, with no increase in ATs during acquisition, there should be not decline in ATs during a retention interval, and selective retrieval proficiency should not change over a retention interval. As the discriminative știmuli become more similar, however, increases in ATs. may be necessary in order to establish selective retrieval. Under these conditions, retention intervals should yield a decrement in ATs, which would disrupt selective retrieval and produce forgetting. Thus, the current model offers a simple explanation for those failures to find forgetting of aiscriminations in animals. The stimulus arrangements in 
these studies may have been such that selective retrieval failure, as a result of changes in ATs during retention intervals, may not have been expected, and the absence of forgetting would have been predicted. Further tests of these assumptions regarding stimulus-performance relationships during discriminative acquisition and retention could easily be conducted with the current preparation.

In conclusion, perhaps the most significant contribution of the current series of experiments is to offer a research alternative for the study of reference memory in pigeons. It has been argued above, that a greater research effort to study reference memory processing in pigeons would provide a valuable contribution to the comparative study of animal memory. The results form the experiments currently described suggest that forgetting of discriminations in pigeons is a robust phenomenon under appropriate conditions. Further research into what these conditions are, the use of the above preparation to study additional problems of animal memory, and further attempts to test and develop the proposed retrieval model are believed to be the successful ramifications of the current research'effort. 


\section{. REFERENCES}

Aiken, E.G. and Gibson, K.L. Continuous and fixed ratio reinforcement effects in extinction one day and three weeks after acquisition. Psychonomic Science, 1965, 3, 527-528.

Alloway, T.M. Effects of low temperature upon acquisition and retention in the grain beetle. Journal of Comparative and Physiological Psychology, 1969, 69, 1-8.

Alloway, T.M. and Routtenberg, A. "Reminiscence" in the elour beetle (Tenebrio molitor). Science, 1967, 158, 1066-1067.

Anderson, A.C. Evidences of reminiscence in the rat in maze learning. Journal of Comparative Psychology, 1940, 30, 399-412.

Askew, H.R., Leibrecht, B.C. and Ratner, S.C. Effects of stimulus duration and repeated sessions on habituation of the head-shake response in the rat. Journal of Comparative and Physiological Psychology, 1969, 67, 497-503.

Atkinson, R.C. and Shiffrin, R.M. Human memory: A proposed system and its control processes. In K.W. spence and J.T. Spence (Eds.), The psychology of learning and motivation, Vol.2 New. York: Academic Press, 1968.

Behrend, E.R., Powers, A.S. ànd Bitterman, M.E. Interference and forgetting in birds and fish. Science, 1970, 167, 389-390. Berk, A.M., Vigorito, M. and Miller, R.R. Retroactive stimuIus interference with conditioned emotional response retention in infant and adult rats: Implications for infantile amnesia. Journal of Experimental Psychology: Animal Behavior Processes, $1979, \underline{5}, 284-299$. 
Bliss, D.K. Dissociated learning and state-dependent retention induced by pentobarbital in the rhesus monkey. Journal of Comparative and Physiological Psychology, 1972, 84, 149-161.

Bolles, R.C. Learning, Motivation and Cognition. In W. K. Estes (Ed.), Handbook of learning and cognitive processes. Hillsdale, N.J.: John wiley \& Soris, 1975.

Bolles, R.C. Some relationships between learning and memory. In D L. Medin, W.A. Roberts and R.T. Davis (Eds.), Processes of animal memory. Hillsdale, N.J.: Lawrence Erlbaum Associates, 1976.

Bouton, M.E. and Bolles, R.C. Role of conditioned contextual stimuli in reinstatement of extinguished fear. Journal of Experimental

- Chology: Animal Behavior Processes, 1979, $5,368-378$. Bower, G. "A multicomponent theory of the memory trace." In G.'Bower (Ed.), The psychology of learning and motivation. New York: Academic Press, 1967.

Brown, J. Some tests of the decay theory of immediate memory. Quarterly Journal of Experimental Psychology, 1958, 10, 12-21. .

Brush, F.R. Retention of aversively motivated behavior. In F.R. Brush (Ed.), Aversive Conditioning and learning. New York: Academic Press, 1971.

Bryan, R. and Spear, N.E. Forgetting of a discrimination after intervals of intermediate length: The Kanin effect with chaice behavior. Journal of Experimental Psychology: Animal Behavior Processes, 1976, 2, 221-234. Bugelski, B.R. and Cadwallader, T.G. A reappraisal of the transfer and 'retroaction surface. Journal of Experimential Psychology, 1956, 52, 360-366. 
Bunch, M.E. A comparison of retention and transfer of training from similar materiai after relatively long intervals of time. Journal of Comparative Psychology, 1941, 32, 217-231.

Burr, D.E.S. and Thomas, D.R. Effect of proactive inhibition upon the post-discrimination generalization gradient. Journal of Comparative and Physiological Psychology; $1972,81,444^{\circ}-448$.

Calhoun, W.H. and Handley, G.W. Long-term memory following serial discrimination reversal learning. Bulletin of the Psychonomic Society, 1973, 1, 354-356.

Campbell, B.A. and Campbell, E.H. Retention and extinction of learned fear in infant and adult rats. Journal of Comparative and Physiological Psychology, 1962, 55, 1-8.

Campbell, B.A: and Jaynes, J. Reinstatement. Psychological Review,

$1966, \underline{73}, 478-480$.

Campbell, B.A. and Jaynes, J. Effect of duration of reinstatement on retention of a visual discrimination learned in infancy. Developmental Psychology, 1969, 1, 71-74.

Campbell, B.A., Jaynes, J. and Misanin, J.R. Retention of a light-dark discrimination in rats of different ages. Journal of Comparative - and Physiological Psychology, 1968, 66, 467-472.

Campbell, B.A. , Misanin, J.R.; White, B.C. and Lytle, L.D. Species differences for neural maturation as̀ a determinant of forgetting. Journal of Compàrative and Physiological Psychology, 1974, 87. 193-202:

Carew, T.J. and Kandel, E.R. Acquisition ană rețention ö long-term habituation in Aplysia: ' Correlation of behavioral and cellular processes. Scienge, $1973,182,1158-1160$. 
$\therefore$ Chiszar, D.A. and Spear, N.E. Proactive interference in a $T$ maze brightness-discrimination task. Psychonomic science, 1968, 11, 107-108.

Chiszar, D.A. and Spear, N.E. "Stimulus change, reversal learning and retention in the rat. Journal of Comparative and Physiological Psychology, 1969, 69, 1980-195.

Corey, S.M. An experimental study of retention in the white rat. Journal of Experimental Psychology, 1931, 14, 252-259.

Coulter, X., Collier, A.C. and Campbell, B.A. Long-term retention of early pavlovian fear conditioning in infant rats. Journal of Experimental Psychology: Animal Behavior Processes, 1976, 2 , $48-56$.

Craik, F.I.M. and Lockhart, R.S. Levels of processing: A frămework for memory research. Journal of Verbal Learning and Verbal Behavior, $1972,11,671-684$.

Crowder, R.G. Proactive and retroactive inhibition in the retention of a T-maze habit in rats. Journal of Experimental Psychology, 1967, 74, 167-171.

Crowder, R.G., Cole, M. and Boucher, R. Extinction and response competition in original and interpolated learning, of a visual discrimination. Journal of Experimental Psychology, 1968, 77, $422-428$.

D'Amato, M.R. Delayed matching and short-term memory, in monkeys. In G.H. Bower (Ed:), The psychology of learning and motivation: advances, in research and theory, V-7. New York: Academic Press; 1973. 
Daniels, D. Acquisition, storage and recall of memory for brightness discrimination by rats following intra-cerebral infusion of acetoxycycloheximide. Journal of Comparative and Physiological" Psychology, 1971, 79, 110-118.

Davis, M. Differential retention of sensitization and habituation of the startle response in the rat. Journal of Comparative and

- Physiological Psychology, 1972, 78, 260-267.

Desiderato, O., Butler, B. and Meyer, C. Changes in fear generalization gradients as a function of delayed testing. Journal of Experimental Psychology, 1966, 72, 678-682.

Deutsch, J.A. and Leibowitz, S.F. Amnesia or reversal of forgetting by anticholinesterase, depending simply on time of injection.

Science, 1966, 153, 1017-1018.

DiCara, L.V. and Miller, N.E. Long-term retention of instrumentally learned heart-rate changes in the curarized rat. Communications $\checkmark$. in Behavioral Biology, 1968, 2, 19-23.

Ehrlich, A. and Musicant, A. Visual discrimination learning and memory in nocturnal prosimians. Animal Learning and Behavior, 1976, $\underline{4}$, $431-435$.

Feighley, D.A. and Spear, N.E. Effect of age and punishment condition on long-term retention by the rat of active-and passive avoidance learning. Journal of Comparative and Physiological Psychology, $1970, \underline{73}, 515-526$.

File, S. Long-term retention of behavioural habituation in the rat. Animal Behavior, 1973, 21, 585-589. 
Frankman, F. Effect of amount of interpolated learning and time interval before test on retention in rats. Journal of Experimental Psychology, 1957, 54, 46-2-466.

Gagne, R.M. The retention of a conditioned operant response. Journal of Experimental Psychology, 1941, 29, 296-305.

Garaner, L.E. Retention and overhabituation of a dual-component response in Lumbricus Terrestris. Journal of Comparative and Physiological Psychology, 1968, 66, 315-318.

Gleitman, H. Forgetting of long-term memories in animals. In W.K. Honig and P.H.R. James (Eds.), Animal memory. New York: Academic Press, 1971

Gleitman, H. and Bernheim, J.W. Retention of fixed-interval performance in rats. Journal of Comparative and physiological Psychology, 1963, 56, 839-841.

Gleitman, H. and Holmes, P.A. Retention of incompletely learned CER in rats. Psychonomic Science, 1967, 7, 19-20.

Gleitman, H. and Jung, L. Retention in rats: The effect of proactive interference. Science, 1963, 142, 1683-1684.

Gleitman, H. and Steinmian, F. Retention of runway performance as a function of proactive interference. Journal of Comparative and Physiological Psychology, 1963, 56, 834-838.

Gonzalez, R.C., Behrend, E.R. and Bitterman, M.E. Reversal learning and forgétting in bird and fish. Science, 1967, 158, 519-521.

Gonzales, R.C., Fernhoff, D. and David, F.G. Contrast, resistance to extinction, and forgetting in rats. Journal of Comparative and Physiological Psychology, 1973, 84, 562-571. 
Gordon, W.C. and Spear, N.E. Effect of reactivation of a previously acquired memory on the interaction between memories in the rat. Journal of Experimental Psychology, 1973, 99, 349-355.

Hamberg, J.M. and Spear, N.E. Alleviation of foretting of discrimina-

tion learning. Learning and Motivation, 1978, 9, 466-476.

Hamilton, T.C., Thompson, J.M. and Eisenstein, E.M. Quantitative Analysis of ciliary and contractile responses during habituation training in Spirostomum ambiguum. Behavioral Biology, 1974, 12, $393-407$.

Hammond, L.J. and Maser, J. Forgetting and conditioned suppression: Role of a temporal discrimination. Journal of the Experimental Analysis of Behavior, $1970,13,333-338$.

Hannum, R.D., Rossellini, R.A. and Seligman, M.E.P. Learned helplessness in the rat: Retention and immunization. Developmental Psychology, 1976, $12,449-454$.

Hearst, E. "Stimulus relationships and feature selection in learning and behavior." In S. Hulse, H. Fowler and W.K. Hönig (Eds.), Cognitive processes in animal behavior. Hillsdale, N.J.: Erlbaum

- Associates, 1978.

Henderson, R.W. Forgetting of conditioned fear inhibition. Learning and Motivation, $1978, \underline{9}, 16-30$.

Hershkowitz, M. and Samuel, D. The retention of learning during metamorphosis of the Crested Newt (Triturus cristatus). Animal Behavior, 1973, 21, 83-85.

Hickis, C.F., Robles, L. and Thomas, D.R. Contextual stimuli and memory retrieval in pigeons. Animal Learning and Behavior, 1977, $\underline{5}$, $161-168$. 
Hicks, R.E., MCDaniel, J.W. and Hensley, J.G. Forgetting of acquisition and extinction in an invertebrate. The Journal of General Psychology, 1973, 88, 65-69.

Hill, W.F., Cotton, J.W., Spear, N.E. and Duncan, C.P. Retention of T-maze learning after varying intervals following partial and continuous reinforcement. Journal of Experimental Psychology, $1969,79,584-585$.

Hill, W.F., Erlebacher, A. and Spear, N.E. Reminiscence and forgetting in a runway. Journal of Experimental Psychology, 1965, 70, 201-209.

Hoffman, H.S., Fleshler, M. and Jensen, P. Stimulus aspects of aversive controls: The retention of conditioned suppression. Journal of the Experimental Analysis of Behavior, 1963, 6, 575-583.

Hoffman, H.S., Selekman, W. and Fleshler, M. Stimulus aspects of aversive controls: Long-term effects of suppression procedures. Journal of the Experimental Analysis of Behavior, 1966, 9, 659-662. Holloway, F.A. and Wansley, R.A. Multiple retention deficits at periodic Intervals after passive avoidance learning. Science, $1973,80,208-210$.

Honig, W.K. Attentional, factors governing the slope of the generalization gradient. In R. Gilbert and N.S. Sutherland (Eds.)', Animal discrimination learning. London Academic Press, 1969. Honig, W.K. Studies of working memory in the pigeon. In S.H. Hulse, H. Fowler, and'w.K. Honig (Eds.), Cognitive processes in animal behavior. Hillsdale, N.J.: Lawrence Erlbaum Associations, 1978. Honig, W.K. and James, P.H.R. Änimal Memory. New York: Academic Press, 1971. 
Horton, D.L. and Turnage, T.W. Human Learning. Englewood Cliffs, N.J.: Prentice Hall, Inc., 1976.

Huber, J.C., Rucker, W.B. and McDiarmid, C.G. Retention of escape training and activity changes in single paramecia. Journal of Comparative and Physiological Psychology, 1974, 86, 258-266. *

Hulse, S.H., Fowler, H. and Honig, W.K. Cognitive Processes in Animal Behavior. Hillsdale, N.J.: Lawrence Erlbaum Associates, 1978. Hunsicker, J.P. and Mellgren, R.I. Multiple deficits in the retention of an appetitively motivated behavior across a $24-\mathrm{h}$ period in rats. Animal Eearning and Behavior, 1977, 5, 14-16.

Jenkins, H.M.. Noticing and responding in a discrimination based on a distinguishing element. Learning and Motivation, 1973, 4, 115-137. Jenkins, J.B. and Dallenbach. Oblivescence during sleep and walking. American Journal of Psychology, 1924, 35, 605-612.

Jenkins, H.M. and Sainsbury, R.S. Discrimination learning with the distinctive feature on positive or negative trials. In D.I. Móstofsky (Ed.), Attention: contemporary theory and analysis. New York: Aplleton-Century-Crofts, 1970.

Jung, J. Verbal Learning. New York: Holt, Rinehart and Winston Inc., 1968.

Kamin, L.J. The retention of an incompletely learned avoidance response. Journal of Comparative and Physiological Psychology, 1957, $50,457-460$

Kehoe,. J. Effects of prior and interpolated learning on retention in pigeons. Journal of Experimental Psychology, $1963,65,537-545$. 
Kimmell, H.D., Brennan, A.F., McLeod, D.C., Raich, M.S. and Schonfeld, L.I. Instrumental electrodermal conditioning in the monkey: Acquisition and long-term retention. Animal Learning and Behavior, $1979, \underline{7}, 447-451$.

Kirby, R.H. Acquisition, extinction, and retention of an avoidance response in rats as a function of age. Journal of Comparative and Physiological Psychology, 1963, 56, 158-162.

Koppenaal, R.J. and Jagoda, E. Proactive inhibition of a maze position habit. Journal of Experimental Psychology, 1968, 76, 664-668.

Leaton, R. Long-term retention of the habituation of lick suppression in rats. Journal of Comparative and Physiological Psychology, $1974,87,1157-1164$.

Leaton, R. Long-term retention of the habituation of lick suppression and startie response produced by a single auditory stimulus. Journal of Experimental Psychology: Animal Behavior Processes, $1976,2,248-259$.

Lewis, D.J. Psychobiology of active and inactive memory. Psychological Bulletin, 1978, 1054-1083.

Loftus, E.F. and Loftus, G.R. On the permanence of stored information in the human brain. American Psychologist, 1980, 35, 409-420.

Logan, C.A. and Beck, H.P. Long-term retention of habituation in the sea anemone (Apthopleura elegantissima). Journal of Comparative and Physiological Psychology, 1978, 92, 928-936.

Ludrigson, H.W., MCCleary, P.H. and Boedecker, C.L. Retention of a running response following appetitive acquisition, extinction and discrimination. Animal Learning and Behavior, 1980, 으, 135-142. 
Magdsick, W.K. The curve of retention of an incompletely learned problem in albino rats at various age levels. Journal of Psychology, $1936,2,25-48$.

Maier, S., Allaway, T. and Gleitman, H. Proactive inhibition in rats

- after partial reversal: a critique of the spontaneous recovery hypothesis. Psychonomic Science, 1967, 9, 63-64.

Maier, S.F. and Gleitman, H. Proactive interference in rats. Psychonomic Science

Markowitz, H., Schmidt, M., Nadal, L. and Squier, L. Do elephants remember? Journal of Applied Behavioral Analysis, 1975, 8, 333-335. . MCAllister, D.E. and MCAllister, W.R. Forgetting of acquired fear. Journal of Comparative and Physiological Psychology, 1968, 65, $352-355$.

MçGovern, J.B. Extinction of associations in four transfer paradigms. Psychological Monographs, 1964, 78 (16, Whole No. 593).

Medin, D.L., Roberts, W.A. and Davis, R.T. Processes of Animal Memory. Hillsdale, New Jersey: Lawrence Erlbaum Associates, 1976. Meinecke, R. Retention of ọne trial learning in neonate, young, adult and aged Japanese Quail. Journal of Gerontology, 1974, 29, $172-176$.

- Melton, A.W. and Irwin, J.M. The influence of degree of interpoláted learning on retroactive inhibition and the overt txansfer of specific responses. American Journal of Psychology, 1940, 53, 173-203.

Miller, N.E. Learning resistance to pain and fear: Effects of overlearning, exposure, and rewarded exposure in context. Journal of Experimental Psychology, 1960,60, 137-145. 
Miller, R.R. and Berk, A.M. Retention over metamorphosis in the African claw toed frog. Journal of Experimental Psychology: Animal Behavior Processes, $1977,3,343-356$

Minami, H. and Dallenbach, K.M. The effect of activity upon learning and retention in the cockroach (Periplaneta americana). American Journal of Psychology, 1946, 59, 1-58.

Moyer, K.E. Stărtle response: Habituation over trials and days, and sex and strain differences. Journal of Comparative and Physiological Psychology, 1963, 56, 863-865.

Nash, R.F., Ronci, F.W. and Girdankas, G.J. Long-term retention of the , habituation of tonic immobility. The Psychological Record, 1976, $26,243-246$

Neylon, A and Brosgale, L. Long-term retention of heat training in mongolian gerbils. Psychologícal Reports, 1974, 34, 511-514.

Norman, D.A. \& Rumelhart, D.E. A system for perception and memory. In D.A. Norman (Ed.) Models of human memory. New York: Academic . Press, 1970.

Olton, D.S. Characteristics of spatial memory.- In S.G. Hulse, $H$. Fowler, and W.J. Honig (Eds.), Cognitive processes in animal behavior. Hillsdale, N.J.: Lawrence Erlbaum Associates, 1978.

Olton, D.S. and Samuelson, R.J. Remembrances of places passed: Spatial memory in rats. Journal of Experimental Psychology: Animal Behavioural Processes, 1976, 2, 97-116.

Osgood; C.E. The similarity paradox in human learning: A resolution. Psychological Review, 1949, 56, 132-143. .

Overton, D. State-dependent or "dissociated" learning produced with pentobaritol. Journal of Comparative and Physiological Psychology, $1964,57,3-12$. 
Parsons, P.J., Fagan, T. and Spear, N.E. Long-term retention of habituation in the rat: A developmental study from infancy to old age. Journal of Comparative and Physiological Psychoalogy, 1973, 84, $545-553$

Parsons, P.J. and Spear, N.E. Long-term retention of avoidance learning by immataure and adult rats as a function of environmental enrichment. Journal of Comparative and Physiological Psychology, $1972,80,277-303$

Pavlov, I.P. Conditioned Reflexes. New York: Dover Publications, Inc., 1927.

Perkins, C.C. and Weyant, R.G. The interval between training and test trials as determiner of the slope of generalization gradients. Journal of Comparative and Physiological Psychology, 1958, 51, 596-600.

Peterson, L.R. and Peterson, M.J. Short term retention of individual verbąl items. Journal of Experimental Psychology, 1959, 58, 193-198.

Pieper, W.A. and Marx, M.H. Effects of wthin-session incentive. contrast on instrumental acquisition and performance. Journal of Experimental Psychology, $1963,65,568-571$.

Pinsker, H., Kupfermann, I., Castellucci, V. and Kandel, E. Habituation and dishabjtuation of the gill-withdrawal reflex in aplysia. Science, 1969, 167, 17,40-1742.

Potash, M. and Ferguson, H. The effect of criterion level on the acquisitipn and retention of a l-way avoidance response in young and old rats. Developmental Psychobiology, 1977, 10, 347-354. 
Ratner; S. and Gilpin, A.R. Habituation and retention of habituation responses to air puff of normal and decerebrate earth worms. Journal of Comparative and Physiological Psychology, 1974, 86;, $911-918$

Rescorla, R.A. and Wagner, A.R. A theory of Pavlovian conditioning: Variations in the effectiveness of reinforcement and non reinforcement. In A.H. Black and W.F. Prokasy (Eds.), Classical conditioning II: Current research and theory. New York: Appleton-CenturyCrofts, 1972 .

Rickard, S. Proactive inhibition involving maze habits. Psychonomic Science, $1965, \underline{3}, 401-402 . \cdot$

Rilling, M. Stimulus control and inhibitory processes. In W.K. Honig and J.E.R. Stadion (Eds.), Handbook of operant behavior. Englewood Cliffs, N.J.: Prentice Hall, 1977.

Roberts, W.A. and Grant, D.S. Studies of short-term memory in the pigeon using delayed matching to samṕle procedure. In D.I. Medin, W.A. Roberts and,R.T. Davis (Eds.), Processes of animal memory. Hillsdale, N.J.: Laẃrence Erlbaum Associates, 1976.

Sainsbury, R.S. Effect of proximity of elements of the feature postive effect. Journal of the Experimental Analysis of Behavior, 1971 ; $16,315-325$.

Sanders, G.D. and Barlow, J.J. Variations in retention performance during long-term memory formation. Nature, 1971, 232, 203-204. Simon, H.A. The information-storage system called "Human Memory" : In M.R. Rosenzweig and E.L. Bennett (Eds.) Neural mechanisms of learning and memory. Cambridge, Mass: MIT press, 1976. 
Skinner, B.F. The Behavior of Organisms: An Experimental Analysis.

New York: Appleton-Century-Crofts, 1938.

Skinner, B.F: Are theories of learning necessary? Psychological

Review, 1950, 57, 193-216. .

Smith, G.J. and Spear, N.E. Alleviating forgetting of active shockavoidance by apparently unrelated food presentations. Learning and Motivation, 1979, 10I, 502-519.

Spear, N.E. Retention of reinforcer magnitude. Psychological Review, $1967,74,216-234$.

Spear, N.E. Forgetting as retrieval failure. In W.K. Honig and P.H.R. James (Eds.) Animal memory. New York: Academic Press, 1971.

Spear, N.'E. Retrieval of memory in animals. psychological Review, $1973,80,163-194$.

Spear, N.E. Retrieval of memories, In W.K. Estes (Ed.), Handbook of learning and cognitive processes, Voi 4 . Hillsdale, N.J.: Lawrence Erlbaum Associates, 1976.

Spear, N.E. The Processing of Memories: Forgetting and Retention. Hillsdale, New Jersey: Lawrence Erlbaum Associates, 1978.

Spear, N.E. and Parsons, P. Analysis of a reactivation treatment: Ontogeny and alleviated forgetting. In D.K. Medin, W.A. Roberts and R.T. Davis (Eds.), Processes of animal memory.- Hillsdale, N.J.: Lawrence Erlbaum Associates, 1976.

Steinman, F. Retention of alley brightness in the rat. Journal of Comparative and Physiological Psychology, 1967, 64, 105-109. Thomas, D.A. Retention of conditioned Inhibition in a bar-press suppression paradigm. Jearnin, and Motivation, 1979, 10, 161-177. 
Thomas, D.A. and Riccio, D.C. Forgetting of a C̣s attribute in a conditioned suppression paradigm. Animal Learning and Behavior; $1979,2,191-195$.

Thomas, D.R. and Burr, D.F.S. Stimulus generalization as a function of the delay between training and testing procedures: A reevaluation. Journal of the Experimental Analysis of Behavior, 1969, 13, 105-109.

Thomas, D.R. and Lopez, L.J. The effects of delayed testing' on generalization slop. Journal of Comparative and Physiological Psychology, 1962, 55, 541-54.4.

Thomas, D.R. McKelvie, A.R., Ranney, M. and Moye, T.B. Interference in pigeons' long-term memory viewed as a retrieval problem Animal $\rightarrow \quad$ Learning and Behavior, 1981, $9,581-586$.

Thomas, P.R. and McKelvie, A.R. Retrieval of memory in the pigeon by context manipulations. Animal Learning and Behavior, 1982,10 . $1-6$.

Thomas, D.R., Ost, J. and Thomas, D. Stimulus generalization as a function of the time between training and testing procedures. Journal of the Experimental Analysis of Behavior, 1960, 3, 9-14. Thompson, C. and Fitzsimions, T. Age differences in aversively motivated visual discripination learning and retention in male Sprague-Dawley rats. Journal of Gerontology, 1976, 31, 47-52.

,Thompqon, R.W., Koenigsberg, L.A. and Tennison, J.C. Effects of age on léarning and retention of an avoidance response in rats. Journal. of Comparative and Physiological Psychology, 1965, 60, 457-459. 
Tryggrason', S. and Tees, $\dot{R}, C^{-}$. Retention of three brightness discriminations by rats following posterior cortical lesions. 'Journal of Comparative and Physiological Psychology, 1974, 86, 637-647.

Tsai, C.A. A comparative study of retention curves for motor habits. Comparative Psychology Monographs, 1924, 2, 11.

Underwood, B.J. Speed of learning and amount retained: A consideration of methodology. Psychological Bulletin, 1954, 51, 277-282.

Underwood, B.J. Interference and forgetting. Psychological Review, $1957,64,49-60$.

Underwood, B.J. Degree of learning and the measurement of forgetting. Journal of Verbal Learning and Verbal Behavior, 1964, 3, 112-129. Underwood, B.J. Attributes of memory. Psychological Review, 1969, 76, 5 559-573.

Underwood, B.J., Runquist, W.N. and SchuIz, R.W. Response learning in paried associate lists as a function of intralist similarity. Journal of -Experimental Psychology, 1959, 58, 70-78.

Wansley, R.A. and Holoway, F.A. Multiple retention deficits following - one-trial appetitive training. Behavioxal Biology, 1975, 14 , $\therefore$ 135-149.:

Wasserman, E.A. Cognitive psychology returns: A review of Hulse, Fowler and Honig's Cognitive Processes in Animal Behavior. Journál of the Experimental Analysis of Behavior, 1981, 35, 243-257.

Waters, R.H. and Vitale, A.G. Dégree of ínterpolated learning and retroactive inhibition in maze learning I. Animal subjects. Journal of Eómparative Psychology, $1945,38, " 119-126$.

Waugh, N.C. and Norman, D.A. Primary memory. Psychological Review, $1965, \underline{72}, 89-104$ 
Welker, R.L., Tomie, A., Davittt, G.A. and Thomas, D.R. Conțextual 。 stimulus control over operant responding in pigeons. Journal of Comparative and"Physiological Psychology, 1974, 86, 549-562. G.R. Two and one-half year retention of a conditioned response. Journal of General Psychology, 1937, 17, 178-180.

Wickens, D.D., Tuber, D.S., Nield, A.F. and Wickens, C. Memory for the conditioned response: The effects of potential interference introduced before and after original conditioning. Journal of'Experimental Psychology: General, 1977, 106, 47-70.

Wimer, R.. Osgood's transfer surface: Extension and test. Journal of Verbal Learning and 'Verbal Behavior, 1964, 3, 274-279.

Winer, B.J. Statistical Principles in Experimental Design. New York: MCGraw-Hill Book Cornpany, 1971

Winograd, E. ' Some issues relating animal memory to human memory. In "W.K. Honig and P.H.R. James (Eds.), Animal memory. New York: Academic Press, $197 i$.

Zentall, T.R.' Effects of context change on forgetting in rats. Journal of Experimental.Psychology, 1970, 86, 440-448. 

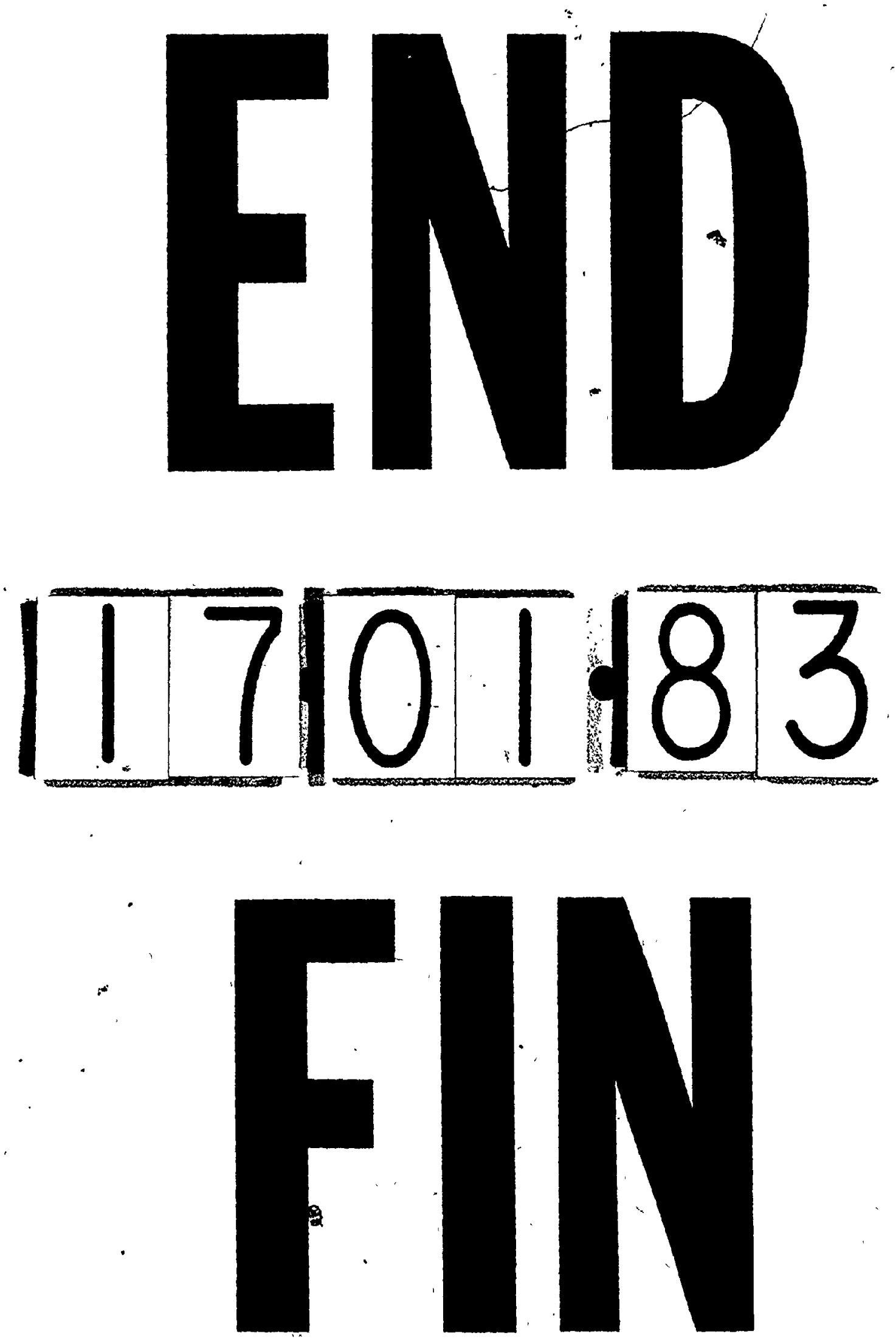